\title{
Exploring Acoustical Approach for Pre-screening of Window Assemblies Airtightness Level in an Existing Building
}

\author{
By \\ Sanam Pouyan, Bachelor of Architecture \\ Azad University - School of Art and Architecture (IAUCTB), Tehran, 2008
}

A Major Research Project (MRP)
presented to Ryerson University

in partial fulfillment of the requirements

for the degree of Master of Building Science

in the program of Building Science

Toronto, Ontario, Canada, 2018

(C) Sanam Pouyan, 2018 


\section{Author's Declaration}

I hereby declare that I am the sole author of this MRP. This is a true copy of the MRP, including any required final revisions. I authorize Ryerson University to lend this MRP to other institutions or individuals for the purpose of scholarly research. I further authorize Ryerson University to reproduce this MRP by photocopying or by other means, in total or in part, at the request of other institutions or individuals for the purpose of scholarly research. I understand that my MRP may be made electronically available to the public. 


\title{
Exploring Acoustical Approach for Pre-screening of Window Assemblies Airtightness Level in an Existing Building
}

\author{
Sanam Pouyan \\ Master of Building Science, Program of Building Science \\ Department of Architectural Sciences, Ryerson University, 2018
}

\begin{abstract}
Air infiltration plays a significant role in designing and evaluating the performance and air quality of a building. Air leakage through an existing building enclosure can be detected by using experimental measurements, such as blower door test, tracer gas method, and transient approach. Estimating building air permeability through these methods can be expensive, time consuming, and weather reliant. The economical and environmental effect of air infiltration through building envelope requires higher level of research on locating air leakage locations and estimating air infiltration rate through new techniques, such as acoustical methods.
\end{abstract}

In this research, a general review of airtightness detection and quantification method is presented and acoustical techniques are explored more in depth. Due to the significant impact of window systems on the total air infiltration through the building envelope, the correlation between the sound transmission loss and the air permeability through seven window assemblies in an existing building are explored to investigate acoustical method further. In addition, the acoustic air leakage detection method based on the standard ASTM E1186 is instigated. The results reveal the poor correlation between the airtightness of the windows and the acoustical analysis and investigations. 


\section{Acknowledgements}

I would like to express my sincere gratitude to my supervisor, Dr. Umberto Berardi for his valuable guidance, encouragement and assistance in carrying out this project.

Furthermore, I would like to thank Dr. Russell Richman, as my second reader, for the critical review of this project and the insight he has shared.

I would also like to thank Greg Labbe, Building Science Research lab technician, for his valuable guidance and best suggestions throughout my field tests.

My sincere thanks go to Ian Dunslow, Site Superintendent of the 101 St. Clair Avenue West project, who gave me the permission to perform my tests on this specific building.

Above all, my sincere thanks also go to my parents and my fiancé, for their endless love, support and assistance they provided throughout my study. This work would not have been possible without them. 


\section{Table of Contents}

AUTHOR'SDECLARATION.............................................................................................................................................................................ii

ABSTRACT ...........................................................................................................................................................................ii

ACKNOWLEDGEMENTS............................................................................................................................................................iv

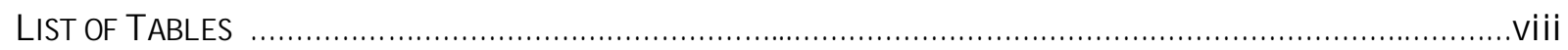

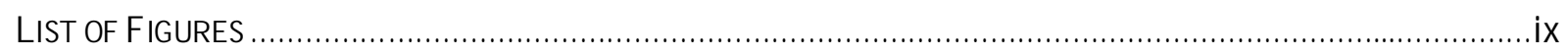

LIST OF APPENDICES.......................................................................................................................................................................xii

1 INTRODUCTION..........................................................................................................................................................................1

2 LITERATURE REVIEW .........................................................................................................................................................2

2.1 BUILDING ENVELOPE AIRTIGHTNESS .....................................................................................................................2

2.2 BUILDING AIR LEAKAGE DETECTIONAND CALCULATION METHODS ..................................................................4

2.2.1 BLOWER DOOR TEST..................................................................................................................................4

2.2.2 TRACERGASDILUTION METHOD ....................................................................................................................6

2.2.3 TRANSIENT APPROACH..............................................................................................................................10

2.2.4 INFRARED SCANNING AIR LEAKAGE DETECTION METHOD....................................................................11

2.2.5 ACOUSTICALAPPROACH......................................................................................................................12

2.3 SOUND SOURCE ESTIMATIONAND LOCALIZATION.............................................................................................15

2.3.1 SINGLE TRANSDUCER METHODD...............................................................................................................15

2.3.2 TWO SPACED ONE DIMENSIONAL TRANSDUCERS SENSORS...............................................................15

2.3.3 AMBISONICSDECOMPOSITION ....................................................................................................................16

2.3.4 BEAMFORMING..................................................................................................................................17 
2.4.1 ASTM STANDARD E 783-02: FIELD MEASUREMENT OF AIR INFILTRATION THROUGH INSTALLED WINDOWSTEST METHOD. 19

THE ROLE OF WINDOW ASSEMBLIES ONTOTAL BUILDING AIR LEAKAGE.. . .19

2.4.2 ASTME1186 STANDARD: ACOUSTIC AIR LEAKAGE DETECTION METHOD 20

3 SPECIFIC OBJECTIVES OFTHE STUDY .21

4 METHODOLOGY .22

4.1 CORRELATION BETWEEN AIR INFILTRATION AND SOUND TRANSMISSION LOSS THROUGH WINDOW ASSEMBLIES .22

4.1.1 AIR INFILTRATION FIELD TEST THROUGH EXPERIMENTAL WINDOW ASSEMBLIES, .22

4.1.2 DETERMINING SOUND TRANSMISSION LOSS THROUGH TESTED WINDOW ASSEMBLIES. .23

4.2 THE INVESTIGATION OF ACOUSTICAIR LEAKAGE DETECTION METHOD. .25

4.3 FIELD STUDY: TEST LOCATIONSAND TESTSRESULTS. .26

4.3.1 WINDOW AIRTIGHTNESS AND SOUND PRESSURE TRANSMISSION LOSS MEASUREMENTS AND RESULTSASSESSMENTS. .29

4.3.1.1 TEST LOCATION NO. 1 .29

4.3.1.2 TEST LOCATION NO. 2 .31

4.3.1.3 TEST LOCATION NO. 3 .33

4.3.1.4 TEST LOCATION NO. 4 .35

4.3.1.5 TEST LOCATION NO. 5 .37 
4.3.1.6 TEST LOCATION NO. 6

4.3.1.7 TEST LOCATION NO. 7

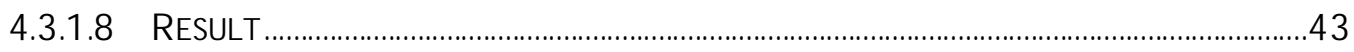

4.3.2 AIR LEAKAGE DETECTION: MEASUREMENTSAND RESULT ASSESSMENTS.............................................46

4.3.2.1 TEST LOCATION No.1 …….................................................................................................46

4.3.2.2 TEST LOCATION No. 2 …...................................................................................................4

4.3.2.3 TEST LOCATION NO. 3 …............................................................................................................48

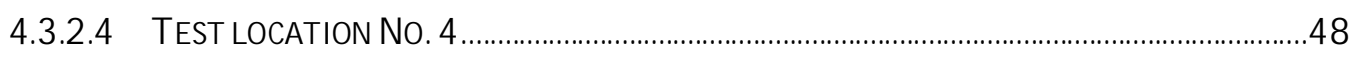

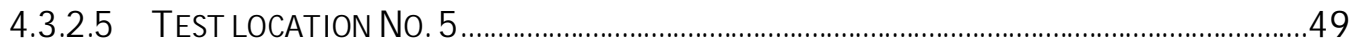

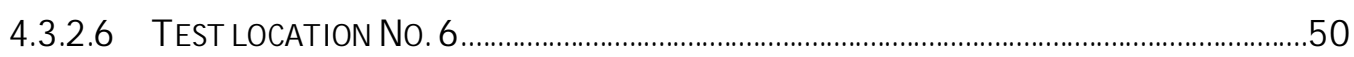

4.3.2.7 TEST LOCATION NO. 7 _...........................................................................................................51

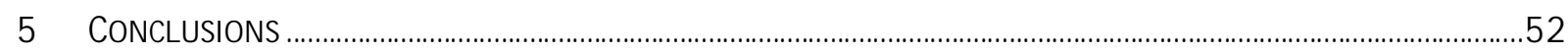

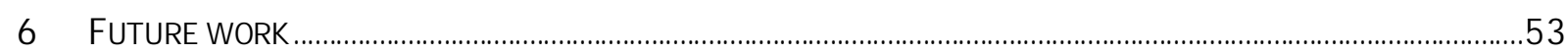

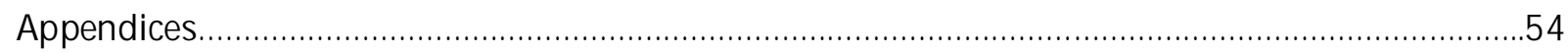

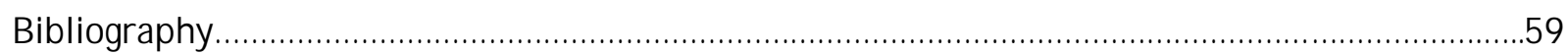




\section{List of Tables}

TABLE 1 - WINDOW AIRTIGHTNESS TEST MEASUREMENTS OF LOCATION NO. 1 .........................................................30

TABLE 2 - SOUND LEVEL MEASUREMENTS OF LOCATION NO. 1 _........................................................................................31

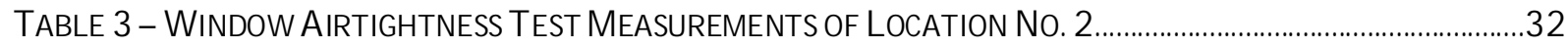

TABLE 4 - SOUND LEVEL MEASUREMENTS OF LOCATION No. 2 _............................................................................33

TABLE 5 - WiNDOW AIRTIGHTNESS TEST MEASUREMENTS OF LOCATION No. 3

TABLE 6 - SOUND LEVEL MEASUREMENTS OF LOCATION NO. 3 ........................................................................................35

TABLE 7 - WINDOW AIRTIGHTNESS TEST MEASUREMENTS OF LOCATION NO. 4..........................................................36

TABLE 8 - SOUND LEVEL MEASUREMENTS OF LOCATIONNO. 4 _.............................................................................37

TABLE 9 - WINDOW AIRTIGHTNESS TEST MEASUREMENTS OF LOCATION No. 5...........................................................38

TABLE 10 - SOUND LEVEL MEASUREMENTS OF LOCATION NO. 5 ......................................................................................

TABLE 11 - WINDOW AIRTIGHTNESS TEST MEASUREMENTS OF LOCATION No. 6 .......................................................40

TABLE 12 - SOUND LEVEL MEASUREMENTS OF LOCATION No. 6 ..................................................................................40

TABLE 13 - WINDOW AIRTIGHTNESS TEST MEASUREMENTS OF LOCATION No. 7 .........................................................42

TABLE 14 - SOUND LEVEL MEASUREMENTS OF LOCATION NO. 7 .........................................................................................42

TABLE 15 - SUMMARY OFTHE TEST RESULTS OF THE SEVEN EXPERIMENTAL WINDOWS ...............................................43 


\section{List of Figures}

FIGURE 1 - BLOWER DOOR TEST: LEFT IMAGE (LAMBDA, 2018), RIGHT IMAGE (USI BLOG, 2018) ............................6

FIGURE 2 - CONCENTRATION DECAY TEST TECHNIQUE (ASTME741 , 2011) ....................................................................7

FIGURE 3- CONSTANT TEST TECHNIQUE (ASTME741 , 2011) ..........................................................................................8

FIGURE 4 - CONSTANT CONCENTRATIONTEST TECHNIQUE (ASTME741 , 2011) .......................................................8

FIGURE 5 - TRACER GASMETHOD (INSPECTAPEDIA, 2017) .............................................................................................10

FIGURE 6 - UPPER LEFT: COMBINED BUILDING DEPRESSURIZATION AND INFRARED SCANNING, UPPER RIGHT: INFRARED SCANNING (KALAMEEST. , 2007) …….........................................................................................12

FIGURE 7 - AMBISONICSDECOMPOSITION (IDIS, 2018) .....................................................................................16

FIGURE 8 - AMBISONICSB-FORMAT LAYOUT ....................................................................................................................16

FIGURE 9 - SAMPLES OF MICROPHONE ARRAYS USED IN BEAMFORMING TECHNIQUE (BRUEL \& KJAER, 2018) .....17

FIGURE 10 - AIR INFILTRATION FIELD TEST THROUGH EXPERIMENTAL WINDOW ASSEMBLY SET UP..........................23

FIGURE 11 - SOUND SOURCE LOCATION AND ACOUSTIC MEASUREMENT POINTS.............................................................2

FIGURE 12- SOUND PRESSURE MEASUREMENTSTAKEN IN ORDER TO IDENTIFY AIR LEAKAGE LOCATIONS...............26

FIGURE 13 - OVERVIEW OF 101 St. ClaIR AvENUE WeSt BUILDING (VANDERSLUIS, 2017) ....................................27

FIGURE 14 - LEFT IMAGE: FLOOR PLAN OF 22ND FLOOR \& RIGHT IMAGE: TEST LOCATION 1, SUTTE 2205,

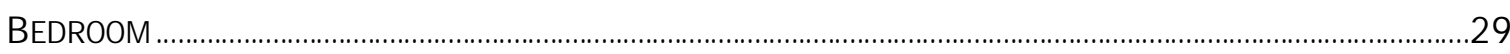

FIGURE 15 - LEFT IMAGE: EXTERIOR VIEW OF WINDOW ASSEMBLY SET UP, RIGHT IMAGE: INTERIOR VIEW OF WINDOW ASSEMBLY SET UP OF LOCATIONNO. 1 . .30

FiguRE 16 - LeFT IMAge: FloOR Plan OF 22ND FLOOR \& Right IMAGE: TEST LOCATION 2, SUTTE 2205, LIVINGROOM... 31

FIGURE 17 - LEFT IMAGE: EXTERIOR VIEW OF WINDOW ASSEMBLY SET UP, RIGHT IMAGE: INTERIOR VIEW OF WINDOW ASSEMBLY SET UP OF LOCATIONNO. 2 . 


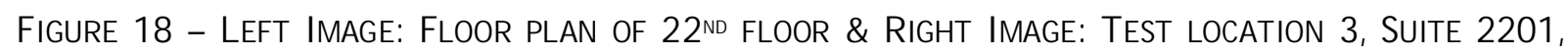
LIVINGROOM

FIGURE 19 - LEFT IMAGE: EXTERIOR VIEW OF WINDOW ASSEMBLY SET UP, RIGHT IMAGE: INTERIOR VIEW OF WINDOW ASSEMBLY SET UP OF LOCATIONNO. 3

FIGURE 20 - LEFT IMAGE: FLOOR PLAN OF $24^{\text {TH }}$ FLOOR \& RIGHT IMAGE: TEST LOCATION 4, SUITE 2402, FAMILY ROOM. .35

FIGURE 21 - LEFT IMAGE: EXTERIOR VIEW OF WINDOW ASSEMBLY SET UP, RIGHT IMAGE: INTERIOR VIEW OF WINDOW ASSEMBLY SET UP OF LOCATION NO. 4

FiguRE 22- LeFT IMAGE: FloOR PLAN OF 22 ${ }^{\text {ND }}$ FLOOR \& Right IMAGE: TEST LOCATION 5, SUTTE 2203, BEDROOM. 37

FIGURE 23 - LEFT IMAGE: EXTERIOR VIEW OF WINDOW ASSEMBLY SET UP, RIGHT IMAGE: INTERIOR VIEW OF WINDOW ASSEMBLY SET UP OF LOCATIONNO. 5 .38

FiguRE 24- LeFT IMAGE: FloOR PLAN OF 22ND FLOOR \& Right IMAGE: TEST LOCATION 6, SUTTE 2203, LIVINGROOM 39

FIGURE 25 - LEFT IMAGE: EXTERIOR VIEW OF WINDOW ASSEMBLY SET UP, RIGHT IMAGE: INTERIOR VIEW OF WINDOW ASSEMBLY SET UP OF LOCATIONNO. 6 .40

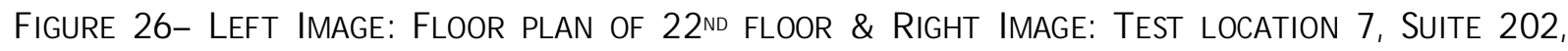
LIVINGROOM

FIGURE 27 - LEFT IMAGE: EXTERIOR VIEW OF WINDOW ASSEMBLY SET UP, RIGHT IMAGE: INTERIOR VIEW OF WINDOW ASSEMBLY SET UP OF LOCATIONNO. 1

FIGURE 28 - RELATIONSHIP BETWEEN THE AIR FLOW AND THE SOUND TRANSMISSION PRESSURE LOSS THROUGH THE EXPERIMENTAL WINDOW ASSEMBLIES. .44

FIGURE 29 - SUMMARY OF OUTPUT, CORRELATION ANALYSIS BETWEEN SOUND LEVEL TRANSMISSION LOSS AND AIR FLOW THROUGH EXPERIMENTAL WINDOW ASSEMBLIES CALCULATED BY MICROSOFT EXCEL 
FIGURE 30- PHYSICAL CORRELATION BETWEEN THE AIR FLOW AND THE SOUND TRANSMISSION PRESSURE LOSS (BASED ON THE TESTS PERFORMED ONTHE SEVEN EXPERIMENTAL WINDOW ASSEMBLIES) .46

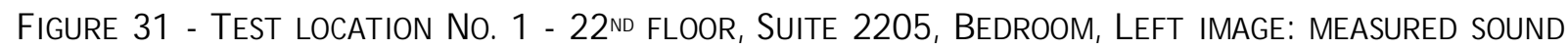
PRESSURE (DB) OF INSIDE OF THE SPECIMEN, RIGHT IMAGE: THERMAL IMAGING OF THE EXPERIMENTAL WINDOW ASSEMBLIES. .47

FIGURE 32 - TEST LOCATION NO. 2 - 22N FLOOR, SUITE 2205, LIVINGROOM, LEFT IMAGE: MEASURED SOUND PRESSURE OF INSIDE OF THE SPECIMEN, RIGHT IMAGE: THERMAL IMAGING OF THE EXPERIMENTAL WINDOW ASSEMBLIES.

FIGURE 33 - TEST LOCATION 3 - 22 ${ }^{\text {ND }}$ FLOOR, SUITE 2201, LIVINGROOM, LEFT IMAGE: MEASURED SOUND PRESSURE OF INSIDE OF THE SPECIMEN, RIGHT IMAGE: THERMAL IMAGING OF THE EXPERIMENTAL WINDOW ASSEMBLIES. .48

FIGURE 34- TEST LOCATION NO. 4 - 22 $2^{\text {ND }}$ FLOOR, SUITE 2402, FAMILY ROOM, LEFT IMAGE: MEASURED SOUND PRESSURE OF INSIDE OF THE SPECIMEN, RIGHT IMAGE: VIEW OF THE EXPERIMENTAL WINDOW ASSEMBLIES4 8 FIGURE 35 - TEST LOCATION 5 - 22 ${ }^{\text {D }}$ FLOOR, SUITE 2203, BEDROOM, LEFT IMAGE: MEASURED SOUND PRESSURE OF INSIDE OFTHE SPECIMEN, RIGHT IMAGE: VIEW OF THE EXPERIMENTAL WINDOW ASSEMBLY .49

FIGURE 36 - TEST LOCATION NO. 5 - 22 ${ }^{\text {ND }}$ FLOOR, SUITE 2203, BEDROOM, LEFT IMAGE: VIEW OF POINT A ON TESTED WINDOW ASSEMBLY, RIGHT IMAGE: VIEW OF POINT B ON THE EXPERIMENTAL WINDOW ASSEMBLY49

FIGURE 37 - TEST LOCATION NO. 6 - 22 ND FLOOR, SUTTE 2203, LIVINGROOM, TOP IMAGE: MEASURED SOUND PRESSURE OF INSIDE OF THE SPECIMEN, BOTTOM IMAGE: VIEW OF THE EXPERIMENTAL WINDOW ASSEMBLIES

FIGURE 38- TEST LOCATION NO. 7- 22 ${ }^{\text {ND }}$ FLOOR, SUITE 202, LIVINGROOM, LEFT IMAGE: MEASURED SOUND PRESSURE OF INSIDE OF THE SPECIMEN, RIGHT IMAGE: VIEW OFTHE EXPERIMENTAL WINDOW ASSEMBLIES51 


\section{List of Appendices}

APPENDIX 1 - SECTION DETAIL OF THE EXPERIMENTAL WINDOWS/ DOORS OF ALLAN WINDOW TECHNOLOGIES...54 APPENDIX 2: TECHNICAL SPECIFICATION OF SC160 SOUND LEVEL METER: .57

APPENDIX 3: ATS PORTABLE AIR TEST EQUIPMENT MODELAW-1000 VERIFICATION DOCUMENT .58 


\section{Exploring Acoustical Approach for Pre-screening of Window Assemblies Airtightness Level in an Existing Building}

\section{Introduction}

One of the building enclosure characteristics which have great influence on the energy consumption and indoor air quality is the building airtightness rate. Improving the building airtightness not only has a positive impact on building acoustical performance and resident comfort, it also decreases the buildings' cooling and heating load. Moreover, moisture, which is transferred by air flow through building enclosure, can influence building's material and structural stability over time, and often moves more through poor airtightness via vapor permeability.

As such, various studies, which are mentioned in the Literature review section of this research, were completed in localizing and quantifying building enclosure air leakage which is one of the initial steps to enhance buildings` performance. In these studies, different methods have been explored to determine building airtightness rate and to detect and quantify air leakage through building enclosure; such as blower door test, tracer gas method (Ghazi et al., 2014), transient approach (Mattsson et al., 2007) and acoustical method (Raman et al., 2014).

The acoustical method is one of the newly proposed methods for building air leakage detection, which is not reliant on weather conditions, and can also cover and examine a greater area within the building envelope. Moreover, time and labour can be reduced significantly with the help of this method. (Iordache et al., 2012)

In this research, a general review of airtightness detection and quantification methods is presented with great emphasis on acoustical method, which is explored more in depth. 
Due to significant impact of window systems on total air infiltration through building envelope, the correlation between sound transmission loss and air permeability through various windows in an existing building is explored. As such, the standard test method ASTM E783 is followed to determine the air leakage rate of the experimental windows. In accordance to this standard, the air permeability of these windows is determined at pressure differential of $75 \mathrm{~Pa}$. A loud speaker, capable of generating white noise is located on one side of the window to help verify and calculate the sound transmission loss through windows via sound pressure measurement on both sides of the window. White noise is defined as a signal, which is produced by combining all various sound frequencies simultaneously and can mask other disturbing background sounds.

In addition, in this study, the acoustic air leakage detection method based on standard ASTM E1186 will be investigated on the experimental windows.

\section{Literature review}

\subsection{Building envelope airtightness}

Building envelope airtightness is one of the most important characteristic of the building. Pressure variance between outside and inside of the building can lead to air transmission through building envelope. This pressure differential can be caused by wind and stack effect (Younes et al., 2011), which is due to indoor and outdoor temperature and moisture variance.

The American Society of Heating, Refrigeration, Air-conditioning Engineers (ASHRAE), describes air infiltration through building envelope as unexpected and accidental indoor and outdoor air exchange (As cited in Younes et al., 2011). Based on information released by ASHRAE, in average, walls, ceiling details, forced air and cooling systems, windows and doors, fireplaces and 
vents in conditioned spaces account for 35\%,18\%,15\%,12\% and 5\% of overall air infiltration in a building (As cited in Younes et al., 2011).

The amount of air tightness can also affect the building envelope hydrothermal performance (Kalamees et al., 2017). Vapour penetrated though cracks and openings of building enclosure will condense at cool areas within the exterior wall and in long term, can cause moisture accumulation issues in building enclosure which is one of the main contributors to deficient indoor air quality and mold growth (Kraus et al., 2016). Performance of ventilation system and acoustical efficiency of the building are also decreased by poor building enclosure tightness (Kraus et al., 2016).

Besides, air infiltration through building enclosure plays a significant role in the energy consumption of buildings (Younes et al., 2011). A study by Jokisalo et al. (2008) shows that 30\% of heating load of a residential detached house in Finland refers to building air infiltration. A research by Ren et al. (2015) on ten houses in Australia reveals that by decreasing $52 \%$ of air infiltration rate, $7 \%$ of annual space heating and cooling can be saved. As reported by Canada Mortgage and Housing Corporation (CMHC) (2007), 24\% of heat loss in multi-unit residential is due to air leakage. In winter, this percentage can reach up to $40 \%$ of space heating energy use. A study by $\mathrm{Ng}$ et al. (2015) reveals that by enhancing building envelope airtightness of a retail building in Atlanta and Chicago, $5 \%$ and $12 \%$ of building energy consumption can be decreased respectively. A simulation research on low rise commercial buildings in US shows that $9 \%$ to $36 \%$ of cooling and heating energy load can be saved by improving buildings enclosure airtightness. According to this study the biggest saving is referred to the buildings located at heating-dominated areas (Emmerich et al., 2007). As recorded by Ghazi et al. (2014), 6 to 9 percent of the total energy cost in buildings is because of air leakage. 
Therefore, establishing an air leakage control plan is one of the key factors in designing a high performance building. The first phase of this project aims to localize and quantify building envelope air leakage (Canada Morgage and Housing Corporation (CMHC), 2007).

\subsection{Building air leakage detection and calculation methods}

Building air leakage can be detected by using experimental measurements; such as blower door test system, tracer gas method, and transient approach (Hassan, 2013). The mentioned experimental methods in addition to field measurement of air infiltration through exterior windows/ doors test technique, infrared scanning air leakage detection method and acoustic technique will be reviewed and explored in this section.

\subsubsection{Blower door test}

Blower door test is the most commonly used method to estimate air leakage amount in residential and small buildings. This method can be used in large and tall buildings; nevertheless, in order to provide the required deferential pressure; various blower door fans with high capacity may be required (Kim, Jo, \& Jeong, 2013). This measurement method was performed first in Sweden in 1977 (Salehi et al., 2017).

Equipment involved in this technique are Blower Door Fan, Digital Gauge to monitor the pressure and airflow, and Blower Door Panel and Frame. Blower Door Panel and Frame are used to seal the door on which the blower door fan is installed during the measurement. The fan pressurizes or depressurizes the test area. The pressure difference being applied between interior and exterior side of the test area pushes or draws the air through all openings of the test area enclosure. To determine the airtightness of test area enclosure, the blower door system monitors and records the air flow through the fan and test area air pressure simultaneously. 
Based on ASTM E779-10 (2010), in order to estimate air leakage rate through building envelope, the pressure within the experimental space is required to be consistent (in the range of $\pm 10 \%$ of the pressure difference between inside and outside of the experimental space). As such all doors joining different rooms of the experimental space should be kept open during the test procedure.

In order to have more accurate outcome, the average temperature difference of indoor and outdoor of the experimental room must be multiplied by the experimental room height and should not exceed $200 \mathrm{~m}^{\circ} \mathrm{C}$. Otherwise, the pressure difference caused by stack effects the result precision of the test (ASTM E779-10, 2010).

After installing the door panel, frame and fan over an opening within the building envelope, such as door or window, and connecting the blower door gauge to the fan, the measurements, such as flow or leakage area, should be taken at increments of 5 to 10 Pa between pressure differences of 10 Pa to 60 Pa (ASTME779-10, 2010). (Figure 1)

Alfano et al. (2012) used fan pressurization technique (Blower door test) to study the airtightness of twenty buildings situated in southern Italy. Based on their study, one of the most important building elements, through which considerable amount of air infiltration happens is the window system. They found that by implementing simple modification on these windows and sealing the frames with proper sealing rubber, the energy loss via infiltration through the experimental building was reduced by half. Alfano et al. (2012) also analyzed some factors, which can contribute to the uncertainty of the blower door test result and made some suggestions to reduce these errors, such as calibrating the measuring devices and reducing error caused by the emvironmental phenomeanas such as wind and temprature altrernation during the test. This was 
done by repeating and performing the test in a more stable weather condition with low wind velocity (Alfano et al., 2012).

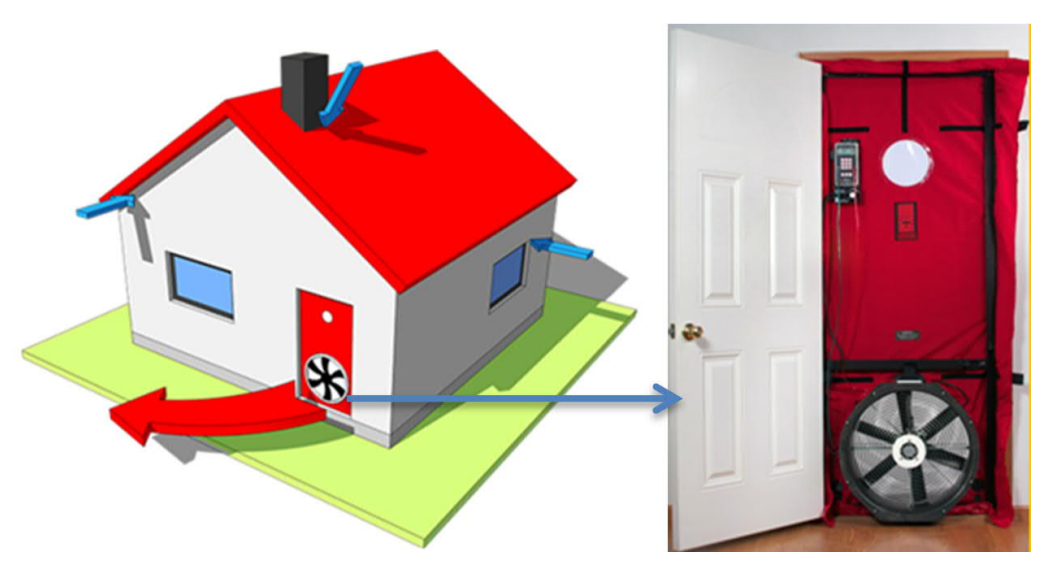

Figure 1 - Blower Door Test: left image (Lambda, 2018), right image (USI Blog, 2018)

By using the blower door test method, total leakage area can be estimated; however, the leakage cannot be localized. One other disadvantage of this method is highly dependant on size of the building or room that needs to be tested. Also, air-conditioning system should be turned off and residences are not permitted to exit or enter the area where the test is being performed. (Iordache \& Catalina, 2012)

\subsubsection{Tracer gas dilution method}

In tracer gas dilution technique, the concentration of a specific gas, which is injected into an experimental zone, is recorded carefully to estimate air change rate or flow of the air penetrating into experimental space through enclosure openings and cracks (Ghazi \& Marshall, 2014). As per ASTM E-741 standard test method (2011) three methods can be used to measure this air change rate or flow through tracer gas dilution technique; "concentration decay, constant injection, and constant concentration". 
By employing concentration decay test method, average air change rate can be estimated. In this method, small amount of tracer gas is distributed uniformly throughout the experimental space. Tracer gas concentration is monitored and measured periodically at certain times. Then, the recorded data is evaluated in order to determine the average air change rate (ASTM E741 ,2011). (Figure 2)

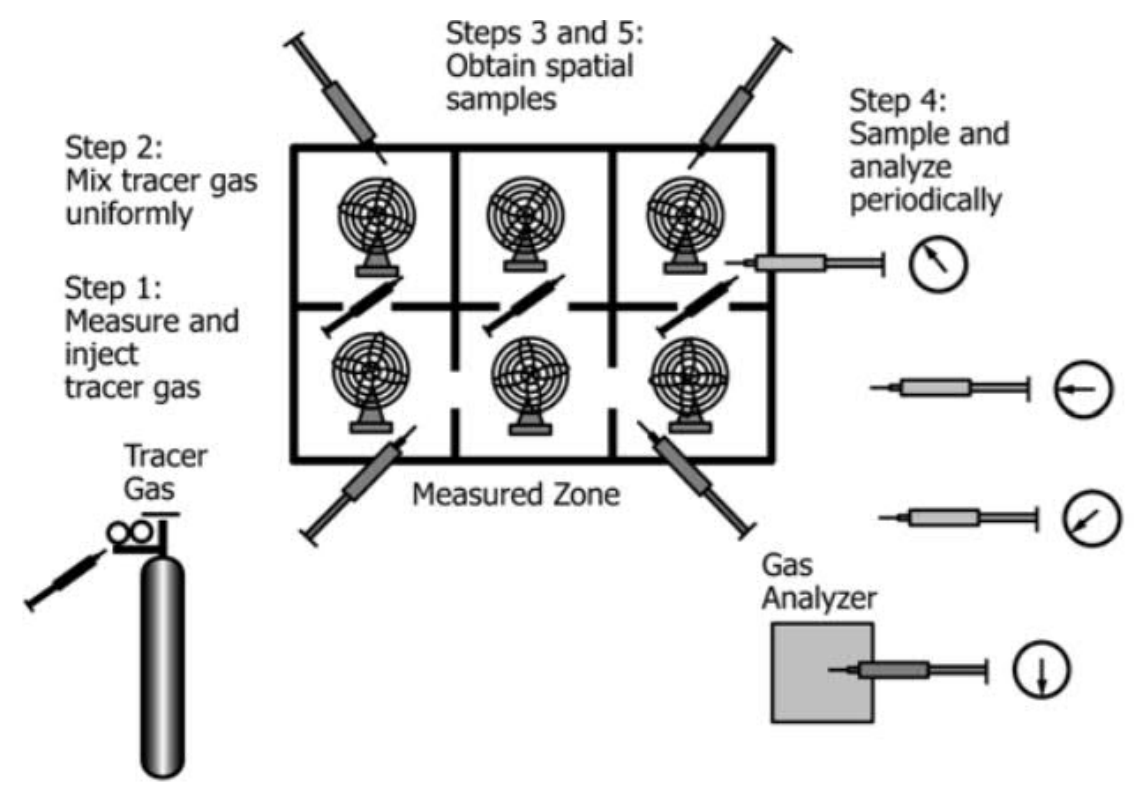

Figure 2 - concentration decay test technique (ASTME741, 2011)

With the use of constant injection test method, average air change flow can be evaluated. In this method tracer gas is inserted in to experimental space with a constant rate. After the gas is evenly distributed, trace gas concentration is monitored at certain times. Average air flow is determined by analyzing the recorded data (ASTME741, 2011).(Figure 3) 


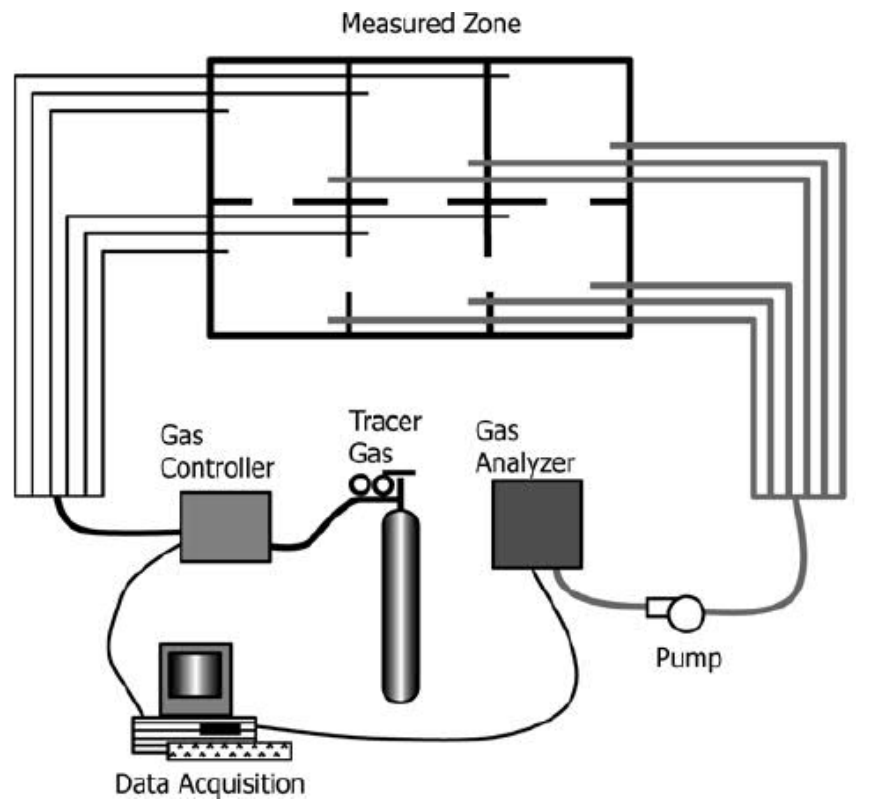

Figure 3- Constant Test Technique (ASTM E741, 2011)

In order to calculate air change flow via constant concentration test technique, an automated device is employed to preserve specific uniform tracer gas concentration with measuring the gas concentration regularly and injecting required gas volume. Based on each measurement and the volume of the gas added to the experimental space, air change flow is estimated (ASTM E741, 2011). (Figure 4)

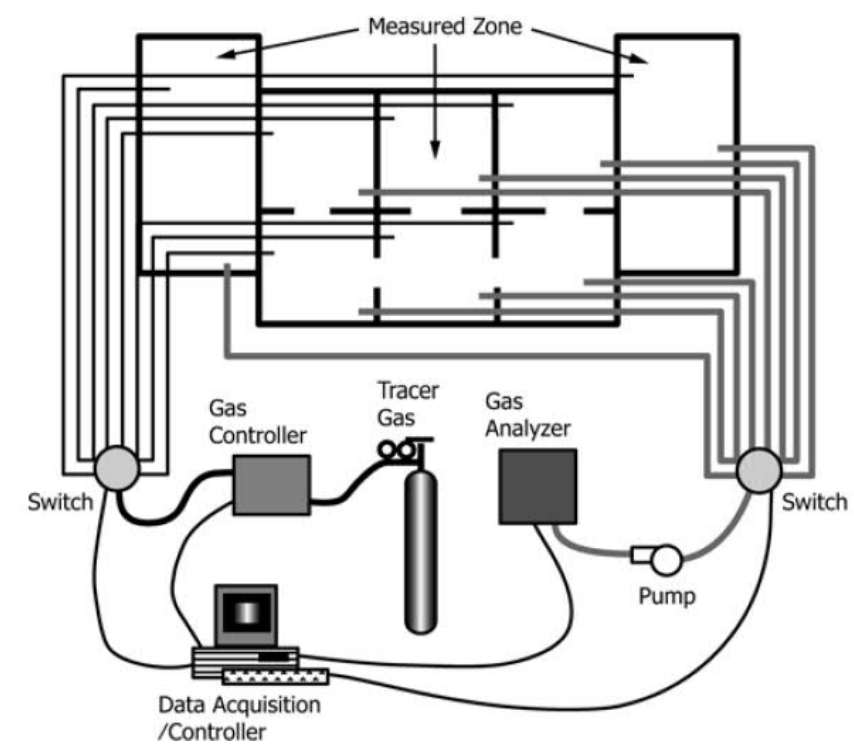

Figure 4 - Constant Concentration Test Technique (ASTME741, 2011) 
Ghazi et al. (2014) investigated the precision of tracer gas technique to estimate the air leakage flow rate through an experimental enclosure. In their investigation, a small chamber was installed over the enclosure/ building component which was to be tested. The chamber was depressurized and small amount of $\mathrm{CO} 2$, as tracer gas, was inserted within the chamber. By regularly checking and controlling chamber pressure and tracer gas concentration, the air leakage flow rate through the experimental enclosure can be estimated. In this technique the airtightness rate of the experimental enclosure can be achieved quickly. One of the difficulties of employing this method on the field is sealing the chamber to the surface around the experimental surface/ component especially rough surfaces.

Tracer gas method compared to blower door test method is more precise; however, it needs to be performed by an experienced and educated professional and it is expensive. Blower door test method is relatively cheaper, easier and more common in relation to tracer gas method. (Salehi et al., 2017)

Smoke trace method can also to be used for localizing the air leakage area. This method is described in ASTM E-1186 standard (2017). Due to pressure differentials between inside and outside of building enclosure, air tends to travel through opening and cracks within building enclosure. By placing smoke/ theatrical fog sources, which is a device that produces dense vapour which is very much identical to smoke and fog, near the suspected leaking area, within roughly 10 cm, the air infiltration area can be visually localized (ASTM E1186 standard, 2017). (Figure 5)

It should be mentioned that the air flow through the HVAC system within the building and air movement outside of the building may affect the test procedures and make the investigation difficult. Besides, this method needs to be used reasonably as the smoke may affect buildings 
material and occupants comfort. Also, when this method is used in cold climate, smoke may condense and make the observation difficult. (ASTME1186 standard, 2017)

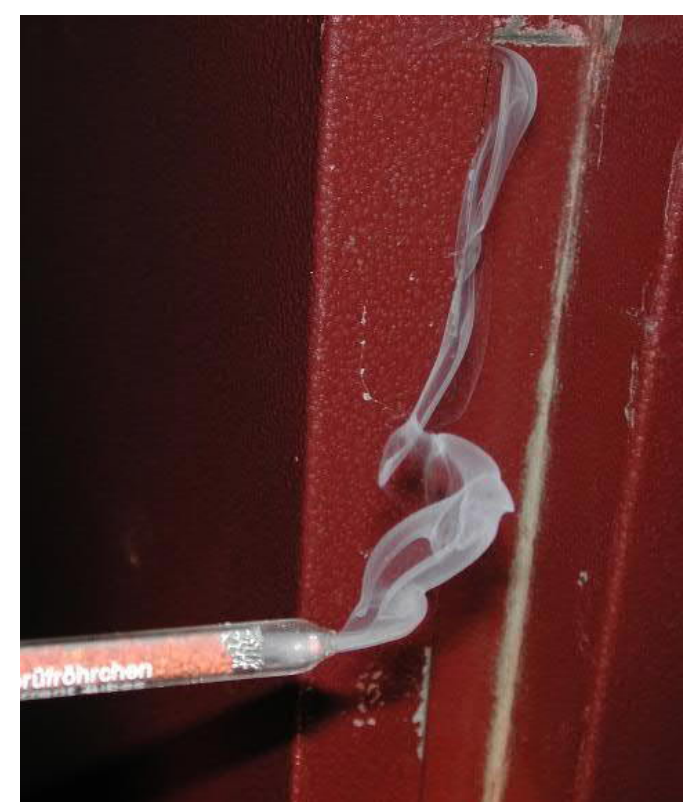

Figure 5 - Tracer Gas Method (InspectAPedia, 2017)

\subsubsection{Transient approach}

Mattsson et al. (2007) proposed transient pressurization technique in order to determine the airtightness rate. In this method, the experimental area was pressurized.

Based on this method, in order to have precise pressure measurement, the experimental room pressure must be increased to exceed atmospheric pressure; however, the room pressure should be raised up to the level that is safe for the experimental room and to avoid any structural damage (Yuill, 1985).

Once the above task is completed, the pressure decline level of a pressurized room will be measured over time and by employing gas law Mattsson et al. (2007) was managed to specify the 
air leakage rate. Based on this technique, the pressure measurements need to be taken at least twenty times per second for higher air flow rates (Mattsson et al., 2007).

\subsubsection{Infrared scanning air leakage detection method}

Another air leakage detection method is infrared scanning. In this technique, air leakage location can be identified by using infrared thermography and based on the experimental surface temperature (ASTME1186 standard, 2017).

This method also can be combined with building pressurisation/depressurisation using blower door fan for detecting the air leakage of building envelope from inside/ outside of the building. In this method the temperature difference between interior and exterior side of the building must be at a minimum of $5^{\circ} \mathrm{C}$. Infiltrated air, with different temperature, through building enclosure openings affects the surface temperature at leakage locations. Using infrared imaging camera, the leakage location can be identified. (ASTM E1186 standard, 2017)

Kalamees (2007) detected the air leakage locations of a new detached house in Estonia with infrared camera. Then, in order to detect the precise locations of the air leakage, he used the combination of thermal imaging camera technique and blower door fan. The outdoor and indoor temperature difference at the test time measured $20^{\circ} \mathrm{C}$. To employ the second method he depressurized the building to $50 \mathrm{~Pa}$ for 30 minutes. Then, he scanned the interior side of the building to determine the main air infiltration locations. (Figure 6) 

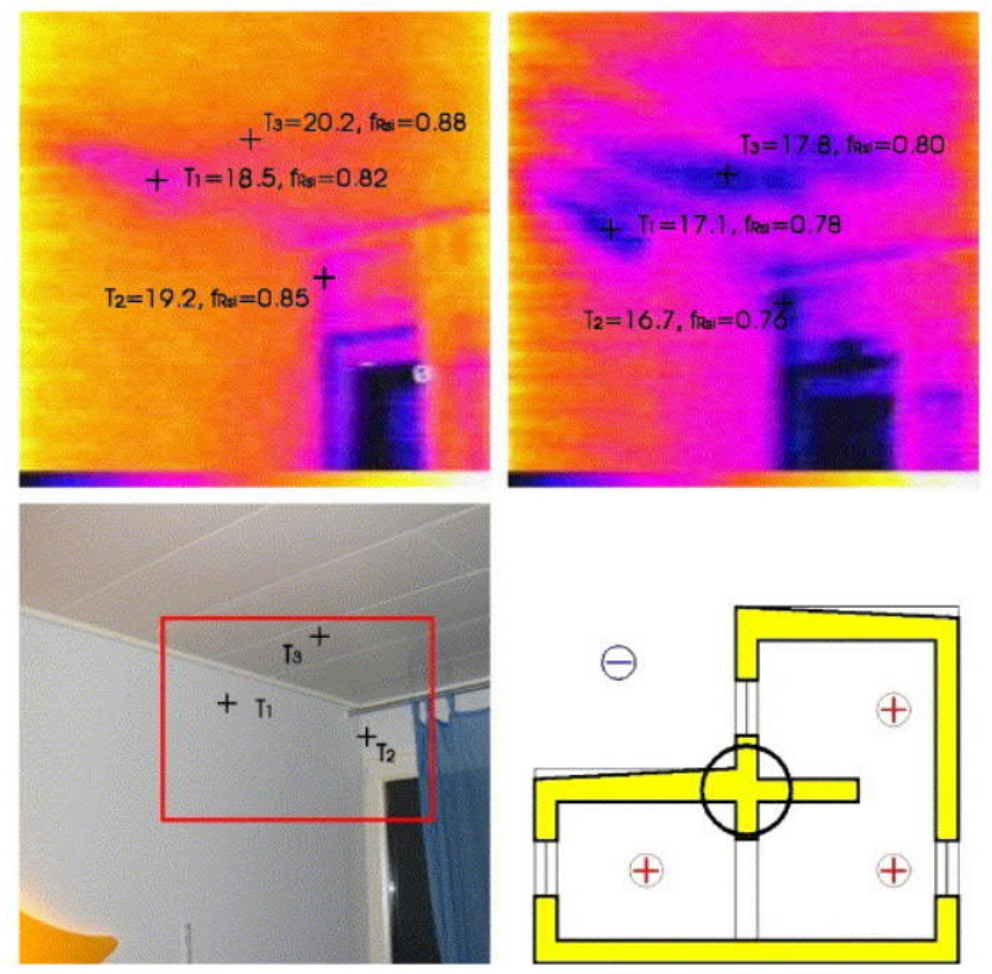

Figure 6 - Upper left: Combined building depressurization and infrared scanning, Upper right: infrared scanning (Kalamees T. , 2007)

\subsubsection{Acoustical approach}

Acoustic approach is a new method for building air permeability detection and estimation. Acoustical method is found on the assumption that sound travel through building enclosure opening through the same path that air does (ASTM E1186 standard, 2017).

Some studies, as outlined below, have been performed to explore the relationship between airtightness and sound transmission loss in order to introduce a technique to identify the air tightness rate of a specimen with just measuring the sound pressure transmission loss across the studied object.

The superiority of this method over the above mentioned methods (blower door test, tracer gas and transient methods) is that it can be faster, less expensive and does not rely on weather 
conditions (Iordache \& Catalina, 2012). Besides, with the help of this technique larger building envelope area can be assessed.

A research was done by Iordache et al. (2012) focusing on investigating the relationship between air permeability and sound transmission through wooden frame of double pane window joints of an existing building. For experimental purposes, the experimental room permeability was measured by mean of blower door test. Pressure difference and air flow rates between indoor and outdoor were taken simultaneously at increments of $5 \mathrm{~Pa}$ between air flow rates of $20 \mathrm{~Pa}$ to $70 \mathrm{~Pa}$ during pressurization and depressurization testing. In order to verify the sound transmission level through the facade of room being tested, two precise sensors were used. With the help of some sonometers softwares, sound pressure rate and reverberation time were documented. Different wooden frame window conditions, in the same room and façade, were examined to determine the relation between sound transfer rate and air permeability only through window joints. The result found in this research indicates that there is a reverse relationship between these two phenomena (Iordache \& Catalina, 2012). As indicated by Iordache and Catalina (2012) this method might work on other window types besides wooden framed double pane windows. Therefore, more research is required to be done in this regard.

Hassan (2013) focused on determining a new general model to calculate air leakage area and air flow of different components of a building, such as walls and floors, through acoustical approach which is based on measuring the building sound reduction index. To achieve this goal, a signal was produced in emitting room and sound pressure rate and background noise were measured in the receiving room. With the help of mathematical modules, he determined the air flow rate, connective heat loss and connective moisture rate of an interior lightweight partition. However, the theoretical calculation cannot be always accurate and certain since these calculations are based on some assumptions. 
Park et al. (2015) investigated the performance of improved windows. By studying aluminium and PVC frame and double pane windows in laboratory and controlled condition, they found that by improving the airtightness of experimental windows, sound reduction index of the window assemblies will also increase.

Varshney et al. (2013) investigate the correlation between sound transmission loss (STL) and air filtration in lab condition within an acoustic chamber isolated with polystyrene. Air leakage was measured using blower door test method at the pressure difference of 50 Pa between interior and exterior sides of the chamber. STL was determined by employing sound level meters. A relation between the air leakage and STL through different types of holes and cracks was obtained within lab environmental condition. Then, this proposed technique was examined to estimate the air filtration of building components in five buildings. It was concluded that the result obtained from this method was close to the blower door test result. However, this method has some restrictions. It cannot be used to estimate air leakage through small openings which are not visible or not accessible nor holes which are not extended from one side of the enclosure to the other. This technique also cannot be employed in a noisy environment (Varshney et al., 2013). In addition, the other drawback of this method is sealing the acoustic chamber to building envelope which may be challenging at uneven surfaces. Also, by using this acoustical method presented by Varshney et al. (2013), only the surface of the building envelope within the chamber can be assessed.

In order to determine the practical implementation of acoustic approach and have more realistic ideas towards this method for air infiltration detection and estimation, more research would be required in field and uncontrolled conditions. To achieve this objective, the correlation between airtightness and sound pressure loss of one of the component of an existing building enclosure will be investigated in this research. 


\subsection{Sound Source Estimation and Localization}

To identify, localize and visualize sound source, different techniques, as noted below, can be employed. These individual methods have their own advantages and disadvantages. These approaches are as follows:

1. Using single transducer

2. Employing two spaced transducer ( One dimensional transducers)

3. Employing four transducer which are arranged in tetrahedral algorithm (Ambisonics decomposition)

4. Beamforming

5. Near field acoustical holography (NAH)

\subsubsection{Single transducer method}

A research was done by Iordache et al. (2012) , in which the correlation between air leakage and sound transmission through an existing building envelope was studied, two single transducer were employed to measure the sound pressure level of interior and exterior side of the building envelope. In this study sound pressure level was measured by two kinds of sound level meters simultaneously; two professional transducer "2250 Investigator" by Bruel \& Kjaer for more precise recording and two common commercial transducers "DT 8852" in order to compare the outcomes of two types of sensors to confirm their practical application.

\subsubsection{Two spaced one dimensional transducers sensors}

Typically, the sound intensity measurement device by one-dimensional transducers consists of two spaced pressure microphone which is connected with a solid spacer (Musha \& Taniguchi, 2005). In this method, pressure gradient is determined in order to calculate the sound intensity 
(Musha \& Taniguchi, 2005). The disadvantage of this approach is that if the distance between the two microphones is more than the wavelength, the pressure estimation will fail. Therefore, the sound intensity measurement preciseness is restricted to the gap between the two transducers. In addition, the two transducers should be phase-matched (Musha \& Taniguchi, 2005).

\subsubsection{Ambisonics decomposition}

At first, sound Ambisonics decomposition was presented by Gazon and Craven in 1975 (Martellotta, 2013). The name of Ambisonics originated from the mixture of a Latin verb, ambire, which means surround and a Latin noun, sonus which means sound. (IDIS, 2018)

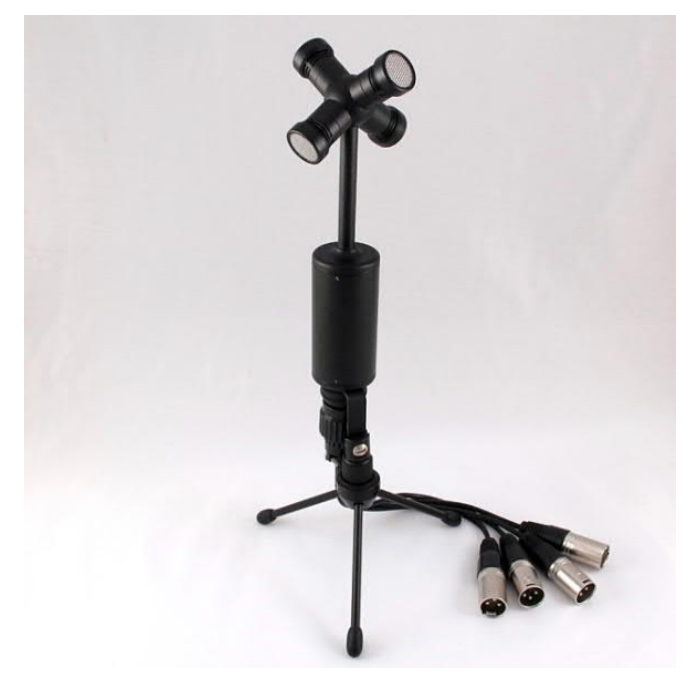

Figure 7 - Ambisonics decomposition (IDIS, 2018)

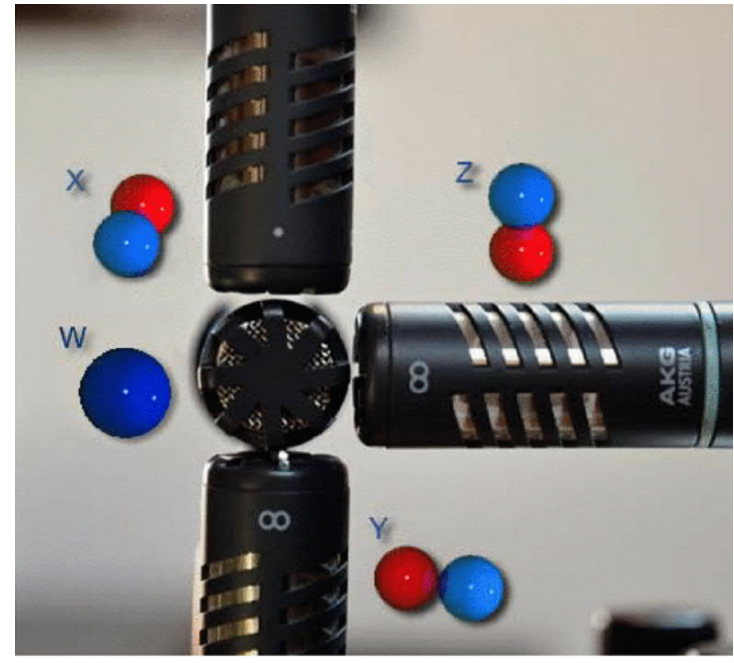

Figure 8 - Ambisonics B-format layout (Ortolani \& Uncini, 2016)

This technique was found on recording sound field by means of four transducers which are placed at the vertices of a tetrahedron. With the help of this approach, sound pressure, velocity and directional data can be determined (Martellotta, 2013)(Figure 7). By ambisonic microphone array two types of signals can be provided; A-format and B-format signals. The A-format signal is the basic signal which is provided by four microphones collectively. B-format signal comprises of four 
components; $\mathrm{W}, \mathrm{X}, \mathrm{Y}$ and $\mathrm{Z}$. W is the center of the array sound pressure and $\mathrm{X}, \mathrm{Y}$ and $\mathrm{Z}$ are pressure gradient along the Cartesian axes. By these set of signals and channels the sound source direction can be identified. However, the accuracy of the sound source localization is dependent on the type of microphones and sound processing device used (Martellotta, 2013). (Figure 8)

\subsubsection{Beamforming}

Beamforming is a sound processing method. In this method, delays and phase changes of every signal reaching to each transducer are considered to specify the direction of sound source (Martellotta, 2013) (Figure 9). Beamforming not only can be used in sound identification and localization remotely but with some adjustments, it can also be used for nearfield sound source imaging (Cho \& Roan, 2009). Raman et al. (2014) used remote acoustic approach to locate leaks out of a window with beamforming technique. Since using beamforming approach cannot quantify the leakage area, employing Nearfield Acoustic Holography (NAH) technique, which has the potential to localize and quantify air infiltration through building envelope, may be the next step in this filed, which was proposed by Raman et al. as a future work.
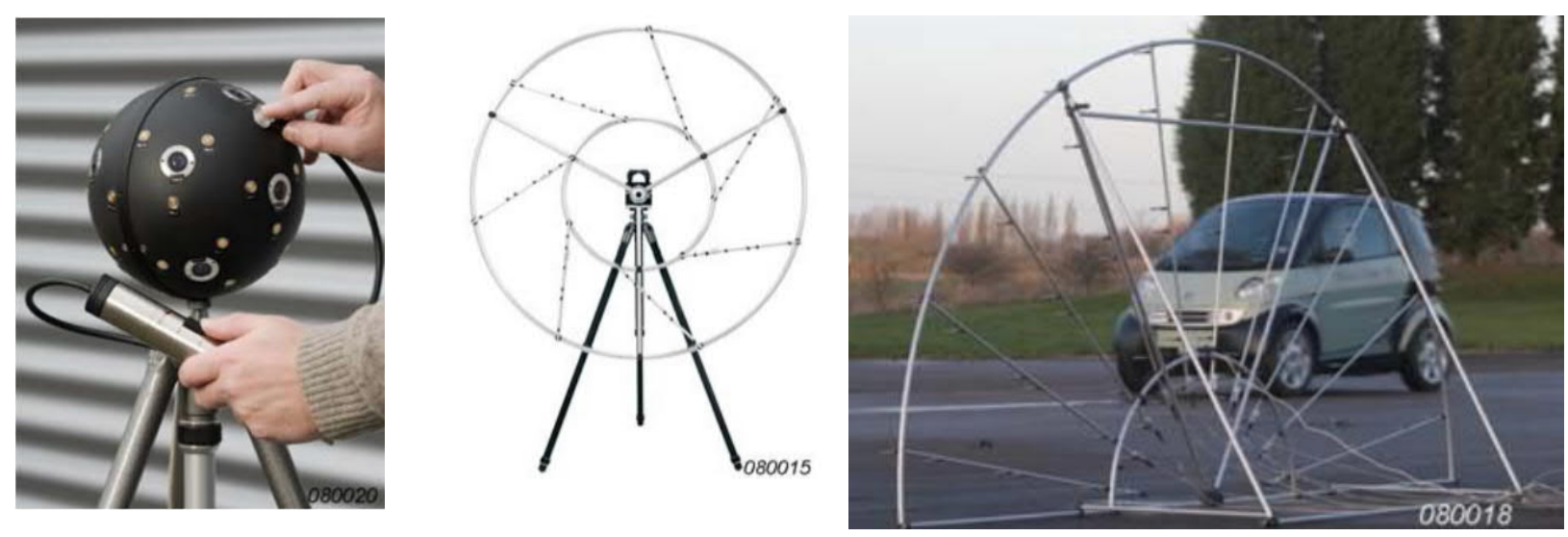

Figure 9 - Samples of microphone arrays used in beamforming technique (Bruel \& Kjaer, 2018) 


\subsubsection{Near field acoustical holography}

Near field acoustical holography (NAH) is a method for recognizing noise sources and rebuilding the sound radiation energy in three-dimensional space. In this procedure, sound pressure is measured at various points on a surface around sound source (Hologram surface) which can be a plane, cylinder or sphere (Muddeen \& Copeland, 2012). Sound pressure, velocity and intensity can be estimated with the help of this technique (Fernandez-Grande, Xenaki, \& Gerstoft, 2017).

NAH requires a spacing of less than half of the acoustic wavelength between the microphone arrays. As such, this method can support a restricted rang of frequency, mostly low frequencies. In addition, in this method, measurements need to be done close to the experimental surface. However, beamforming provide accurate results at medium to high frequencies. The microphone arrays spacing is required to be up to twice or three times of wavelength and the measurement needs to be done at a greater distance. (Hald, 2016). Haled (2016) presents a technique named wideband holography (WBH), which is based on an iterative algorithm. With this method the entire frequency range can be covered with one measurement at a relatively small distance.

Chelliah et al. (2014) investigated sound source localization with the help of NAH. They studied this acoustic approach based on Generalized Inverse (GINV) technique in order to locate the air leakage of an actual building. As such, they employed a blower to pressurize the test room and the acoustic pressure was recorded by 24 microphone arrays at the same time around a window opening. Two frequency ranges were examined in their research. Based on their study, it was concluded that GINV method was performed well at lower frequencies. Also, once the higher frequency range is used in this method, the closer measurement from surface to sound origin needs to be employed. 


\subsection{ASTM Standards}

\subsubsection{ASTM standard E 783-02: Field measurement of a ir infiltration through installed windows test method \\ The role of window assemblies on total building air leakage}

The impact of window systems on total air infiltration through building envelope is significant. In a typical residential building, windows can be accounted for about half of the energy loss through building enclosure (Cuce, 2017). One of the main reasons of heat loss through window systems is due to air infiltration. In mild climate, approximately $20 \%$ of heat loss though windows is caused by air leakage. The impact of air leakage through windows on energy consumption becomes more noticeable in cold climate (Cuce, 2017).

As per different studies done before, various percentages of window systems' contributing to total air leakage amount through building envelope are reported ranging from $7 \%$ to $25 \%$ (Almeida et al., 2017). Study was done by Alimeida et al. (2017) on Southern European buildings reveals that window systems account for $15 \%$ of the entire air infiltration amount through building enclosure.

A research by Henry et al. (1998) on 35 windows in a controlled condition laboratory shows that air infiltration through window assemblies is rising at cold temperature. Based on their research, the amount of air infiltration through the tested windows at the temperature of $-30^{\circ} \mathrm{C}$ in the worst case scenario was five times of that at temperature of $20^{\circ} \mathrm{C}$ at the pressure difference of $75 \mathrm{~Pa}$.

Therefore, determining air leakage and air flow through installed windows/ doors is crucial in decreasing windows related heat loss and energy consumption especially in cold climates. 


\section{ASTM standard E 783-02}

Based on ASTM standard E 783-02, in order to determine the air infiltration through exterior windows/ doors, after visual inspection of the test specimen, a chamber is set up over each face of the experimental windows/ doors. Air is exhausted or blown within the chamber at one side of the test window/ door assembly to achieve the pressure difference on which the specimen is designed for. If no pressure difference rate assigned for the specimen, pressure difference of $75 \mathrm{~Pa}$ (1.57 $\mathrm{lb} / \mathrm{ft} 2$ ) should be considered for the test (ASTM E779-10, 2010) in order to reduce the impact of outside temperature variance and wind on field test result and achieve more precise result (Anis et al., 2013) .After measuring the extraneous air flow though the test chamber during the first test, air flow through the window/ door assemblies is measured. The difference between these two measurements will define the air flow through the specimen. In order to determine the air leakage rate through the experimental window/ door assemblies, the calculated air flow through the specimen should be divided by the specimen area or specimen length of operable crack (ASTM E783-02 Standard, 2010)

\subsubsection{ASTM E1186 standard: Acoustic air leakage detection method}

This technique, which is easy, inexpensive and requires minimal amount of training, was established on the basis of which sound and air transfer passages through building enclosure openings are the same.

In this method, any sound source which can produce adequate sound can be employed. White noise is a preferable sound for this method. In order to localize leakage area, sound source needs to be placed at one side the building enclosure and by moving the Sound level meter over the other side of the envelope, the area with local increase in pressure, which are the leakage areas, can be identified. The meter needs to be moved preferably $1 \mathrm{~cm}$ away from the experimental surface to have more accurate result. (ASTM E1186 standard, 2017) 


\section{Specific Objectives of the Study}

The economical and environmental effects of air infiltration through building envelope lead towards more research on methods for detecting air leakage locations and estimation. As presented in previous sections, different methods and techniques are available for detecting building enclosure air infiltration. Due to some superiority and advantages of acoustical method over the other methods, such as blower door test system, tracer gas method, and transient approach, and also due to the lack of research in this field, further study on this technique is required.

The aim of this study is to explore the acoustical approach for pre-screening of building envelope airtightness level. As such, the correlation between airtightness and sound transmission loss will be investigated.

Window assemblies are identified as one of the influential building components on air infiltration rate of the building. As per ASHRAE, approximately $15 \%$ of air leakage of the building is through windows and doors (As cited in Canada Mortgage and Housing Corporation (CMHC), 2007). As such, at the present research, windows will be investigated as building enclosure experimental component in an existing building.

The research question for this study will be:

- If there is any correlation between air infiltration and sound transmission loss through window assemblies in field condition.

The answer to this question may lead to presenting a method for pre-screening of building envelope airtightness level. 
In addition, to identify the possible leakage area, the acoustic air leakage detection method based on standard ASTM E1186 will be explored on the experimental windows and compared with Infrared scanning air leakage detection method.

\section{Methodology}

\subsection{Correlation between air infiltration and sound transmission loss through window assemblies}

Air infiltration and sound transmission loss through window assembly joints of an existing building are measured to investigate the relationship between these two phenomena. The tests were performed at seven locations on a building located at 101 St. Clair Avenue West. The test methods used are as follows:

\subsubsection{Air infiltration field test through experimental window assemblies}

The air infiltration tests were performed based on ASTM standard E 783-02 field test method. First, the experimental window assemblies were visually studied. Then, both faces of windows (Front \& Back) where covered with chambers made of 6 mill polyethylene sheets and secured to the window perimeters with tuck tape. Various support rods were used to prevent the contact of the polyethylene sheet and the test specimen and to help the pressure spread equally throughout the chamber.

ATS portable air test equipment model AW-1000 was employed to provide 75Pa differential air pressure across the experimental window assemblies in order to determine the air flow though the specimen. 
The measuring device tubes were connected to the chamber, which was mounted on the interior side of the windows, and was sealed completely with tuck tape. The chamber was negatively depressurized with the attached air test device. The extraneous air infiltration though and around the experimental window, chamber and measuring device was recorded at the deferential pressure of 75Pa. Later, the exterior chamber was removed and again the differential pressure was set at 75Pa and the flow rate through the window assemblies was measured. The total airflow though the experimental windows was determined by subtracting the first reading, extraneous air flow, from the second reading. (Figure 10)

During each test both temperature and relative humidity of inside and outside of the building were measured. Speed and direction of wind were also recorded.

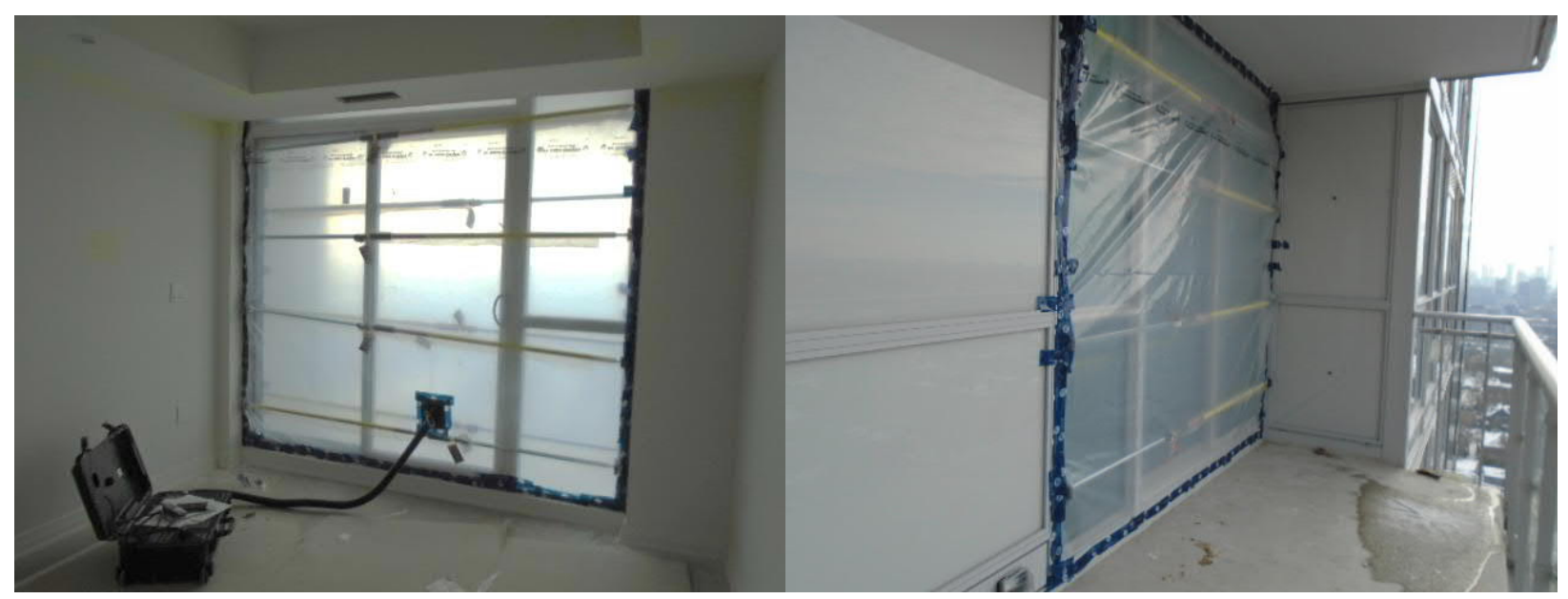

Figure 10 - Air infiltration field test through experimental window assembly set up

\subsubsection{Determining sound transmission loss through tested window assemblies}

To explore sound level transmission loss through the tested specimen, Dodecahedron speaker of Bruel \& Kjaer Canada Ltd. was used as sound source in order to produce white noise. White noise is the signal which is produced by combining all various sound frequencies simultaneously and can mask other disturbing background sounds. The speaker was situated at the 
center of exterior side of each window assembly and spaced approximately $1.12 \mathrm{~m}$ (4 ft.) far from the specimen at the height of one meter from the floor slab.

In order to prevent the effect of background noise on the test results, the sound pressure level, which was produced by the sound source, had to exceed by $15 \mathrm{~dB}$ more than the back ground noise pressure level (Iordache \& Catalina, 2012). According to Hassan (2013) if the measured sound level is $10 \mathrm{~dB}$ more than the background noise sound level, no adjustment is required to the measured sound level. However, if this variance becomes less than $3 \mathrm{~dB}$ the test cannot be done due to the high background noise sound level. In this research, this difference was more than $10 \mathrm{~dB}$; therefore, no adjustment was required. Moreover, the tests were performed in unoccupied building floors with low level back ground noise to have more precise results.

Cesva SC160 sound level meter was used to measure the sound pressure at both sides of the window assemblies. The width of each experimental window assembly was broken down into four equal sections providing three equal measuring points at each side of the specimen. The measurements were taken at equal spacing from the specimen on each side of the experimental window assembly at a specific height of approximately one meter from the floor slab. The sound pressure measurement was taken for 20 seconds and the average during this time was considered as the sound pressure of each measurement point. The average of three inside/ outside points was used as the sound level pressure of inside/ outside of the window assemblies being tested. (Figure 11)

In order to calculate the sound pressure transmission loss through the window, the average of inside sound pressure was subtracted from the average sound pressure measured outside. 

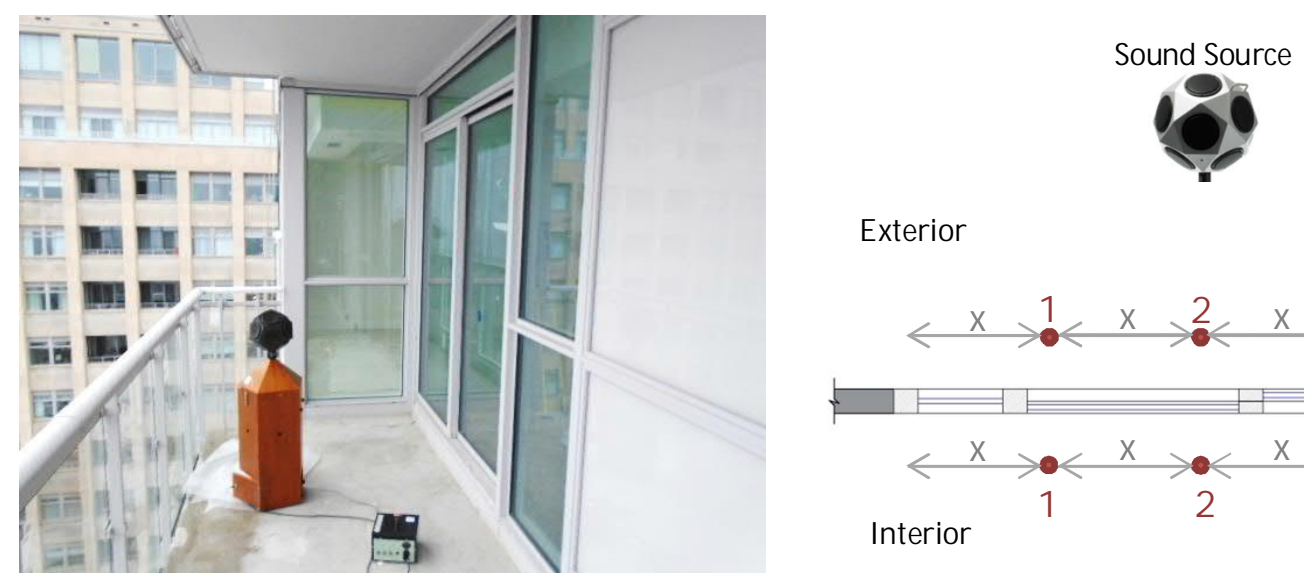

Exterior

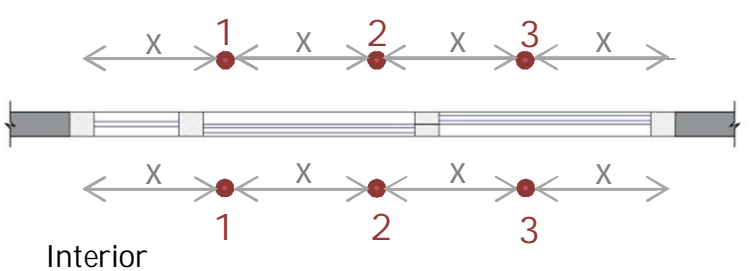

Figure 11 - Sound source location and acoustic measurement points

Within the next sections of this study, all seven test locations will be analyzed, along with measurements data and test results to investigate the correlation between sound transmission loss and air flow through the experimental windows.

\subsection{The investigation of acoustic air leakage detection method}

In order to explore acoustic air leakage detection method, which is based on standard ASTM E1156 (2017) and was explained on section 2.2.6 of this report, further, it was used to pre-screen the air infiltration locations of the seven experimental window assemblies. A loudspeaker was placed outside and at the center of each window assembly and spaced approximately $1.12 \mathrm{~m}$ (4 ft.) far from the specimen at the height of one meter from the floor slab to produce white noise. Since air infiltration through window assemblies mostly happen through window frames and sashes, the Sound level meter was moved over to the interior side of the tested window sashes/frame, by approximately $1 \mathrm{~cm}$ from the specimen surface. The sound pressure was recorded every $0.25 \mathrm{~m}$ (10 inches) (Figure 12). 

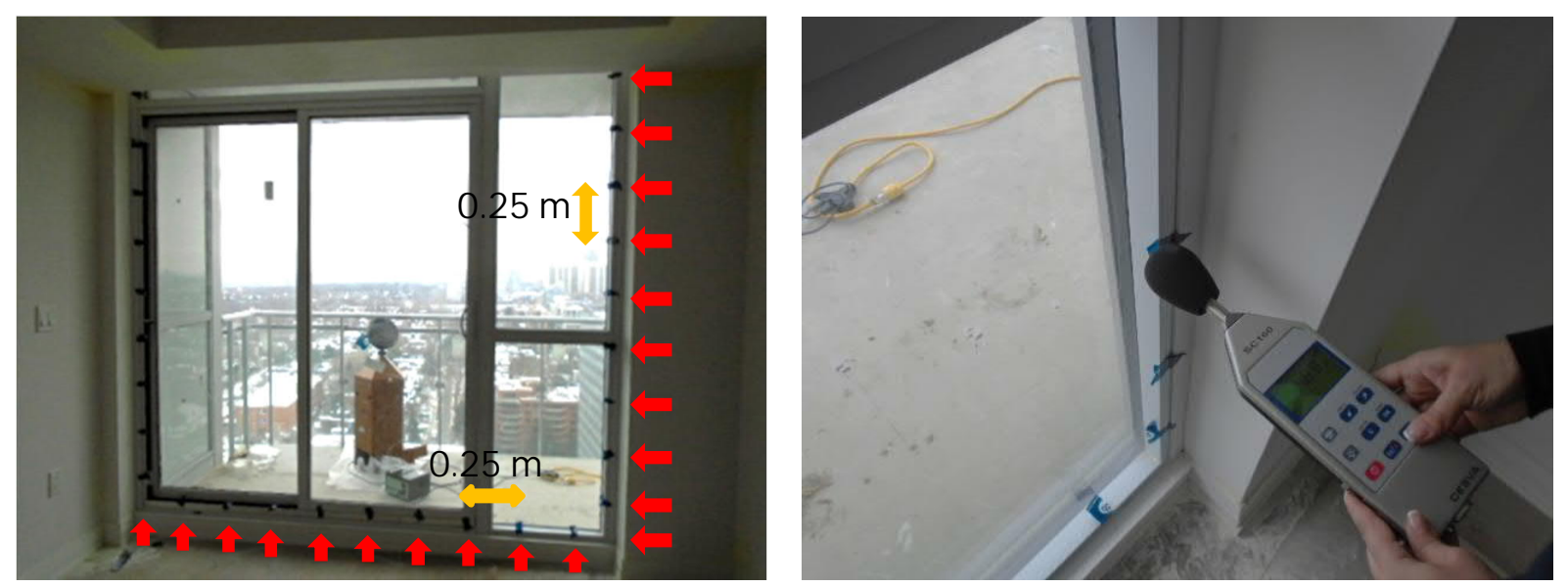

Figure 12-Sound pressure measurements taken in order to identify air leakage locations

With the use of thermal imaging camera and visual inspection of tested area, the experimental window assemblies were scanned and will be analyzed and compared with the measured acoustic data. This analysis and the data obtained from these tests will be presented within the next sections of this research.

In the following analysis and sound pressure measurements, the increase in sound pressure at the top section of the windows which is located behind bulkhead will be ignored due to the sound reflection at this area.

\subsection{Field study: Test locations and Tests Results}

For the purposes of this study, seven randomly selected window assemblies, which are manufactured by Allan Window Technology and installed on a 27 story building located at 101 St. Clair Avenue West, were studied. (Figure 13) 


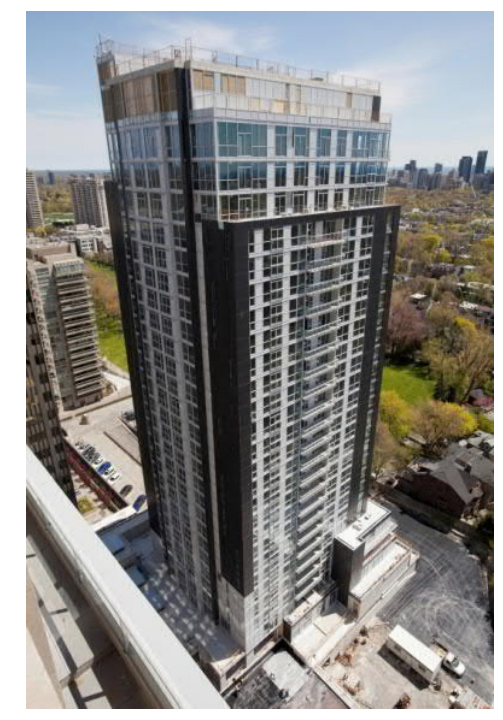

Figure 13 - Overview of 101 St. Clair Avenue West Building (Vandersluis, 2017)

The window assemblies of the building consist of thermally broken aluminum frames and the vision glass, which is double glazed Argon filled with warm spacer along the glass pane premier. The exterior caulking was completed around the perimeter of the experimental window assemblies and the interior drywall was installed.

The experimental windows were located at following suites:

1. Location No. 1:

$22^{\text {nd }}$ floor, Suite 2205, Bedroom
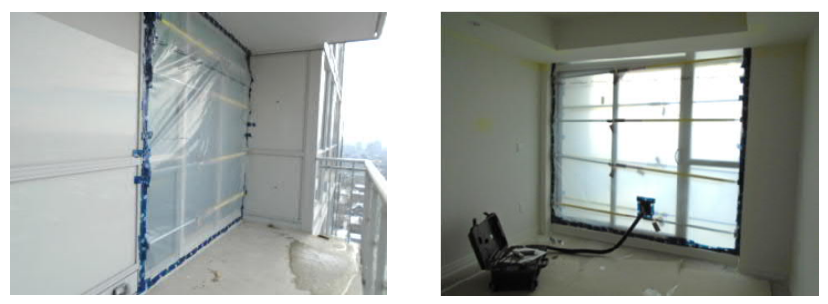

2. Location No. 2:

$22^{\text {nd }}$ floor, Suite 2205, Livingroom
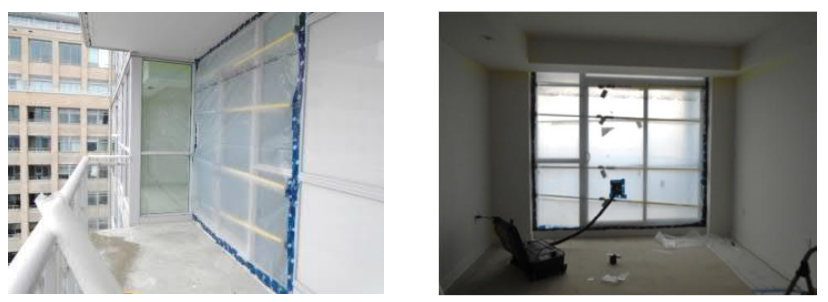
3. Location No. 3:

$22^{\text {nd }}$ floor, Suite 2201, Livingroom
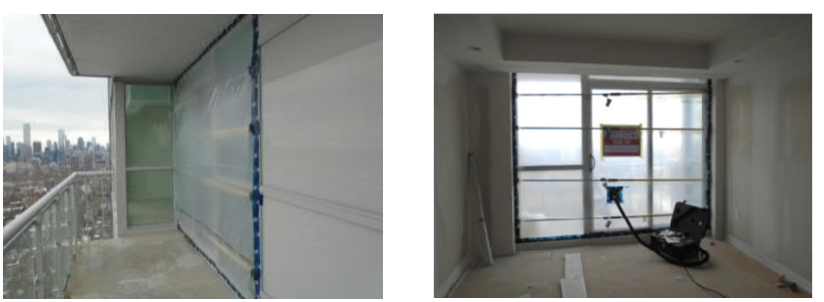

4. Location No. 4:

$24^{\text {th }}$ floor, Suite 2402 , Family room
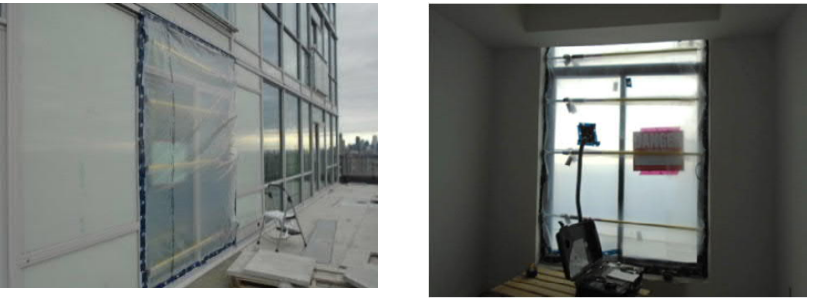

5. Location No. 5:

22nd floor, Suite 2203, Bedroom
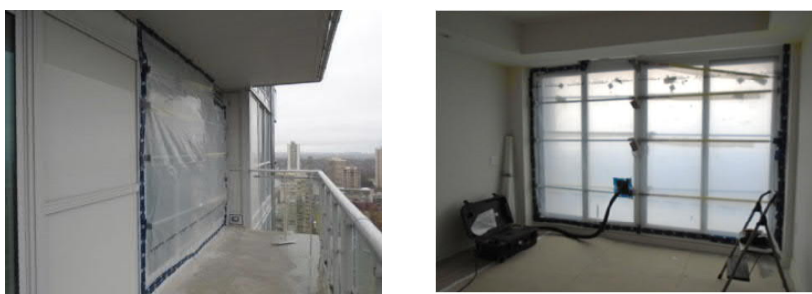

6. Location No. 6:

$22^{\text {nd }}$ floor, Suite 2203, Livingroom
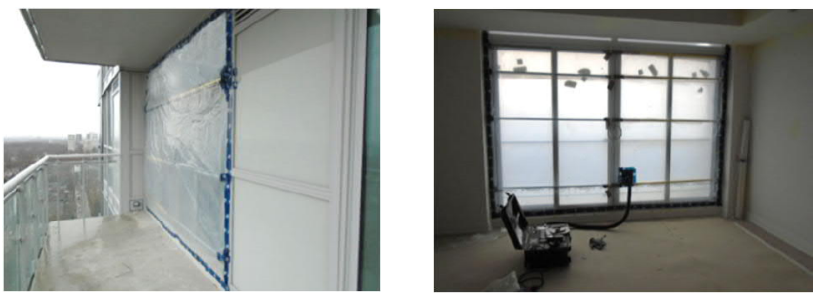

7. Location No. 7:

$2^{\text {nd }}$ floor, Suite 202, Livingroom
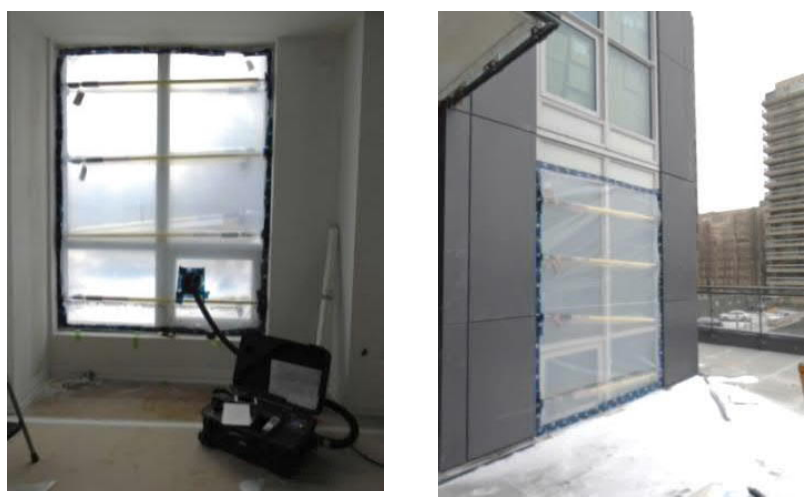


\subsubsection{Window airtightness and sound pressure transmission loss measurements and results assessments}

\subsubsection{Test location No. 1}

This window assembly was located in the bedroom of suite \#2205 on 22nd floor and was tested at 12:00 p.m. on January 10, 2018. The experimental window assembly, which was facing west, consisted of three fixed windows and one sliding door (with one side fixed and the other slider) (Figure 14).
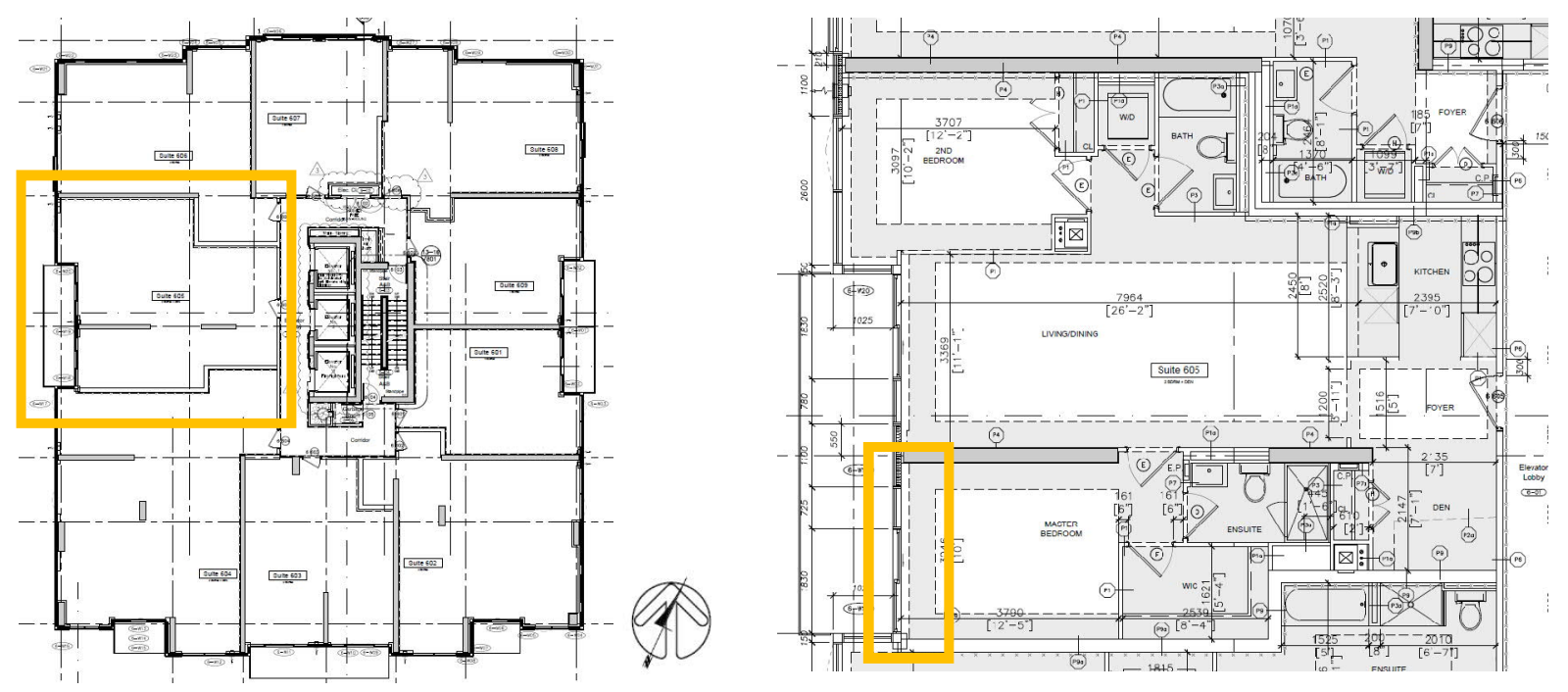

Figure 14 - Left Image: Floor plan of $22^{\text {nd }}$ floor \& Right Image: Test location 1, Suite 2205, Bedroom

Airtightness test was performed based on standard ASTM-E783 as described in section 4.1.1 of this report (Figure 15). The test results and environmental conditions during the test are noted in following table (Table 1). 


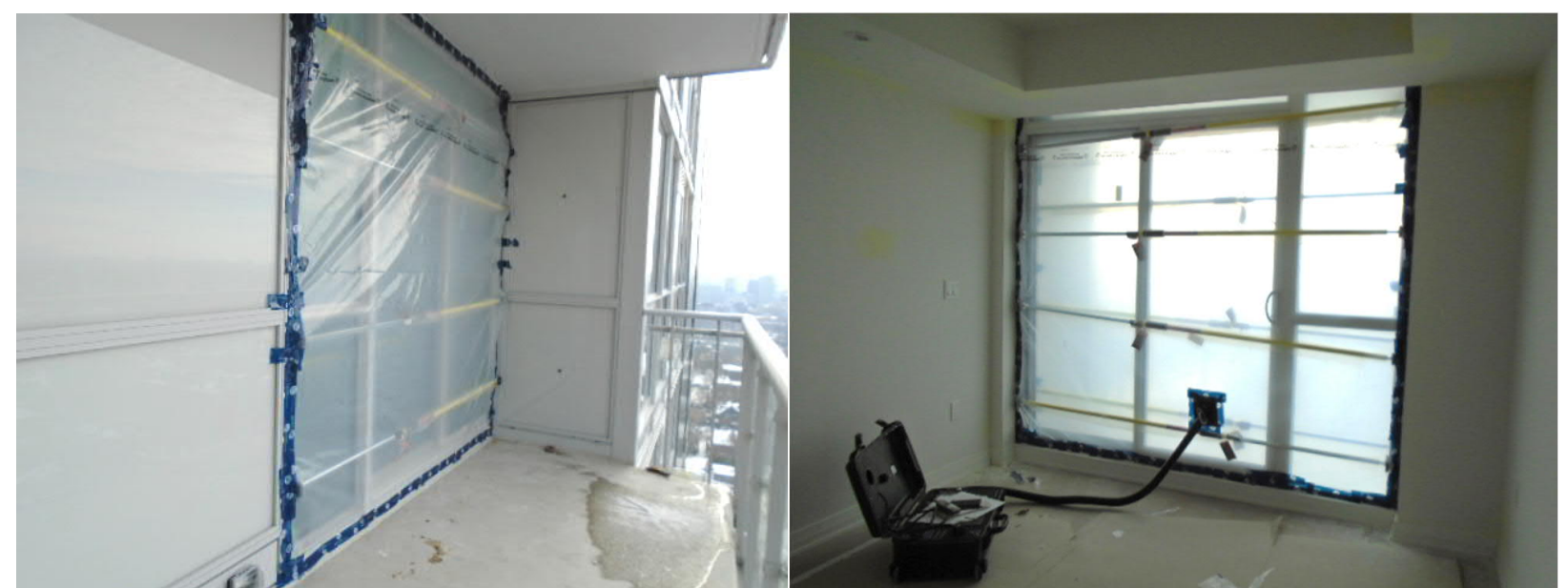

Figure 15 - Left image: Exterior view of window assembly set up, Right image: Interior view of window assembly set up of Location No. 1

\begin{tabular}{|c|c|c|}
\hline \multicolumn{3}{|c|}{ Environmental Conditions During window Airtightness Test, Suite 2205, Bedroom } \\
\hline \multicolumn{2}{|c|}{ Indoor temperature } & $19^{\circ} \mathrm{C}$ \\
\hline \multicolumn{2}{|c|}{ Outdoor temperature } & $1{ }^{\circ} \mathrm{C}$ \\
\hline \multicolumn{2}{|c|}{ Indoor Relative Humidity } & $23 \%$ \\
\hline \multicolumn{2}{|c|}{ Outdoor Relative Humidity } & $68 \%$ \\
\hline \multicolumn{2}{|l|}{ Wind speed } & WNW $10 \mathrm{KPh}$ \\
\hline \multicolumn{2}{|l|}{ Weather } & Cloudy \\
\hline \multicolumn{3}{|c|}{ Window Airtightness Test Measurements, Suite 2205, Bedroom } \\
\hline Tare (A) & Extraneous air infiltration Flow, depressurization (75 Pa) & $11.75 \mathrm{~L} / \mathrm{S}$ \\
\hline Reading (B) & Air infiltration Flow, depressurization (75 Pa) & $11.86 \mathrm{~L} / \mathrm{S}$ \\
\hline Net (B-A) & \multicolumn{2}{|l|}{$0.11 \mathrm{~L} / \mathrm{S}$} \\
\hline
\end{tabular}

Table 1 - Window Airtightness Test Measurements of Location No. 1

Sound level transmission loss through the tested specimen was measure as described in section 4.1.2 of this report. The measured data and sound level transmission loss are outlined in Table 2. 


\begin{tabular}{|l|l|l|l|l|}
\hline \multicolumn{5}{|c|}{ Sound Pressure Measurements, Suite 2205, Bedroom } \\
\hline & Point 1 & Point 2 & Point 3 & Average \\
\hline Outdoor (A) & $80.1 \mathrm{~dB}$ & $79.1 \mathrm{~dB}$ & $80.2 \mathrm{~dB}$ & $79.8 \mathrm{~dB}$ \\
\hline Indoor (B) & $45.6 \mathrm{~dB}$ & $45.3 \mathrm{~dB}$ & $46.2 \mathrm{~dB}$ & $45.7 \mathrm{~dB}$ \\
\hline B $_{\text {Average-A Average }}$ & $34.1 \mathrm{~dB}$ & & \\
\hline
\end{tabular}

Table 2 - Sound level measurements of Location No. 1

\subsubsection{Test location No. 2}

This experimental window was located in the Livingroom of suite \#2205 on the $22^{\text {nd }}$ floor and was tested at 4:00 p.m. on January 10, 2018. The experimental window assembly, which was facing west, consisted of two fixed windows and one sliding door (with one side fixed and the other slider) (Figure 16).
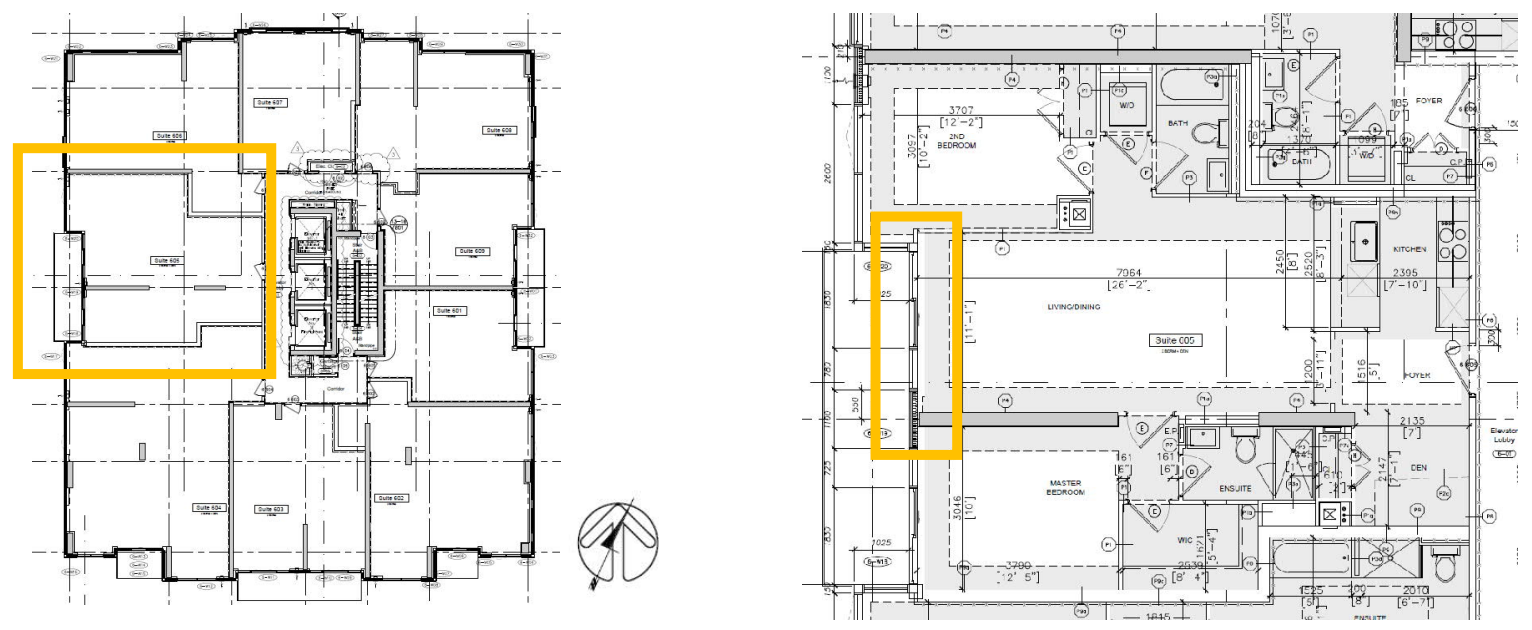

Figure 16 - Left Image: Floor plan of 22nd floor \& Right Image: Test location 2, Suite 2205, Livingroom

Airtightness test was performed based on standard ASTM-E783 as described in the section 4.1.1 of this report (Figure 17). The test results and environmental conditions during the test are noted in flowing table (Table 3). 


\begin{tabular}{|c|c|c|}
\hline \multicolumn{3}{|c|}{ Environmental Conditions During window Airtightness Test, Suite 2205, Livingroom } \\
\hline \multicolumn{2}{|c|}{ Indoor temperature } & $22.5^{\circ} \mathrm{C}$ \\
\hline \multicolumn{2}{|c|}{ Outdoor temperature } & $2{ }^{\circ} \mathrm{C}$ \\
\hline \multicolumn{2}{|c|}{ Indoor Relative Humidity } & $24.71 \%$ \\
\hline \multicolumn{2}{|c|}{ Outdoor Relative Humidity } & $87 \%$ \\
\hline \multicolumn{2}{|l|}{ Wind speed } & WNW $12 \mathrm{KPh}$ \\
\hline \multicolumn{2}{|l|}{ Weather } & Cloudy \\
\hline \multicolumn{3}{|c|}{ Window Airtightness Test Measurements, Suite 2205, Livingroom } \\
\hline Tare (A) & Extraneous air infiltration Flow, depressurization ( $75 \mathrm{~Pa}$ ) & $10.76 \mathrm{~L} / \mathrm{S}$ \\
\hline Reading (B) & Air infiltration Flow, depressurization (75 Pa) & $11.62 \mathrm{~L} / \mathrm{S}$ \\
\hline $\operatorname{Net}(B-A)$ & \multicolumn{2}{|l|}{$0.86 \mathrm{~L} / \mathrm{S}$} \\
\hline
\end{tabular}

Table 3 - Window Airtightness Test Measurements of Location No. 2

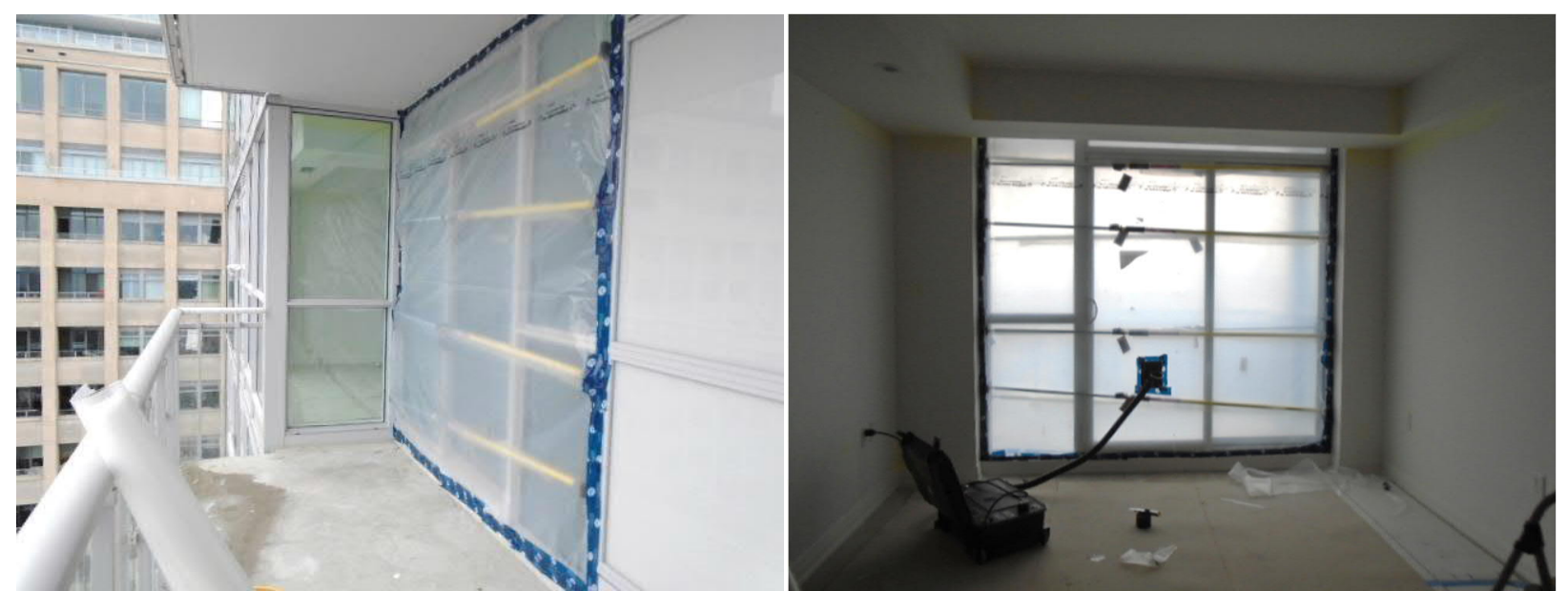

Figure 17 - Left image: Exterior view of window assembly set up, Right image: Interior view of window assembly set up of Location No. 2

Sound level transmission loss through the tested specimen was measure as described in section 4.1.2 of this report. The measured data and sound level transmission loss are outlined in Table 4. 


\begin{tabular}{|l|l|l|l|l|}
\hline \multicolumn{5}{|c|}{ Sound Pressure Measurements, Suite 2205, Livingroom } \\
\hline & Point 1 & Point 2 & Point 3 & Average \\
\hline Outdoor (A) & $78.9 \mathrm{~dB}$ & $79.4 \mathrm{~dB}$ & $79.3 \mathrm{~dB}$ & $79.2 \mathrm{~dB}$ \\
\hline Indoor (B) & $47.1 \mathrm{~dB}$ & $48.5 \mathrm{~dB}$ & $46.3 \mathrm{~dB}$ & $47.3 \mathrm{~dB}$ \\
\hline B $_{\text {Average-A Average }}$ & $31.9 \mathrm{~dB}$ & & \\
\hline
\end{tabular}

Table 4- Sound level measurements of Location No. 2

\subsubsection{Test location No. 3}

This window assembly was located in the Livingroom of suite \#2201 on the 22nd floor and was tested at 9:40 a.m. on January 11,2018. The experimental window assembly which was facing east, consisted of three fixed windows and one sliding door (with one side fixed and the other slider) (Figure 18).
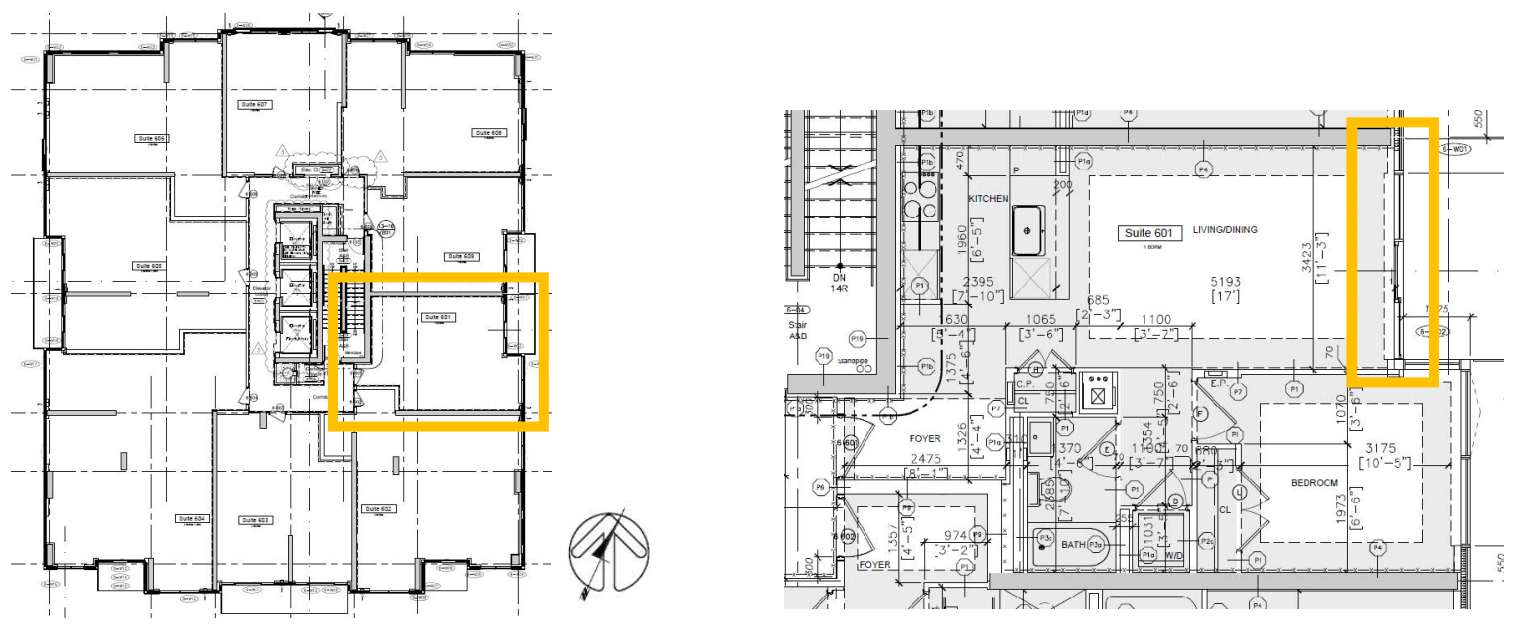

Figure 18 - Left Image: Floor plan of 22nd floor \& Right Image: Test location 3, Suite 2201, Livingroom

Airtightness test was performed based on standard ASTM-E783 as described in the section 4.1.1 of this report (Figure 19). The test results and environmental conditions during the test are noted in following table (Table 5) 


\begin{tabular}{|c|c|c|}
\hline \multicolumn{3}{|c|}{ Environmental Conditions During window Airtightness Test, Suite 2201, Livingroom } \\
\hline \multicolumn{2}{|c|}{ Indoor temperature } & $22.7^{\circ} \mathrm{C}$ \\
\hline \multicolumn{2}{|c|}{ Outdoor temperature } & $8^{\circ} \mathrm{C}$ \\
\hline \multicolumn{2}{|c|}{ Indoor Relative Humidity } & $32 \%$ \\
\hline \multicolumn{2}{|c|}{ Outdoor Relative Humidity } & $77 \%$ \\
\hline \multicolumn{2}{|l|}{ Wind speed } & $\mathrm{S} 10 \mathrm{KPh}$ \\
\hline \multicolumn{2}{|l|}{ Weather } & Cloudy \\
\hline \multicolumn{3}{|c|}{ Window Airtightness Test Measurements, Suite 2205, Livingroom } \\
\hline Tare (A) & Extraneous air infiltration Flow, depressurization (75 Pa) & $13.86 \mathrm{~L} / \mathrm{S}$ \\
\hline Reading (B) & Air infiltration Flow, depressurization (75 Pa) & $14.94 \mathrm{~L} / \mathrm{S}$ \\
\hline Net (B-A) & \multicolumn{2}{|l|}{$1.08 \mathrm{~L} / \mathrm{S}$} \\
\hline
\end{tabular}

Table 5 - Window Airtightness Test Measurements of Location No. 3

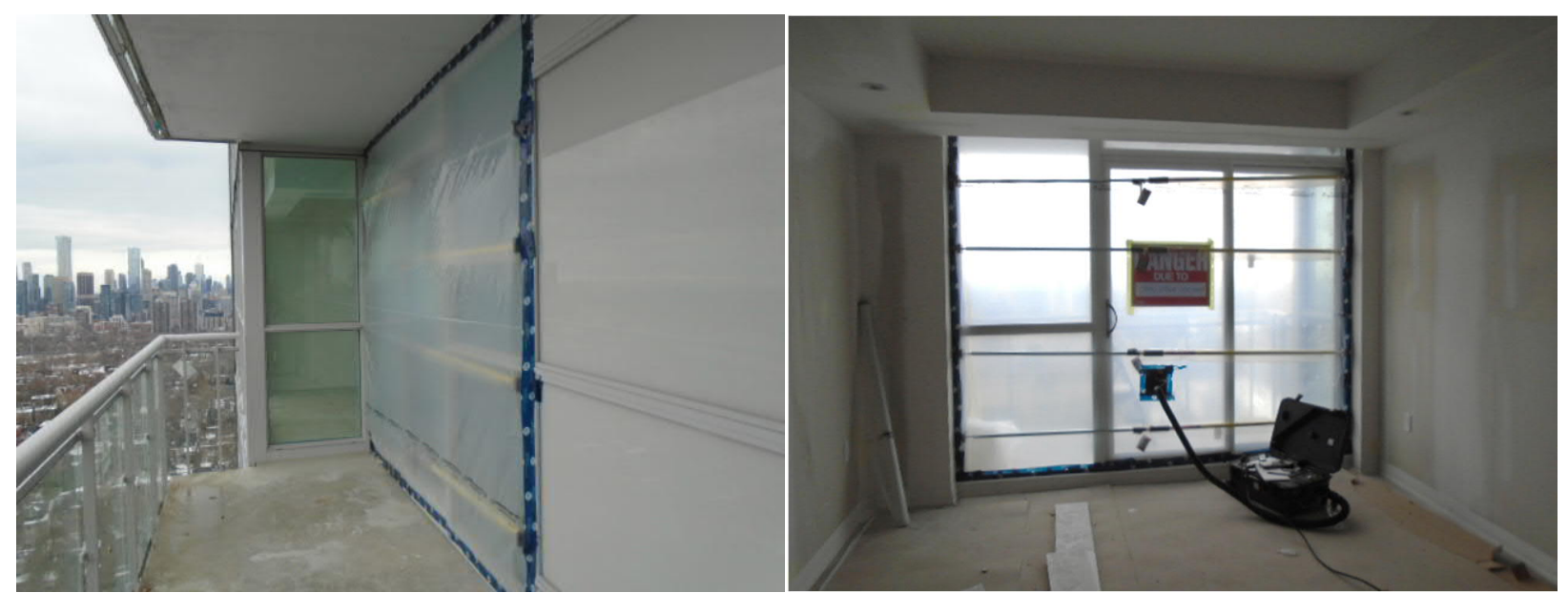

Figure 19 - Left image: Exterior view of window assembly set up, Right image: Interior view of window assembly set up of Location No. 3

Sound level transmission loss through the tested specimen was measured as described in section 4.1.2 of this report. The measured data and sound level transmission loss are outlined in Table 6. 


\begin{tabular}{|l|l|l|l|l|}
\hline \multicolumn{5}{|c|}{ Sound Pressure Measurements, Suite 2201, Livingroom } \\
\hline & Point 1 & Point 2 & Point 3 & Average \\
\hline Outdoor (A) & $80.6 \mathrm{~dB}$ & $80.8 \mathrm{~dB}$ & $79.5 \mathrm{~dB}$ & $80.3 \mathrm{~dB}$ \\
\hline Indoor (B) & $55.8 \mathrm{~dB}$ & $48.5 \mathrm{~dB}$ & $46.1 \mathrm{~dB}$ & $50.1 \mathrm{~dB}$ \\
\hline B $_{\text {Average-A Average }}$ & $30.2 \mathrm{~dB}$ & & & \\
\hline
\end{tabular}

Table 6- Sound level measurements of Location No. 3

\subsubsection{Test location No. 4}

This assembly was located in the family room of suite \#2402 on the $24^{\text {th }}$ floor and was tested at 2:00 p.m. on January 11,2018. The experimental window assembly, which was facing west, consisted of one fixed window and one sliding door (with one side fixed and the other slider) (Figure 20).
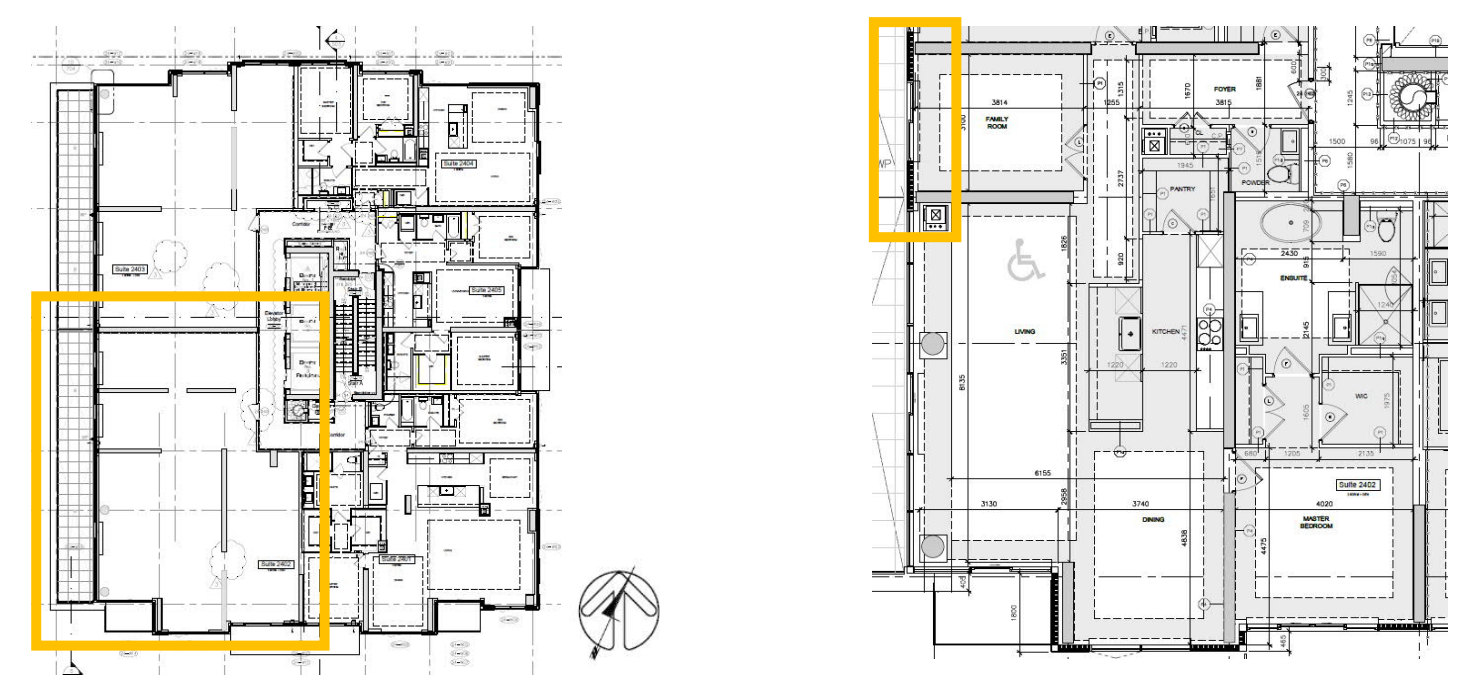

Figure 20 - Left Image: Floor plan of $24^{\text {th }}$ floor \& Right Image: Test location 4, Suite 2402, Family room

Airtightness test was performed based on standard ASTM-E783 as described in section 4.1.1 of this report (Figure 21). The test results and environmental conditions during the test are noted in following table (Table 7) 


\begin{tabular}{|l|l|}
\hline \multicolumn{2}{|c|}{ Environmental Conditions During window Airtightness Test, Suite 2402, Family room } \\
\hline Indoor temperature & $21^{\circ} \mathrm{C}$ \\
\hline Outdoor temperature & $10^{\circ} \mathrm{C}$ \\
\hline Indoor Relative Humidity & $41 \%$ \\
\hline Outdoor Relative Humidity & $71 \%$ \\
\hline Wind speed & SW $12 \mathrm{KPh}$ \\
\hline Weather & Mostly Cloudy \\
\hline
\end{tabular}

\begin{tabular}{|l|l|l|}
\hline \multicolumn{3}{|c|}{ Window Airtightness Test Measurements, Suite 2402, Family room } \\
\hline Tare (A) & Extraneous air infiltration Flow, depressurization (75 Pa) & $17.69 \mathrm{~L} / \mathrm{S}$ \\
\hline Reading (B) & Air infiltration Flow, depressurization (75 Pa) & $18.65 \mathrm{~L} / \mathrm{S}$ \\
\hline Net (B-A) & $0.96 \mathrm{~L} / \mathrm{S}$ & \multicolumn{2}{|l|}{} \\
\hline
\end{tabular}

Table 7 - Window Airtightness Test Measurements of Location No. 4
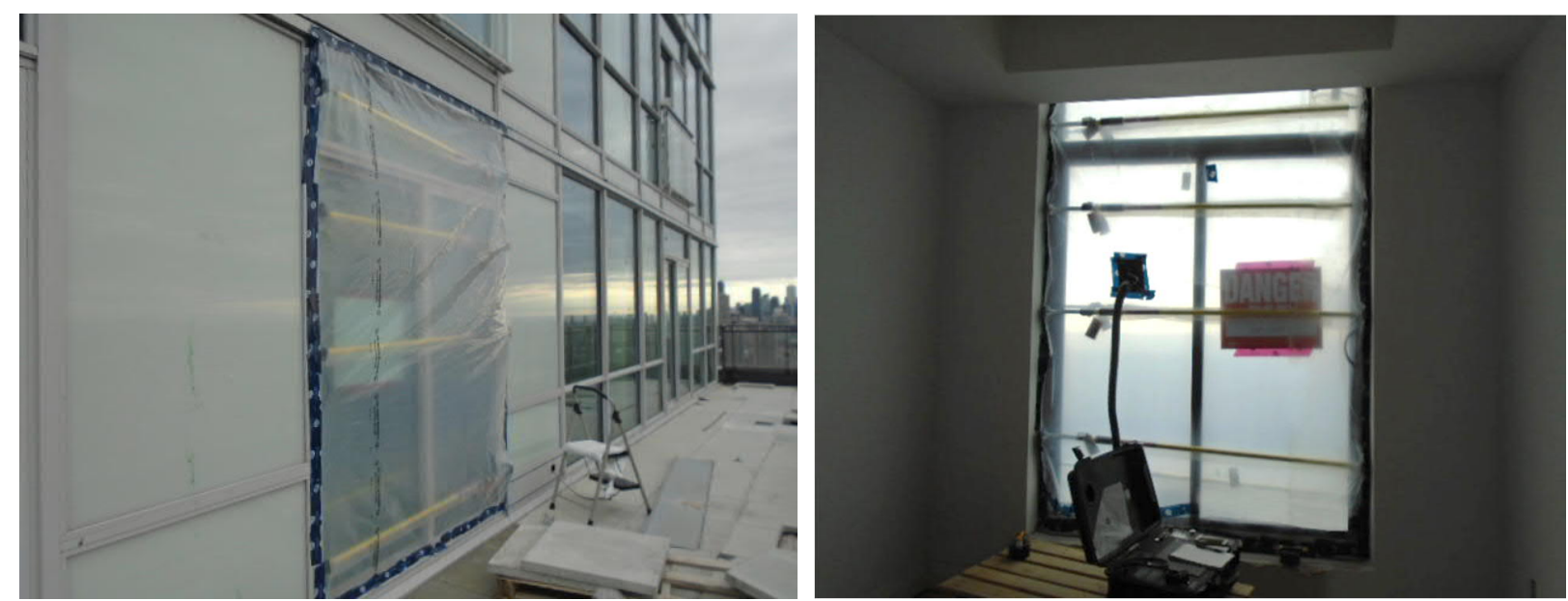

Figure 21 - Left image: Exterior view of window assembly set up, Right image: Interior view of window assembly set up of Location No. 4

Sound level transmission loss through the tested specimen was measured as described in section 4.1.2 of this report. The measured data and sound level transmission loss are outlined in Table 8. 


\begin{tabular}{|l|l|l|l|l|}
\hline \multicolumn{5}{|c|}{ Sound Pressure Measurements, Suite 2402, Family room } \\
\hline & Point 1 & Point 2 & Point 3 & Average \\
\hline Outdoor (A) & $77.1 \mathrm{~dB}$ & $76.2 \mathrm{~dB}$ & $77 \mathrm{~dB}$ & $76.7 \mathrm{~dB}$ \\
\hline Indoor (B) & $44.2 \mathrm{~dB}$ & $42.9 \mathrm{~dB}$ & $48.7 \mathrm{~dB}$ & $45.2 \mathrm{~dB}$ \\
\hline B $_{\text {Average-A Average }}$ & $31.5 \mathrm{~dB}$ & \multicolumn{4}{|l|}{} \\
\hline
\end{tabular}

Table 8 - Sound level measurements of Location No. 4

\subsubsection{Test location No. 5}

This window assembly was located in the bedroom of suite \#2203 on the $22^{\text {nd }}$ floor and was tested at 10:15 a.m. on January 12, 2018. The experimental window assembly, which was facing south, consisted of four fixed windows and one sliding door (with one side fixed and the other slider) (Figure 22).
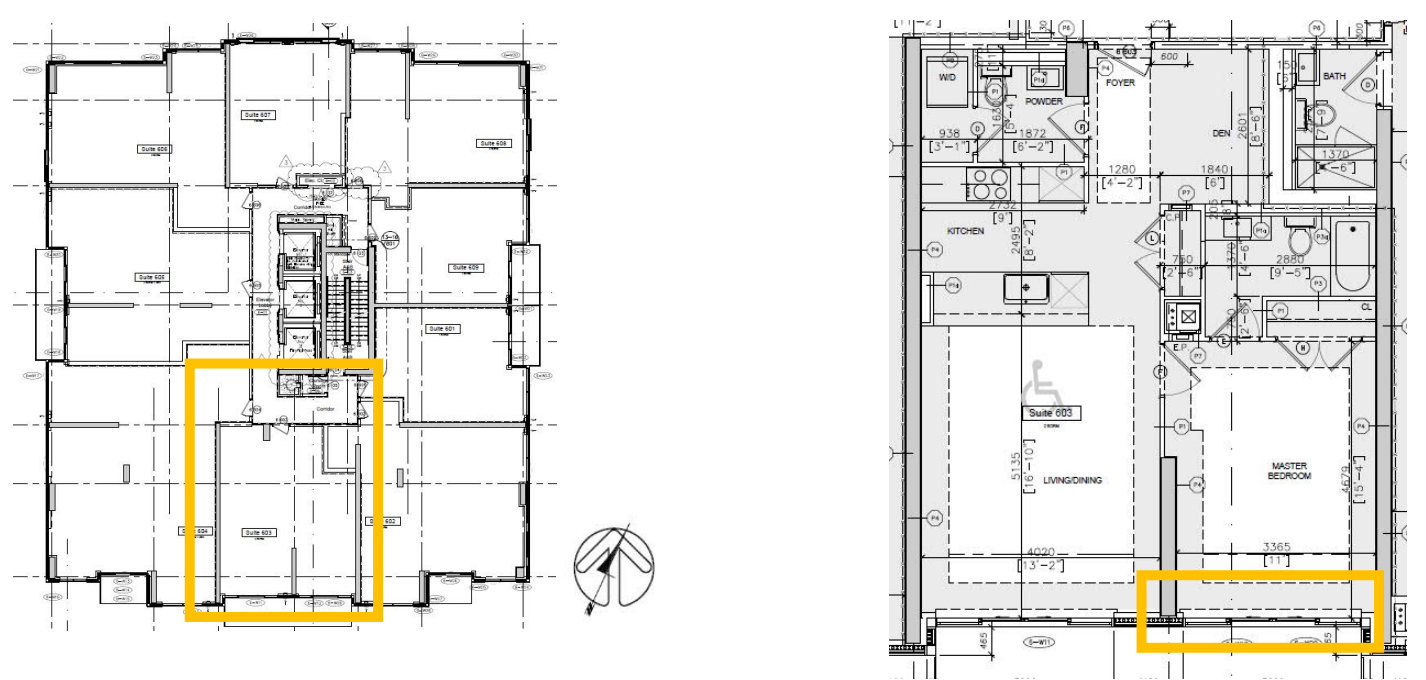

Figure 22- Left Image: Floor plan of 22nd floor \& Right Image: Test location 5, Suite 2203, Bedroom

Airtightness test was performed based on standard ASTM-E783 as described in section 4.1.1 of this report (Figure 23). The test results and environmental conditions during the test are noted in following table (Table 9). 


\begin{tabular}{|c|c|c|}
\hline \multicolumn{3}{|c|}{ Environmental Conditions During wind ow Airtightness Test, Suite 2203, Bedroom } \\
\hline \multicolumn{2}{|c|}{ Indoor temperature } & $21.47^{\circ} \mathrm{C}$ \\
\hline \multicolumn{2}{|c|}{ Outdoor temperature } & $7^{\circ} \mathrm{C}$ \\
\hline \multicolumn{2}{|c|}{ Indoor Relative Humidity } & $39 \%$ \\
\hline \multicolumn{2}{|c|}{ Outdoor Relative Humidity } & $87 \%$ \\
\hline \multicolumn{2}{|l|}{ Wind speed } & SSW $11 \mathrm{KPh}$ \\
\hline \multicolumn{2}{|l|}{ Weather } & Rainy/Cloudy \\
\hline \multicolumn{3}{|c|}{ Window Airtightness Test Measurements, Suite 2203, Bedroom } \\
\hline Tare (A) & Extraneous air infiltration Flow, depressurization (75 Pa) & $12.8 \mathrm{~L} / \mathrm{S}$ \\
\hline Reading (B) & Air infiltration Flow, depressurization (75 Pa) & $14.96 \mathrm{~L} / \mathrm{S}$ \\
\hline Net (B-A) & \multicolumn{2}{|l|}{$2.16 \mathrm{~L} / \mathrm{S}$} \\
\hline
\end{tabular}

Table 9- Window Airtightness Test Measurements of Location No. 5
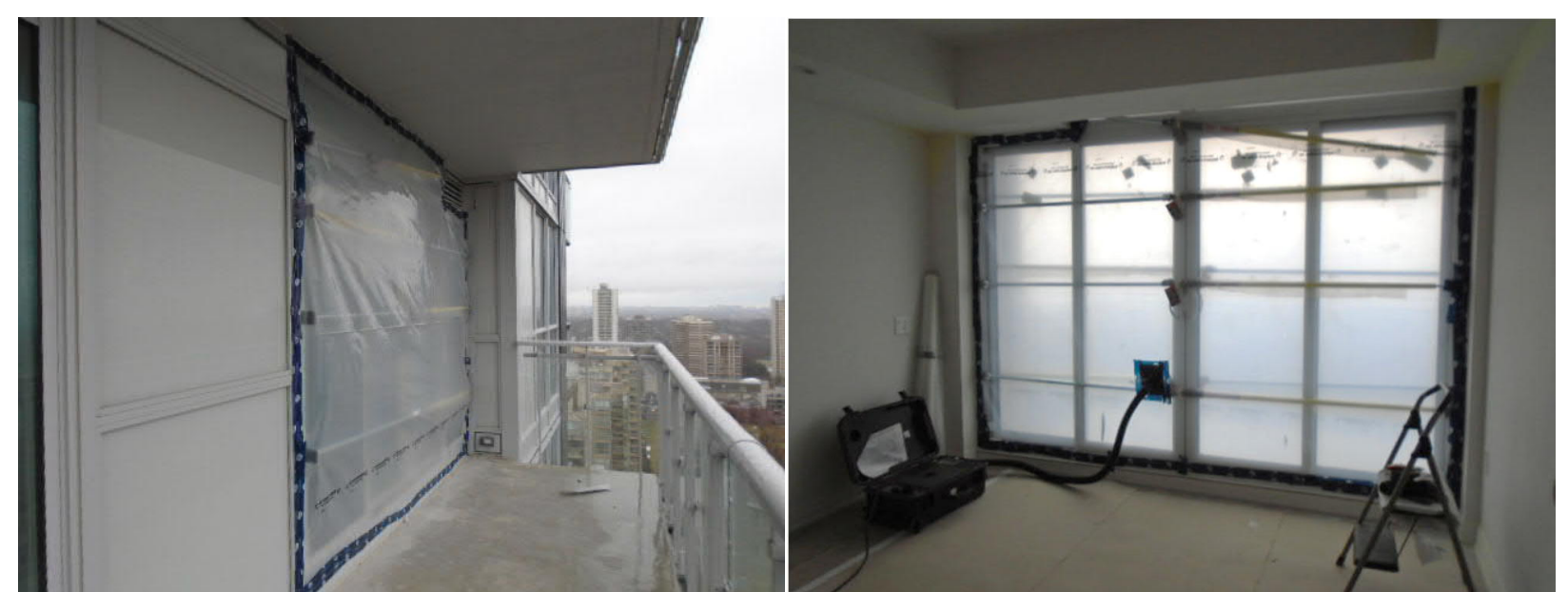

Figure 23 - Left image: Exterior view of window assembly set up, Right image: Interior view of window assembly set up of Location No. 5

Sound level transmission loss through the tested specimen was measured as described in section 4.1.2 of this report. The measured data and sound level transmission loss are outlined in Table 10. 


\begin{tabular}{|l|l|l|l|l|}
\hline \multicolumn{5}{|c|}{ Sound Pressure Measurements, Suite 2203, Bedroom } \\
\hline & Point 1 & Point 2 & Point 3 & Average \\
\hline Outdoor (A) & $81.4 \mathrm{~dB}$ & $81.1 \mathrm{~dB}$ & $80.2 \mathrm{~dB}$ & $80.9 \mathrm{~dB}$ \\
\hline Indoor (B) & $49.2 \mathrm{~dB}$ & $52.3 \mathrm{~dB}$ & $49.7 \mathrm{~dB}$ & $50.4 \mathrm{~dB}$ \\
\hline B $_{\text {Average-A Average }}$ & $30.5 \mathrm{~dB}$ & \multicolumn{4}{l|}{} \\
\hline
\end{tabular}

Table 10 - Sound level measurements of Location No. 5

\subsubsection{Test location No. 6}

This window assembly was located in the living room of suite \#2203 on the $22^{\text {nd }}$ floor and was measured at 1:00 p.m. on January 12,2018 . The experimental window assemblies, which were facing south, consisted of four fixed windows and one sliding door (with one side fixed and the other slider) (Figure 24).
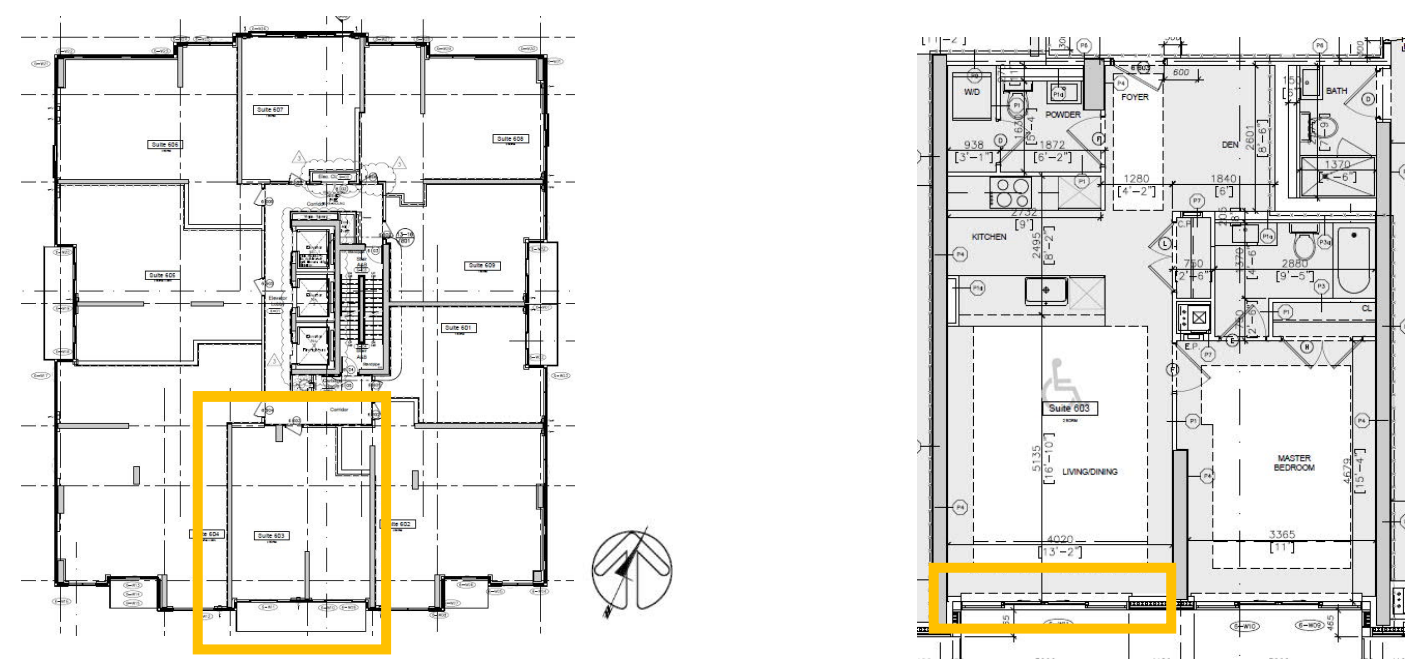

Figure 24- Left image: Floor plan of 22nd floor \& Right Image: Test location 6, Suite 2203, Livingroom

Airtightness test was performed based on standard ASTM-E783 as described in the section 4.1.1 of this report (Figure 25). The test results and environmental conditions during the test are noted in following table (Table 11) 


\begin{tabular}{|c|c|c|}
\hline \multicolumn{3}{|c|}{ Environmental Conditions During window Airtightness Test, Suite 2203, Living room } \\
\hline \multicolumn{2}{|c|}{ Indoor temperature } & $21.14^{\circ} \mathrm{C}$ \\
\hline \multicolumn{2}{|c|}{ Outdoor temperature } & $-1^{\circ} \mathrm{C}$ \\
\hline \multicolumn{2}{|c|}{ Indoor Relative Humidity } & $37.7 \%$ \\
\hline \multicolumn{2}{|c|}{ Outdoor Relative Humidity } & $83 \%$ \\
\hline \multicolumn{2}{|l|}{ Wind speed } & SW $14 \mathrm{KPh}$ \\
\hline \multicolumn{2}{|l|}{ Weather } & Cloudy \\
\hline \multicolumn{3}{|c|}{ Window Airtightness Test Measurements, Suite 2203, Living room } \\
\hline Tare (A) & Extraneous air infiltration Flow, depressurization (75 Pa) & $11.43 \mathrm{~L} / \mathrm{S}$ \\
\hline Reading (B) & Air infiltration Flow, depressurization (75 Pa) & $11.62 \mathrm{~L} / \mathrm{S}$ \\
\hline Net (B-A) & $0.19 \mathrm{~L} / \mathrm{S}$ & \\
\hline
\end{tabular}

Table 11- Window Airtightness Test Measurements of Location No. 6

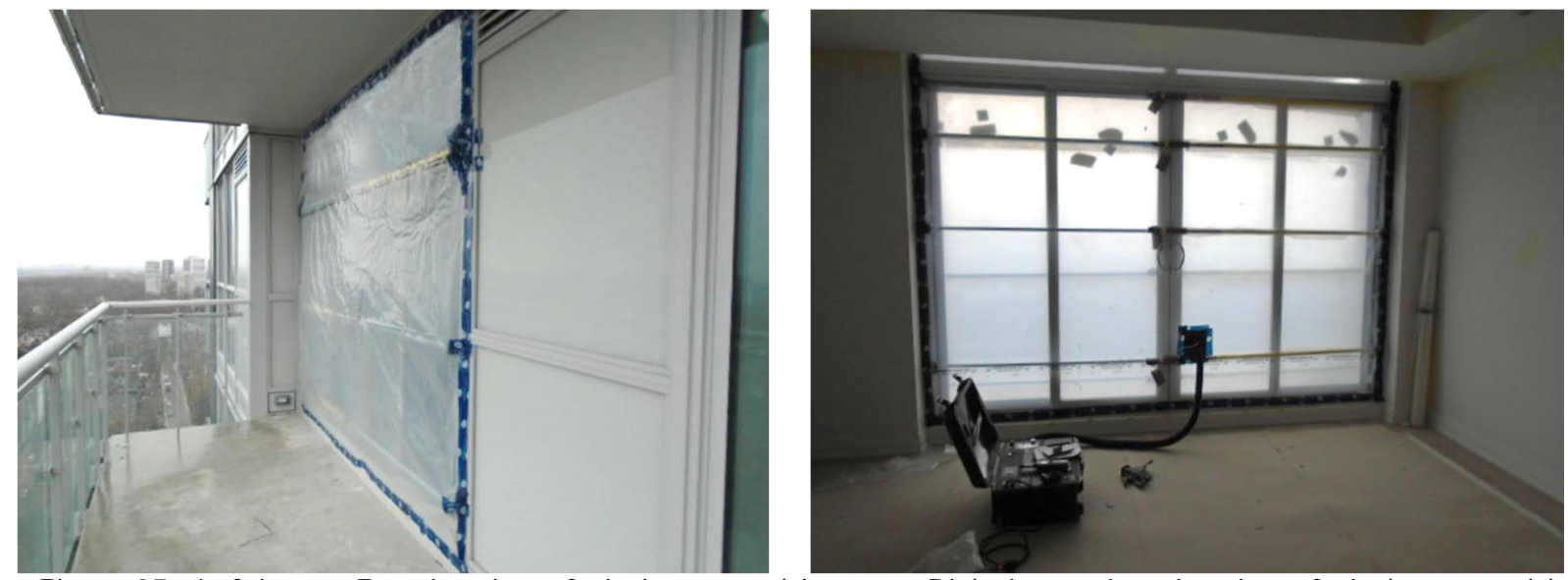

Figure 25 - Left image: Exterior view of window assembly set up, Right image: Interior view of window assembly set up of Location No. 6

Sound level transmission loss through the tested specimen was measured as described in section 4.1.2 of this report. The measured data and sound level transmission loss are outlined in Table 12.

\begin{tabular}{|l|l|l|l|l|}
\hline \multicolumn{5}{|c|}{ Sound Pressure Measurements, Suite 2203, Living room } \\
\hline & Point 1 & Point 2 & Point 3 & Average \\
\hline Outdoor (A) & $80.6 \mathrm{~dB}$ & $81.2 \mathrm{~dB}$ & $80.1 \mathrm{~dB}$ & $80.6 \mathrm{~dB}$ \\
\hline Indoor (B) & $44.6 \mathrm{~dB}$ & $46 \mathrm{~dB}$ & $45.8 \mathrm{~dB}$ & $45.4 \mathrm{~dB}$ \\
\hline B $_{\text {Average-A Average }}$ & $35.2 \mathrm{~dB}$ & \multicolumn{3}{l}{} \\
\hline
\end{tabular}

Table 12 - Sound level measurements of Location No. 6 


\subsubsection{Test location No. 7}

This window assembly was located in the living room of suite \#202 on the $2^{\text {nd }}$ floor and was measured at 4:00 p.m. on January 12,2018. The experimental window assembly, which was facing south, consisted of three fixed windows and one awning window (Figure 26).
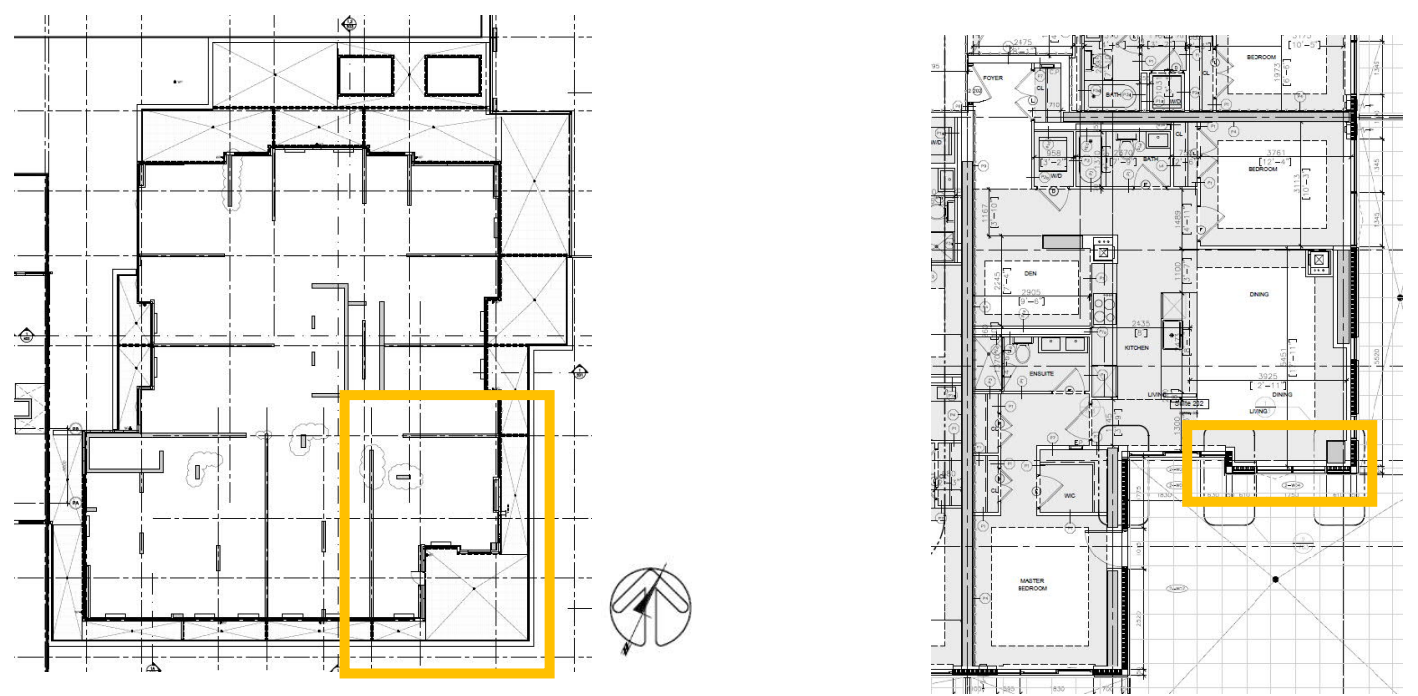

Figure 26- Left Image: Floor plan of 22nd floor \& Right Image: Test location 7, Suite 202, Livingroom

Airtightness test was performed based on standard ASTM-E783 as described in the section 4.1.1 of this report (Figure 27). The test results and environmental conditions during the test are noted in the following table (Table 13).
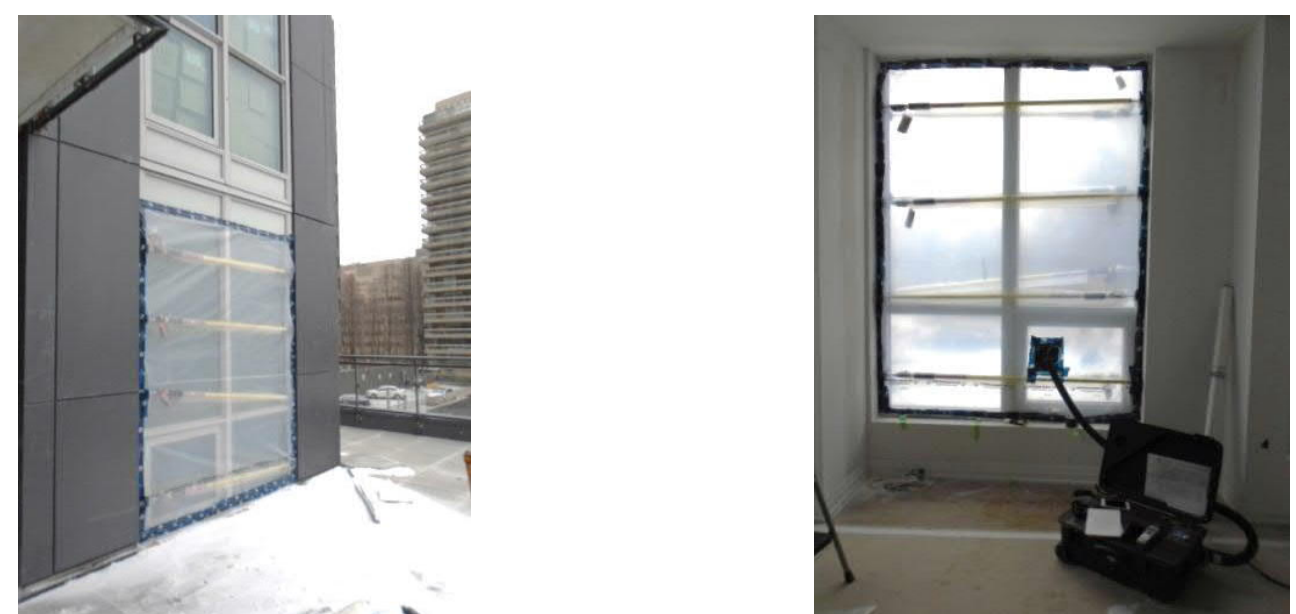

Figure 27 - Left image: Exterior view of window assembly set up, Right image: Interior view of window assembly set up of Location No. 1 


\begin{tabular}{|c|c|c|}
\hline \multicolumn{3}{|c|}{ Environmental Conditions During window Airtightness Test, Suite 202, Livingroom } \\
\hline \multicolumn{2}{|c|}{ Indoor temperature } & $13^{\circ} \mathrm{C}$ \\
\hline \multicolumn{2}{|c|}{ Outdoor temperature } & $-3^{\circ} \mathrm{C}$ \\
\hline \multicolumn{2}{|c|}{ Indoor Relative Humidity } & $51.3 \%$ \\
\hline \multicolumn{2}{|c|}{ Outdoor Relative Humidity } & $86 \%$ \\
\hline \multicolumn{2}{|l|}{ Wind speed } & SSE $12 \mathrm{KPh}$ \\
\hline \multicolumn{2}{|l|}{ Weather } & Light Snow \\
\hline \multicolumn{3}{|c|}{ Window Airtightness Test Measurements, Suite 202, Livingroom } \\
\hline Tare (A) & Extraneous air infiltration Flow, depressurization (75 Pa) & $10.26 \mathrm{~L} / \mathrm{S}$ \\
\hline Reading (B) & Air infiltration Flow, depressurization (75 Pa) & $10.73 \mathrm{~L} / \mathrm{S}$ \\
\hline Net (B-A) & \multicolumn{2}{|l|}{$0.47 \mathrm{~L} / \mathrm{S}$} \\
\hline
\end{tabular}

Table 13- Window Airtightness Test Measurements of Location No. 7

Sound level transmission loss through the tested specimen was measured as described in section 4.1.2 of this report. The measured data and sound level transmission loss are outlined in Table 14.

\begin{tabular}{|l|l|l|l|l|}
\hline \multicolumn{5}{|c|}{ Sound Pressure Measurements, Suite 202, Livingroom } \\
\hline & Point 1 & Point 2 & Point 3 & Average \\
\hline Outdoor (A) & $76.2 \mathrm{~dB}$ & $80.4 \mathrm{~dB}$ & $76.5 \mathrm{~dB}$ & $77.7 \mathrm{~dB}$ \\
\hline Indoor (B) & $41.3 \mathrm{~dB}$ & $43.6 \mathrm{~dB}$ & $41.7 \mathrm{~dB}$ & $42.2 \mathrm{~dB}$ \\
\hline B $_{\text {Average-A Average }}$ & $35.5 \mathrm{~dB}$ & & & \\
\hline
\end{tabular}

Table 14 - Sound level measurements of Location No. 7 


\subsubsection{Result}

Table below (Table 15) summarizes the test results of the seven experimental windows:

\begin{tabular}{|l|c|c|}
\hline Locations & $\begin{array}{c}\text { Sound pressure transmission loss } \\
\text { though the experimental windows } \\
\text { (dB) }\end{array}$ & $\begin{array}{c}\text { Airflow though the experimental } \\
\text { windows (L/ S) }\end{array}$ \\
\hline Location No.1 & 34.1 & 0.11 \\
\hline Location No.2 & 31.9 & 0.86 \\
\hline Location No.3 & 31.5 & 1.08 \\
\hline Location No.4 & 30.2 & 2.16 \\
\hline Location No.5 & 30.5 & 0.19 \\
\hline Location No.6 & 35.2 & 0.47 \\
\hline Location No.7 & 35.5 & \\
\hline
\end{tabular}

Table 15 - Summary of the test results of the seven experimental windows

The points in blue on the figure below (Figure 28) illustrate the air flow and the red points show the sound transmission pressure loss through each seven experimental window assemblies. The maximum error of SC160 sound level meter, based on technical specification of the device (Appendix 2) is $\pm 0.5 \mathrm{~dB}$ was illustrated on the chart for each point (Figure 28). Based on ATS portable air test equipment model AW-1000 verification document (Appendix 3), the error of the device, which is shown on Figure 28 should be no more than \pm 5 percent for flows more than 0.9444 $\mathrm{L} / \mathrm{s}$ and \pm 10 percent for flows less than $0.9444 \mathrm{~L} / \mathrm{s}$.

The seven test locations were organized from the lowest to the highest airflow. Overall, it can be seen that while there is an upward trend in the amount of air flow though the specimens, in contrast, the general trend for the measured sound transmission pressure loss through the same window assemblies has declined. (Figure 28) 
In some test locations, as a case in point location No. 7, the measured sound transmission loss is not following the decline trend. This may be caused by sudden background noise which may occur during the test measurements. This shows that the accuracy of results is very dependent on the background noise (Figure 28).

As it can be witnessed Figure 28, while the amount of airflow through the tested specimens rise noticeably and the measurements range from $0.11 \mathrm{~L} / \mathrm{S}$ to $2.16 \mathrm{~L} / \mathrm{S}$, the amount of sound transmission pressure loss through the window assemblies drop gently and sort from $35.5 \mathrm{~dB}$ to $30.2 \mathrm{~dB}$.

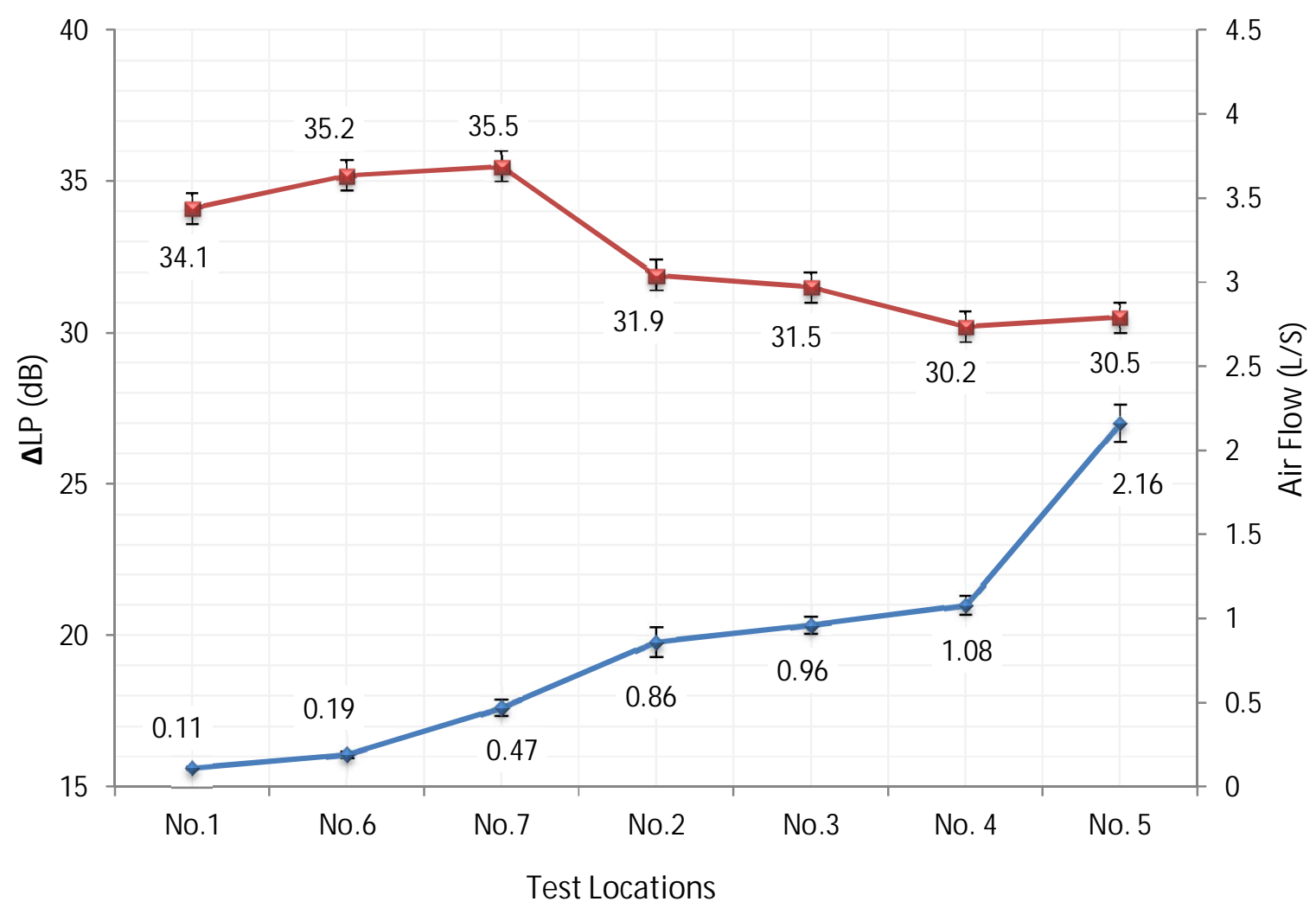

Figure 28 - Relationship between the air flow and the sound transmission pressure loss through the experimental window assemblies 
The measured data was analyzed in Microsoft Excel in order to find if there is a correlation between sound level transmission loss and air flow through experimental window assemblies. Based on this analysis, a negative relationship between these two phenomena with the correlation coefficient (Pearson`s r) of -0.79 was identified. (Figure 29)

The P-value (probability value) of equal or less than 0.05 confirms the strong evidence against the null hypothesis, which is a general statement that there is no correlation between two sets of data. The P-value, based on data measured during the tests on the seven window assemblies, was calculated by Microsoft Excel which was 0.031 . This also confirms the relationship between these two phenomena. (Figure 29)

SUMMARY OUTPUT

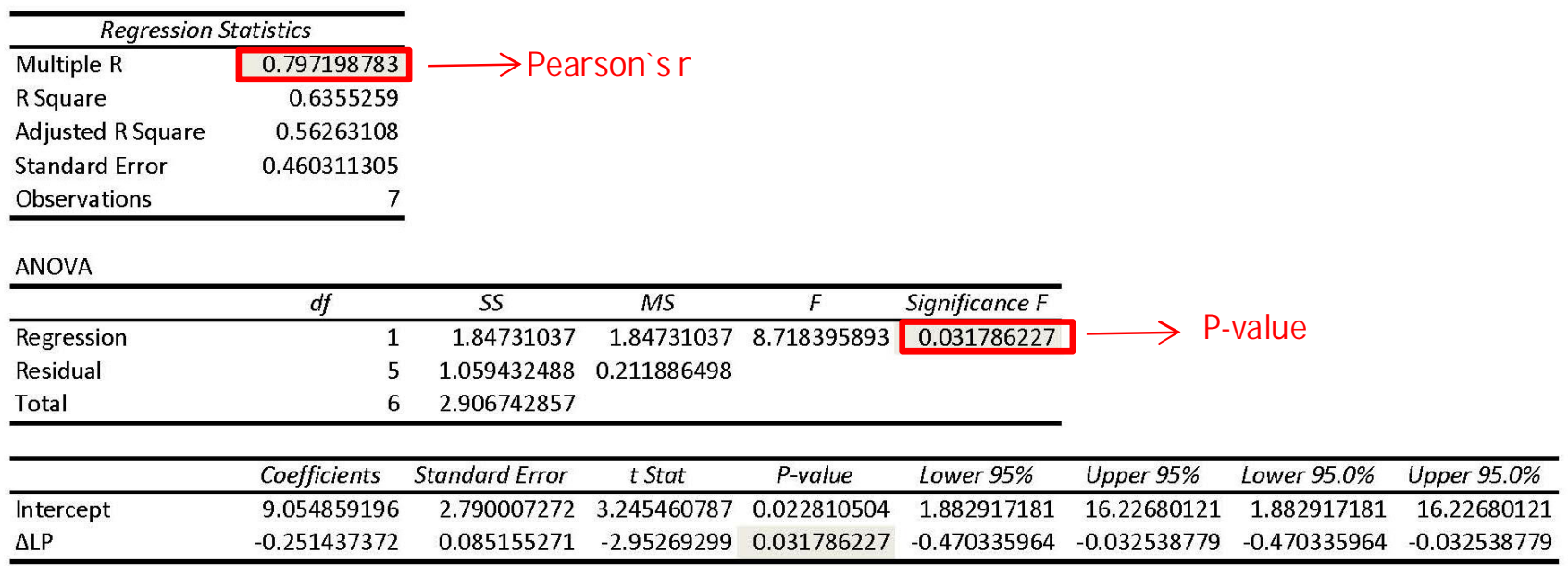

Figure 29 - Summary of Output, Correlation analysis between sound level transmission loss and air flow through experimental window assemblies calculated by Microsoft Excel

The following scatted chart also reveals the negative relationship between these two phenomena. The tighter the window assembly, the less sound is transmitted through the window assemblies. (Figure 30) 


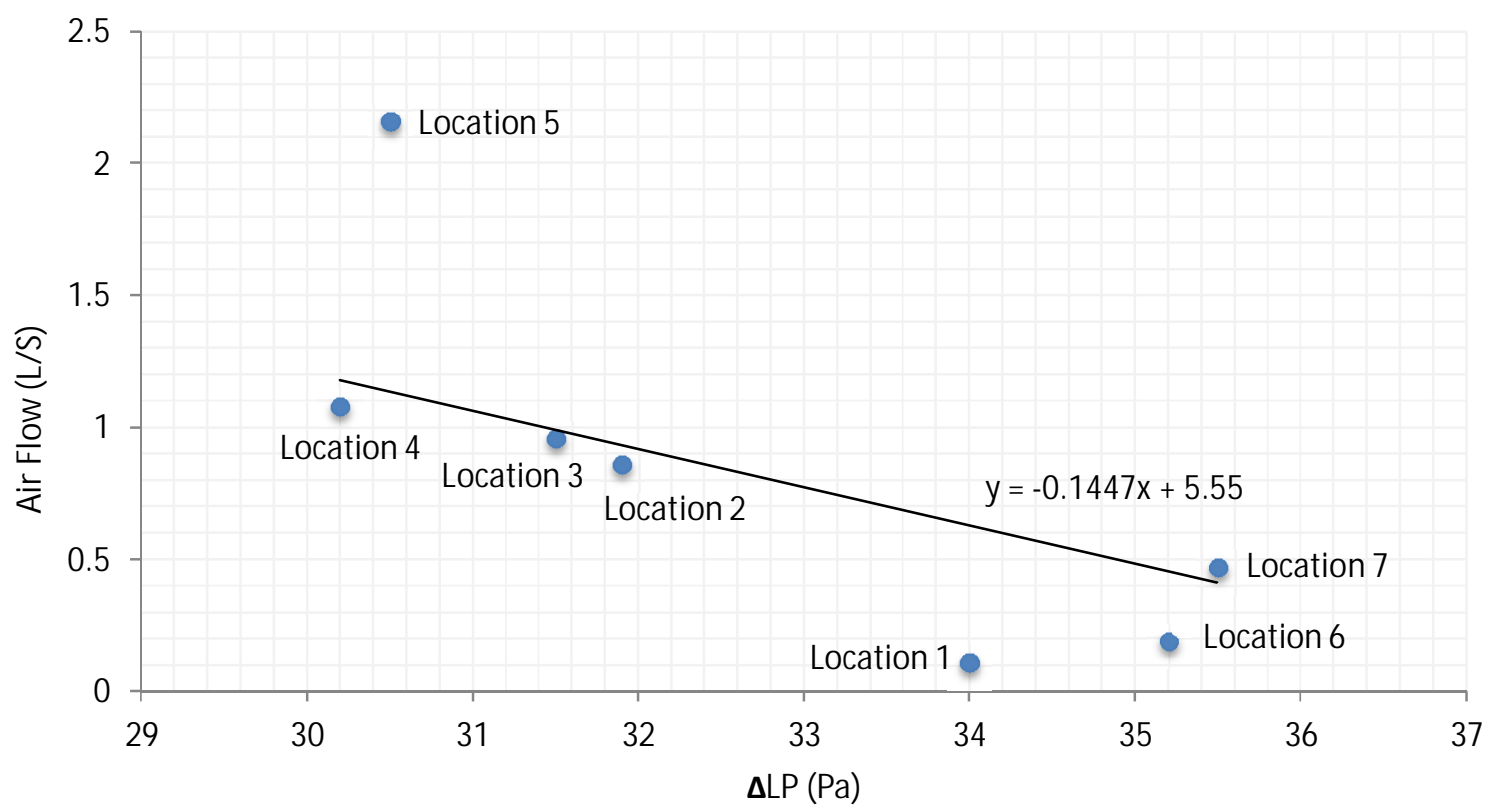

Figure 30- Physical correlation between the air flow and the sound transmission pressure loss (Based on the tests performed on the seven experimental window assemblies)

The mathematical relationship between these two phenomena, based on these seven field tests, which was estimated by excel, is:

$\mathrm{y}=-0.1432 \mathrm{x}+5.55$

$\mathrm{y}=$ the amount of air flow through the tested window assemblies

$\mathrm{x}=$ the sound transmission pressure loss through the tested window assemblies (Valid rage:

$35.5 \mathrm{~dB}$ to $30.2 \mathrm{~dB})$

\subsubsection{Air leakage detection: measurements and result assessments}

\subsubsection{Test location No. 1}

Figure 31 presents the measurements of sound pressure $(\mathrm{dB})$ of interior side of the test location One (1) window assembly and also the thermal image of this specimen. It can be observed that the sound pressure measured at the perimeter of the fixed panel of the sliding door is amplified. The thermal image also shows a lower temperature at this area compared to other sections of the tested window assembly. It appears that one of the main air leakage locations of this 
window is at the perimeter of the fixed panel of the sliding door due to the surface temperature alteration and the increase in sound pressure.

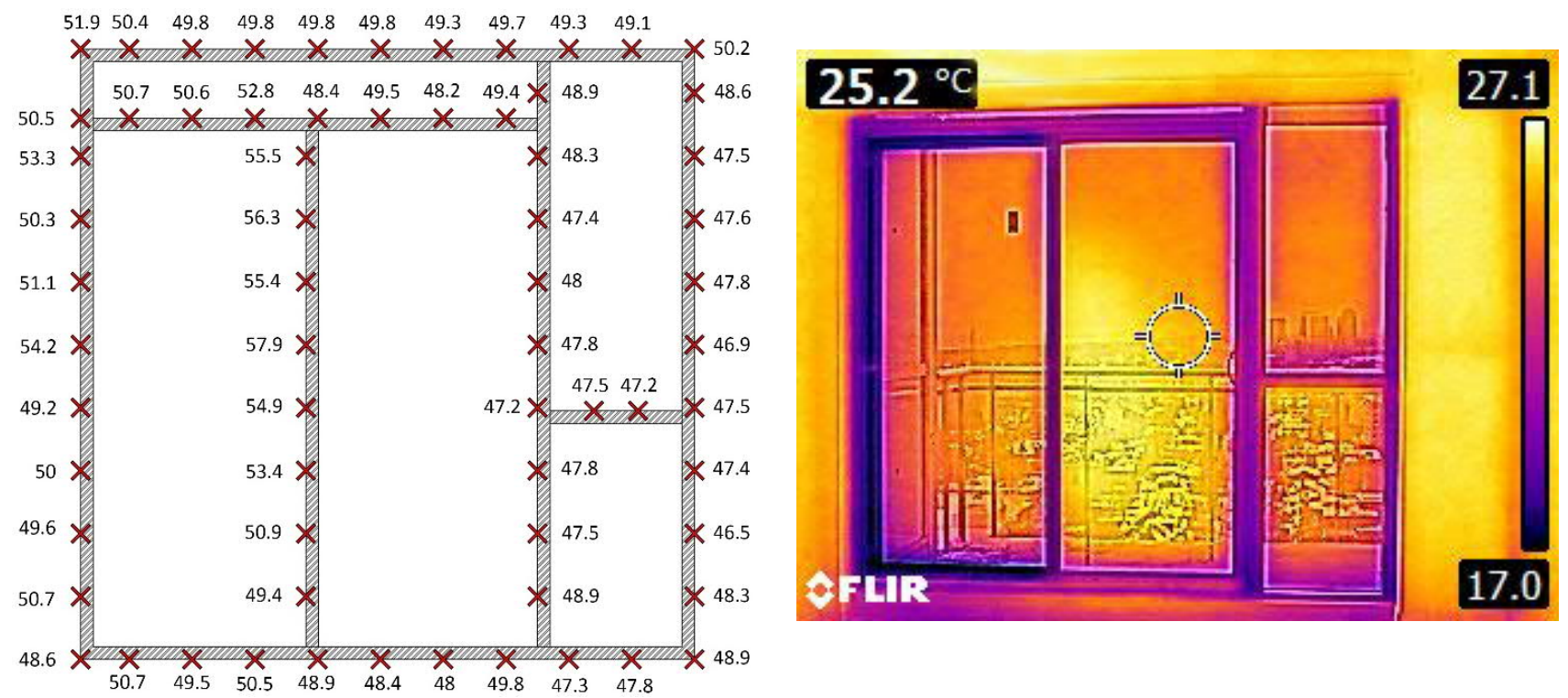

Figure 31 - Test location No. 1 - 22nd floor, Suite 2205, Bedroom, Left image: measured sound pressure (dB) of inside of the specimen, Right image: thermal imaging of the experimental window assemblies

The same situation and air infiltration location can be observed and localized at test locations

2, 3 and 4. (Figure 32, Figure 33 and Figure 34)

\subsubsection{Test location No. 2}
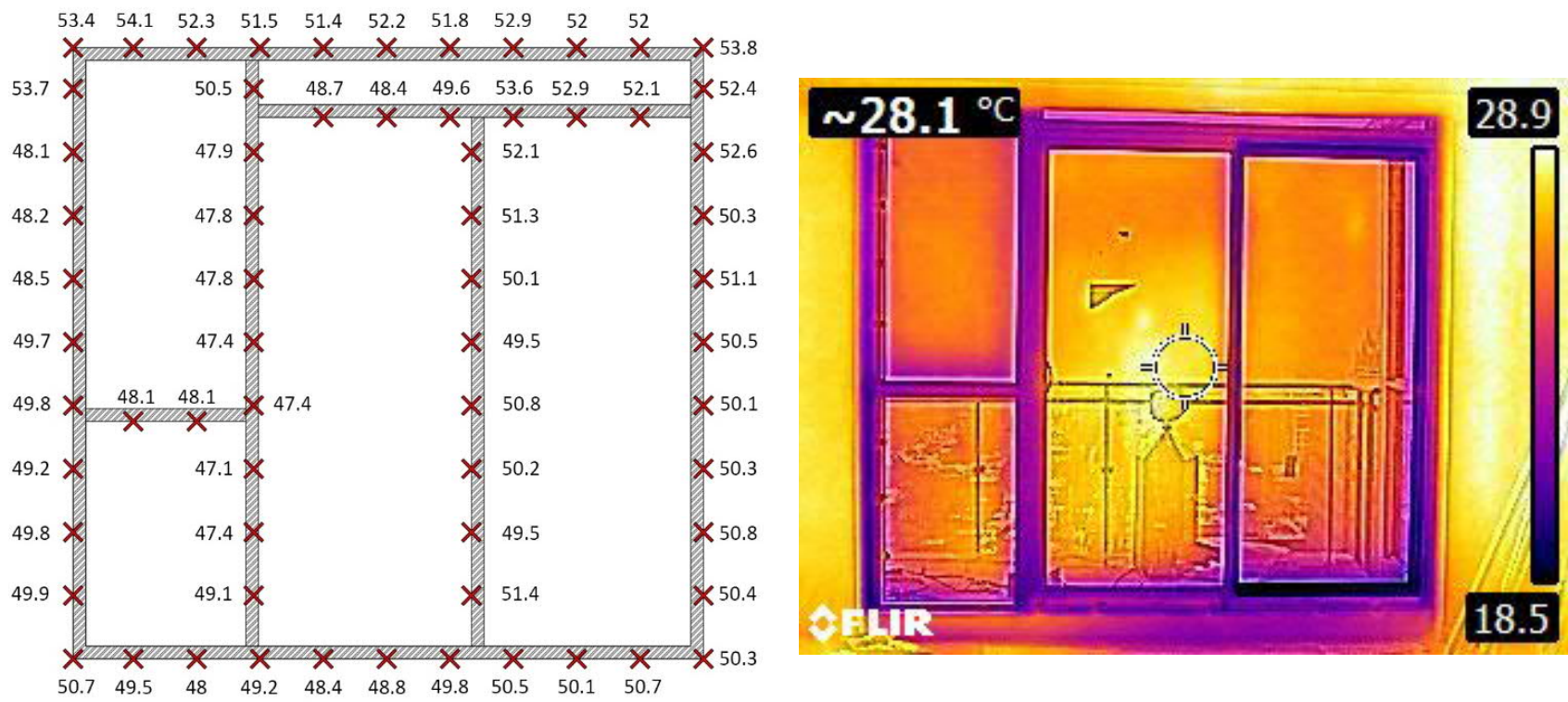

Figure 32 - Test location No. 2 - 22nd floor, Suite 2205, Livingroom, Left image: measured sound pressure of inside of the specimen, Right image: thermal imaging of the experimental window assemblies 


\subsubsection{Test location No. 3}
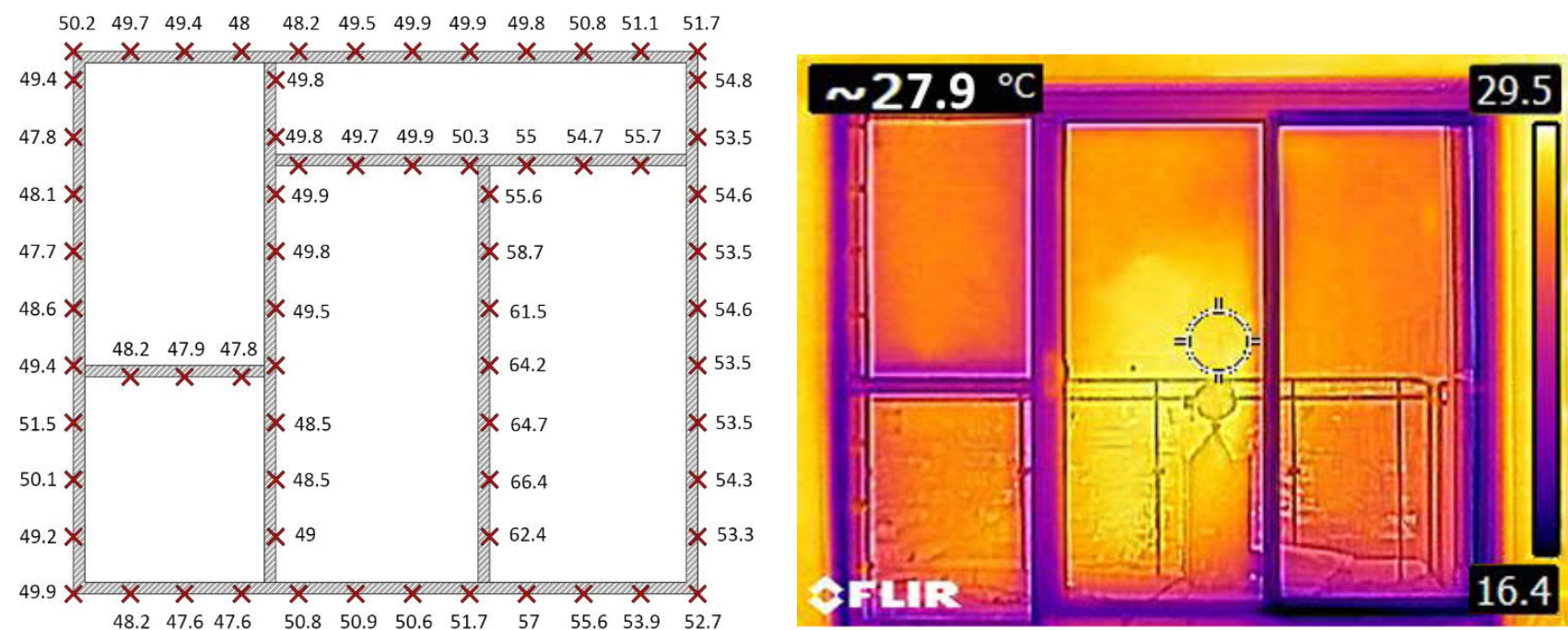

Figure 33 - Test location 3 - 22nd floor, Suite 2201, Livingroom, Left image: measured sound pressure of inside of the specimen, Right image: thermal imaging of the experimental window assemblies

\subsubsection{Test location No. 4}
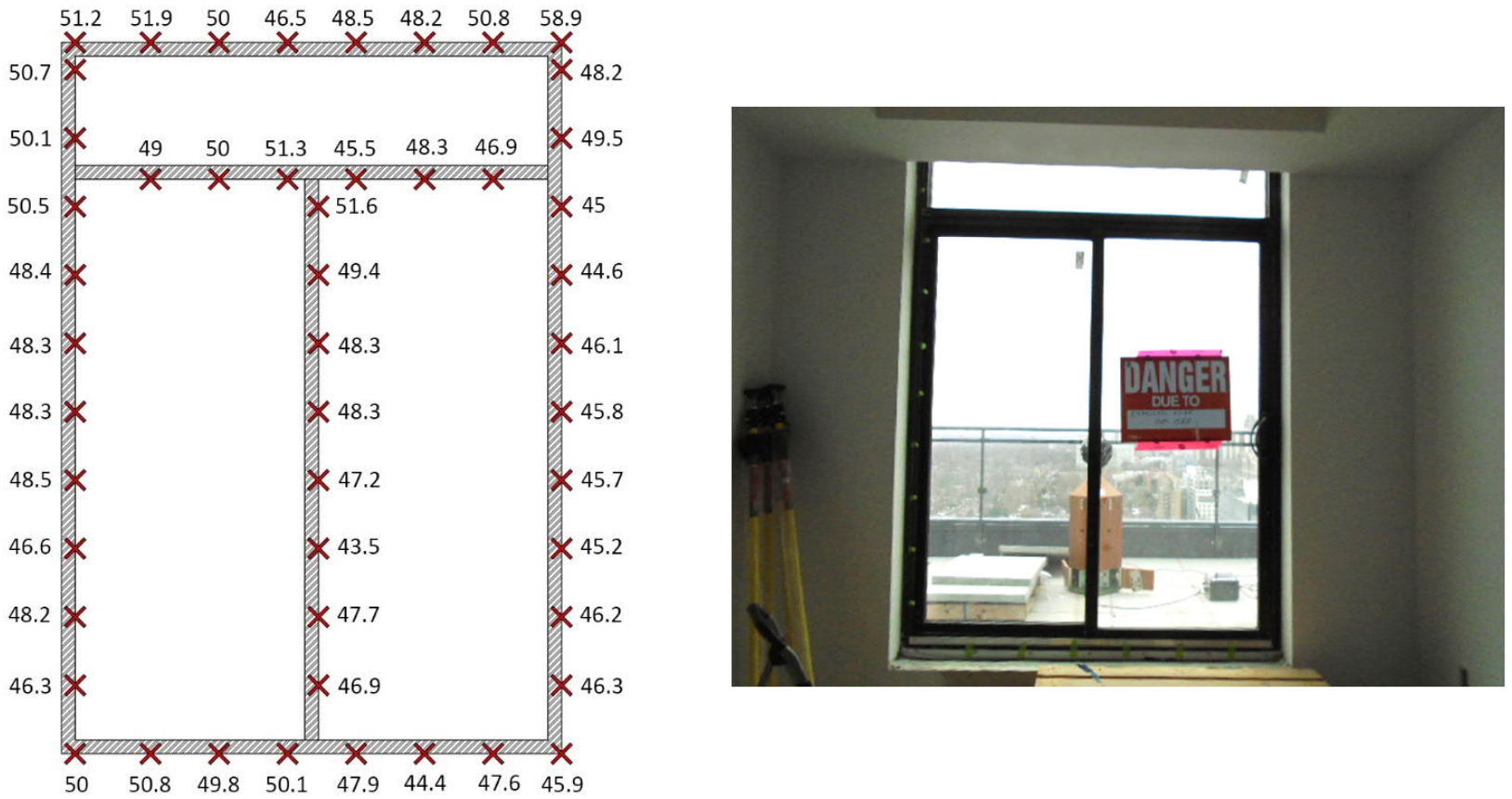

Figure 34- Test location No. 4 - 22 ${ }^{\text {nd }}$ floor, Suite 2402, Family room, Left image: measured sound pressure of inside of the specimen, Right image: view of the experimental window assemblies 


\subsubsection{Test location No. 5}

As illustrated in Figure 35, an increase in measured sound pressure can be observed at locations below (air infiltration locations):

1. Location A and B

2. The joint between two slider panels
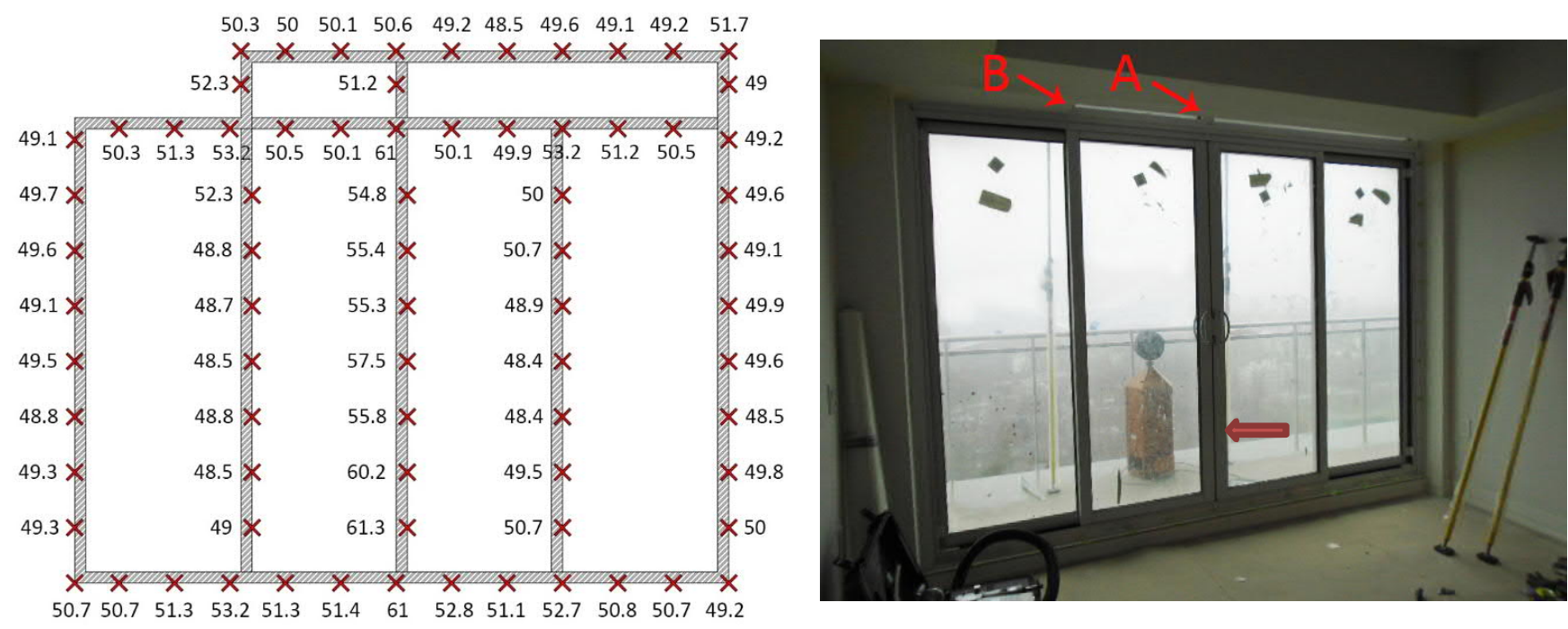

Figure 35 - Test location 5 - 22nd floor, Suite 2203, Bedroom, Left image: measured sound pressure of inside of the specimen, Right image: view of the experimental window assembly
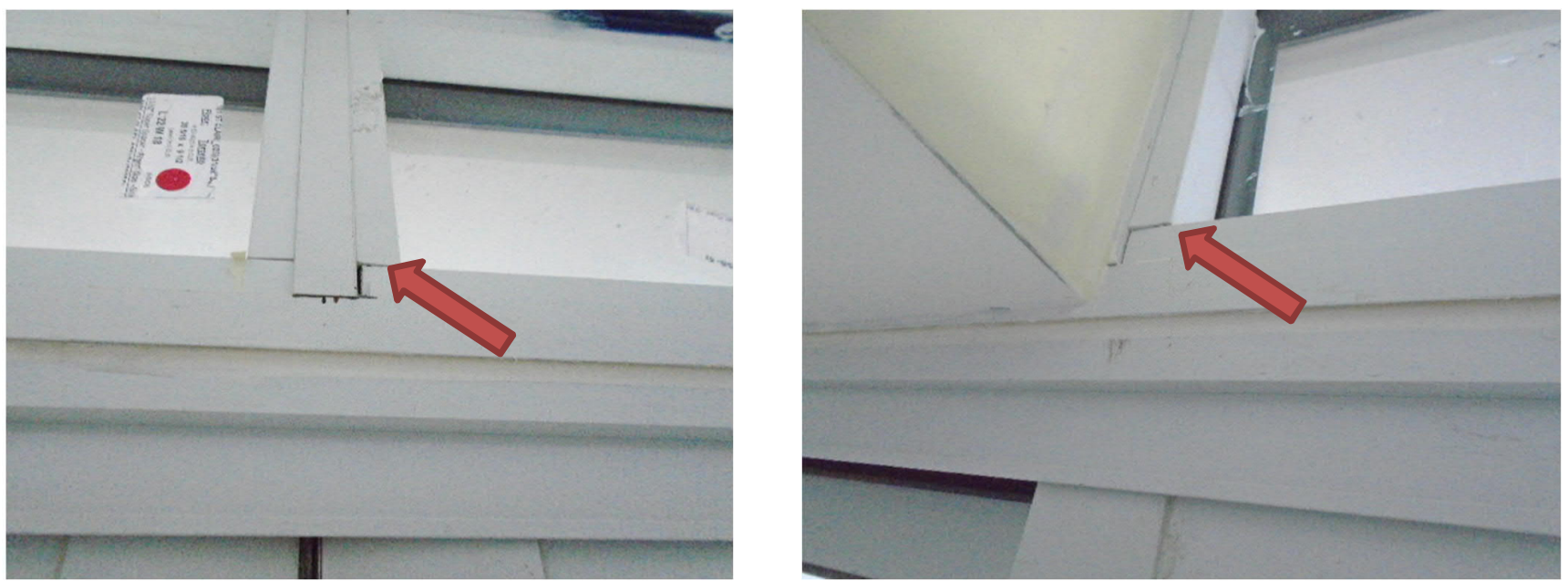

Figure 36 - Test location No. 5 - 22nd floor, Suite 2203, Bedroom, Left image: view of point A on tested window assembly, Right image: view of point $B$ on the experimental window assembly 
After visual inspection of these areas, a gap was observed on the window frame joints which were not sealed and may allow air infiltration through these locations. (Figure 36)

\subsubsection{Test location No. 6}

A raise in measured sound pressure was identified at the joint between two slider panels at the bottom section of the tested window assembly. After visual inspection of the specimen, it appears that these slider panels, as the movable parts of the window assembly, are not perfectly adjusted. This may cause air flow through the experimental window at these locations and cause increase in the recorded sound pressure. (Figure 37)

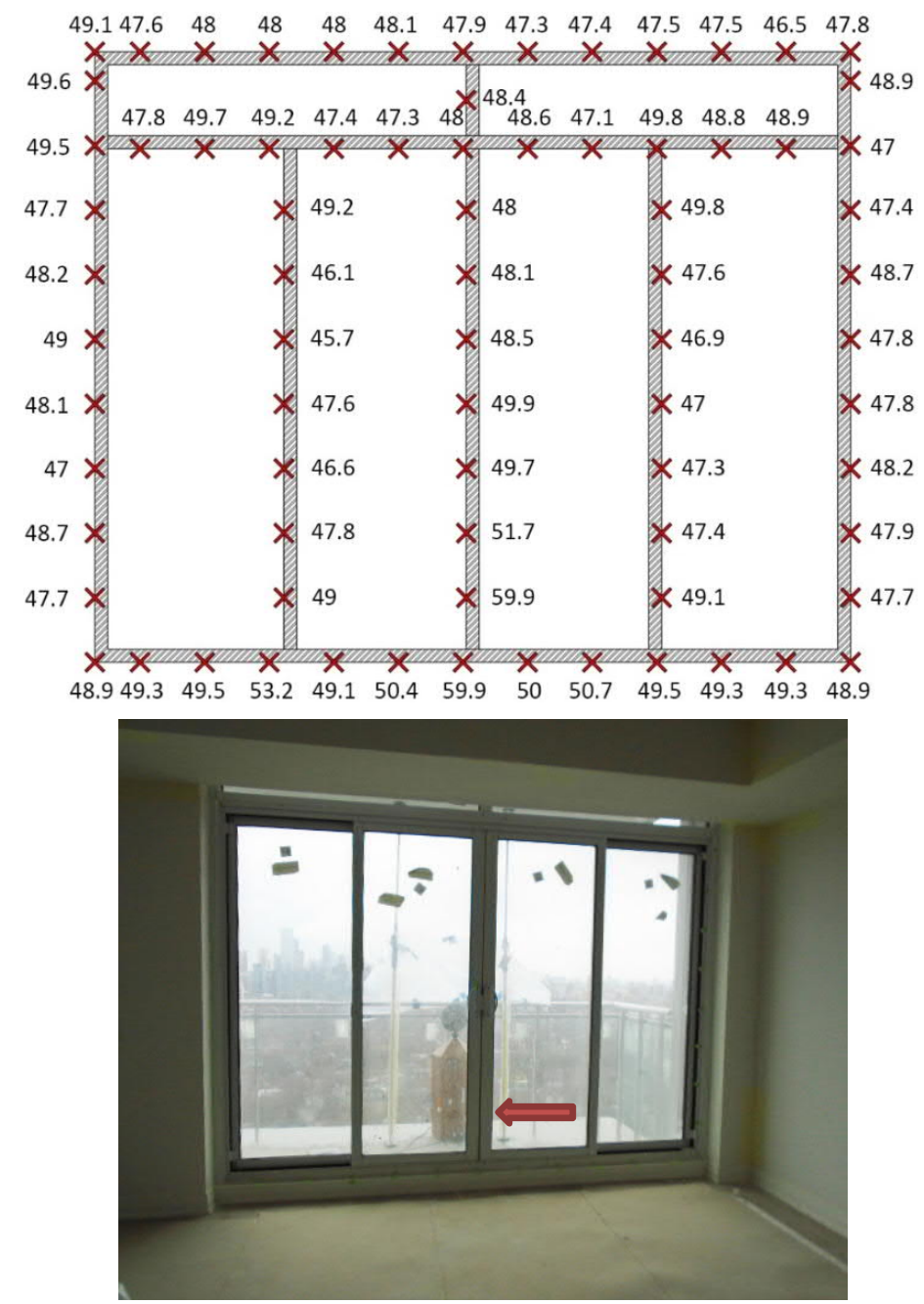

Figure 37 - Test location No. 6 - 22nd floor, Suite 2203, Livingroom, Top image: measured sound pressure of inside of the specimen, Bottom image: view of the experimental window assemblies 


\subsubsection{Test location No. 7}

At this test location, the noted sound pressure was increased at bottom and sides of the awning window of the specimen. It appears that the rubber gasket installed at this location did not completely prevent the air infiltration through this window. As illustrated on Figure 38, this air flow slightly affected the measured sound pressure.
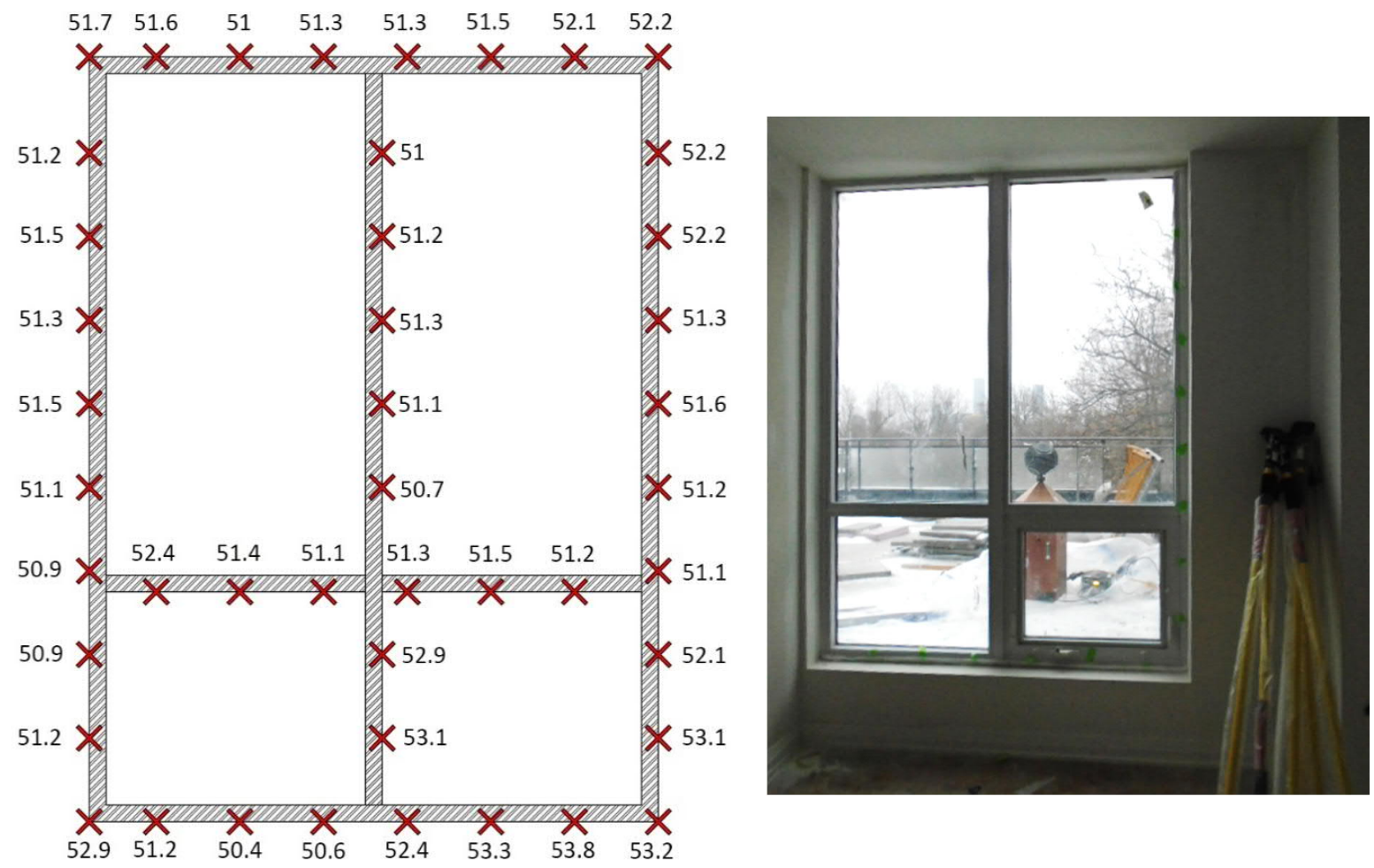

Figure 38- Test location No. 7- 22nd floor, Suite 202, Livingroom, Left image: measured sound pressure of inside of the specimen, Right image: view of the experimental window assemblies

Overall, based on performed investigations on all seven selected windows, the air infiltration locations were identified. It appears this acoustical method is one of the most helpful and fast practices for identifying the air infiltration locations through the window assemblies. 
However, two drawbacks and limitations of this technique for air leakage detection were recognized during these field tests:

- The background noise of the tested units was measured at about $30 \mathrm{~dB}$ to $35 \mathrm{~dB}$ during the tests which proves that the noise level within the unit itself was fairly low. Test results are highly dependent on the amount of noise within the environment and any change in sound level can significantly impact the outcome of the tests.

- The second limitation of this method is that it cannot be used in area where sound can be reflected or bounced back such as bulkheads that are directly located on top or near the window assembly being tested.

\section{Conclusions}

The great impact of air infiltration through the buildings enclosure on the energy consumption and indoor air quality of the building cannot be neglected. Improving building airtightness within a building will noticeably increase building acoustical performance and resident comfort and will significantly impact and decrease the amount of green gas production and buildings' cooling and heating load.

As such, in this report, multiple numbers of experiments were performed in order to explore acoustical approach for pre-screening of building envelope airtightness level. Since the impact of window systems on total air infiltration through building envelope is significant, seven individual window assemblies in an existing building were selected in order to investigate the correlation between airtightness and sound transmission loss via these assemblies. Based on tests completed we can confirm the negative relationship between airtightness and sound transmission loss meaning when one decreases in value, the other will rise. 
In addition, the acoustical detection method also helped investigate further and to estimate the air infiltration locations of these seven window assemblies. Aside from some of the mentioned limitations of this method, acoustical technique, this practice was found to be one of the simplest and fastest methods for air leakage detection. Only items required to perform these tests are a sound source, sound level meter and a device to be able to run all numbers on and analyze the outcome.

\section{Future work}

Further studies should investigate the acoustical method and the correlation between airtightness and sound transmission loss:

- Through other types of window assemblies, other than the ones were examined in this research (aluminium frame double glazed windows).

- Through other building envelop components. For instance, exterior walls with different materials, finishes, and details.

- Through a building envelope component using multiple devices to identify the error of each device on test results

- Through a building component with various background noise and investigate the impact of background noise on the results

- Through a building component with using various range of sound source frequencies and sound source types to identify the proper frequency range and sound type that can be used in the acoustical method. 


\section{Appendices}

Appendix 1 - Section detail of the experimental windows/ doors of Allan Window technologies

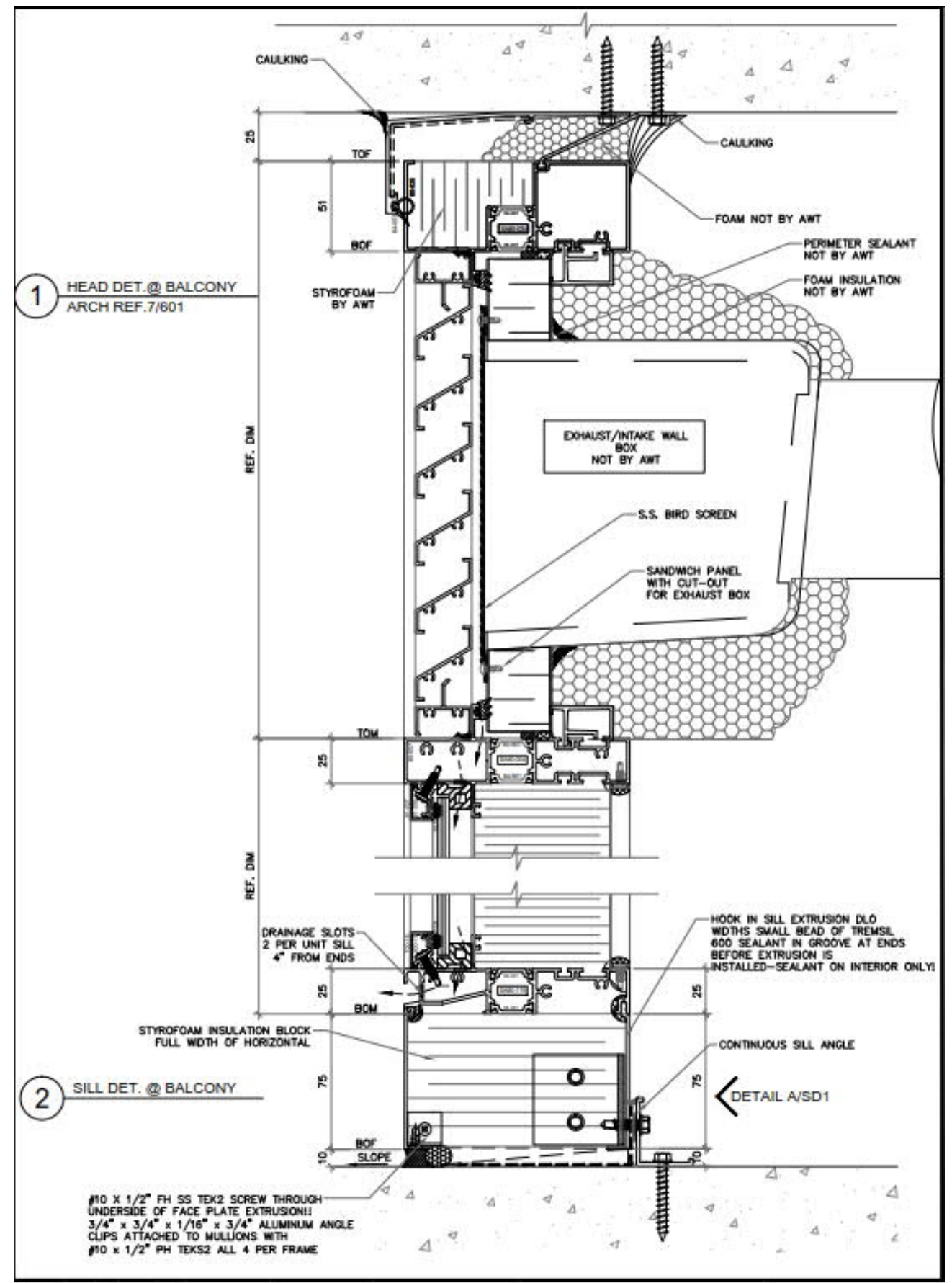




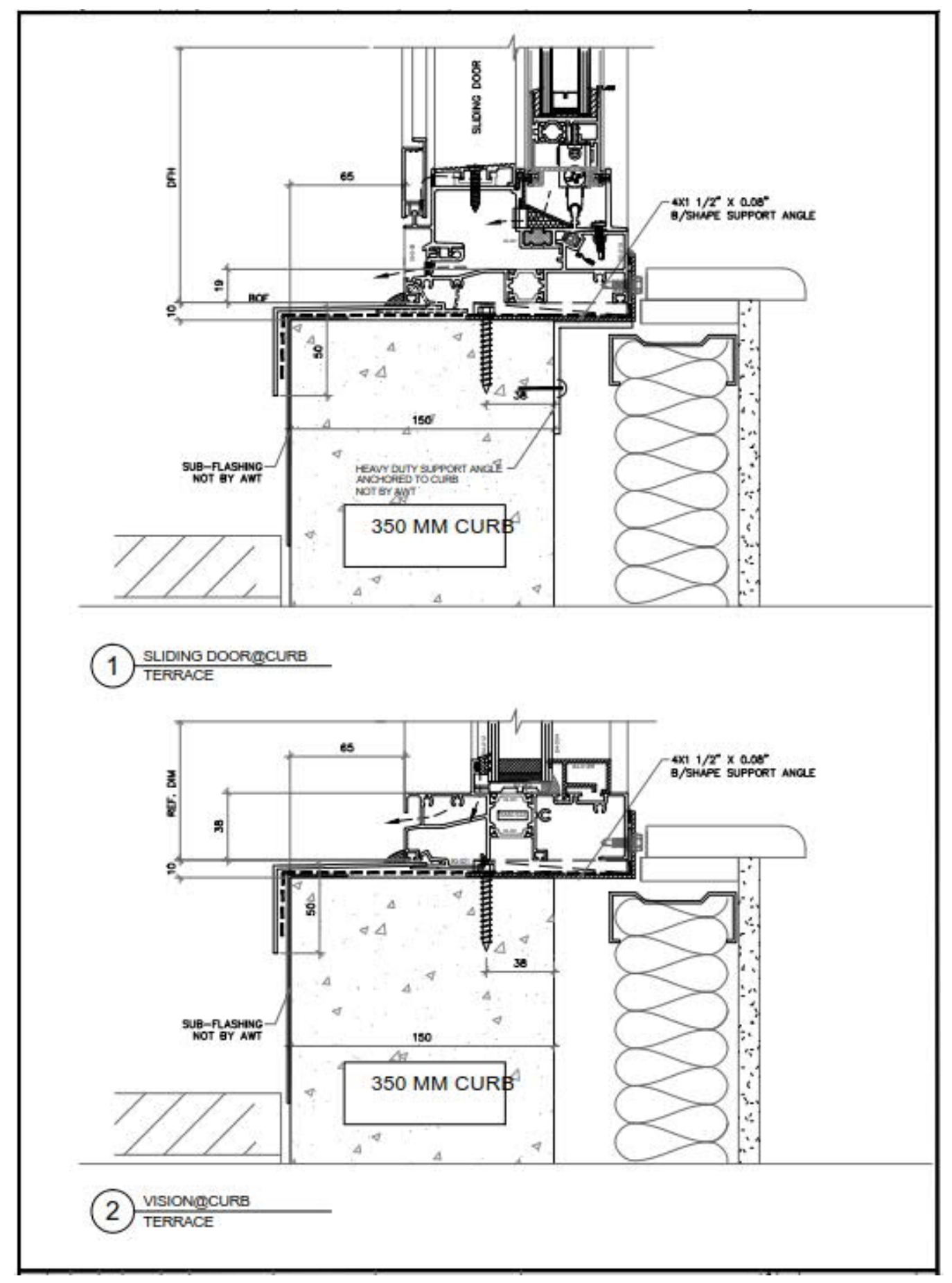




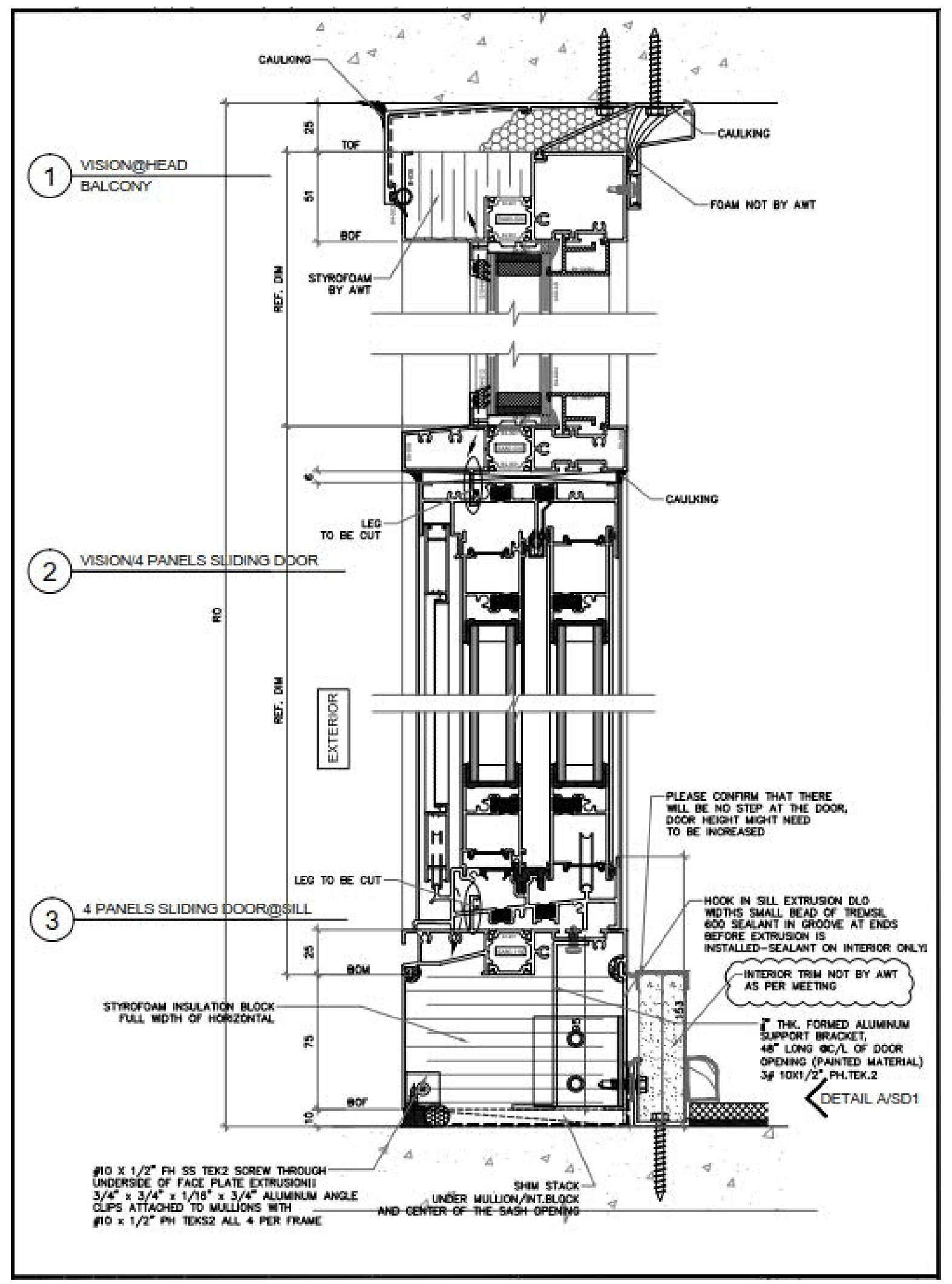


Appendix 2: Technical specification of SC160 sound level meter:

\section{Technical Specifications SC160 INTEGRATING SOUND LEVEL METER REAL TIME FREQUENCY ANALYZER REAL TIME ROOM NOISE EVALUATOR (NC CURVES)}

STANDARDS AND SPECIFICATIONS
Complies with the following standards:
- EN 60651:94 (A1:94) (A2 :01) type 2,
EN 600004:00 type 2, EN 61260:95
(A1:01) type 2
- IEC 60651:01 type 2, IEC 60804:00
type2, IEC $61260: 95$ (A1:01) type2
- ANS1 S1.4:83 (A1:85) type 2, ANS1
S1.43:97 type 2, ANSI S1.11:86
- CE mark. Complies with 73/23/CEE
and CEM 89/336iCEE low-tension
regulations, the latter amended by
93/68/CEE.
MEASUREMENT RANGE

\begin{tabular}{|c|c|c|c|}
\hline \multicolumn{4}{|c|}{$\begin{array}{l}L_{s}, L_{s}, L_{,} L_{T} \text { and } L_{1} \\
\text { Indicator limits: } 0=130 \text { d8 }\end{array}$} \\
\hline Primary range & A & c & $z$ \\
\hline Upper limit & 113 & 113 & 113 \\
\hline Lower limit & 36 & 38 & 40 \\
\hline \multicolumn{4}{|c|}{ Measurement range: } \\
\hline $\begin{array}{l}\text { Upper limit : } \\
\text { Crest factor 3: }\end{array}$ & $\begin{array}{r}130 \\
123\end{array}$ & $\begin{array}{r}130 \\
123\end{array}$ & $\begin{array}{r}130 \\
123\end{array}$ \\
\hline Crest factor 5: & 119 & 119 & 119 \\
\hline Crest factor 10: & 113 & 113 & 113 \\
\hline Lower limit : & 19 & 21 & 32 \\
\hline
\end{tabular}

ELECTRICAL NOISE

Electrical noise: A C $\mathbf{Z}$ $\begin{array}{llll}\text { Maximum } & 9.1 & 12.1 & 23.1\end{array}$

$\begin{array}{llll}\text { Typical } & 8.7 & 11.4 & 22.2\end{array}$

Total noise

(elec. + thermal of microphone P-05)

$\begin{array}{lll}\text { Maximum } 27.1 & 31.0 & 39.0\end{array}$

$\begin{array}{llll}\text { Typical } & 25.3 & 29.0 & 35.0\end{array}$

FREQUENCY WEIGHTING

Complies with the EN 60651 type 2

standard

Weightings $A, C$ and $Z$

AC OUTPUT
Frequency weighting: linear
Sensitivity to $130 \mathrm{~dB}$ and $1 \mathrm{kHz}$ (Gain =
OdB): 7.4 Vrms (max)
Upper limit: 8.1 Vrms (typical)
Output impedance: $100 \Omega$
Gain: 0 and $40=0.2 \mathrm{~dB}$
MICROPHONE
Model: CEgVA P-05
1/2- condenser microphone with
preamplifier
Equivalent Impedance: $3000 \Omega$
Nominal sensitivity: $16.0 \mathrm{mV} / \mathrm{Pa}$ in
reference conditions.

\section{TIME WEIGHTING}

$\mathrm{L}_{\mathrm{f}}, \mathrm{L}_{\mathrm{s}}, \mathrm{L}$, according to class 2 tolerances

\section{PARAMETERS}

See previous table| Resolution: $0.1 \mathrm{~dB}$

\section{OCTAVE FILTERS}

Type 2 according to IEC 61260:95/ A1:01

Nominal octave bands central freq.

$31.5,63,125,250,500,1000,2000$,

$4000,8000,16000 \mathrm{~Hz}$

\section{INFLUENCE OF TEMPERATURE}

Operation range: -10 to $+50^{\circ} \mathrm{C}$

Maximum error $\left(-10\right.$ to $\left.+50^{\circ} \mathrm{C}\right): 0.5 \mathrm{~dB}$

Storage without batteries: 20 to $+60^{\circ} \mathrm{C}$

\section{INFLUENCE OF HUMIDITY}

Operation range: $\quad 30$ to $90 \%$

Maximum error at $30 \%<$ R.H. $<90 \%, 40^{\circ} \mathrm{C}$ and $1 \mathrm{kHz}=0.5 \mathrm{~dB}$

Storage without batteries: $<93 \%$

\section{EFFECTS OF MAGNETIC FIELDS}

In an $80 \mathrm{Am}$ magnetic field (1

Dersted) at $50 \mathrm{~Hz}$, all gives a reading of less than $25 \mathrm{~dB}(\mathrm{~A})$ is given.

\section{EFFECTS OF VIBRATIONS}

For frequencies between 20 and 1000 $\mathrm{Hz}$ and $1 \mathrm{~m} / \mathrm{s}^{2}:<75 \mathrm{~dB}(\mathrm{~A})$

\section{BATTERY}

Battery: $9 V$ type 6LF22:

Battery Ife with continuous use.

Soun Level Meter mode : 8 hours

Spectrum Analyzer mode: 6 hours

Mains feeder: A-200 (EU) of

AM201(USA)

\section{DIMENSIONS and WEIGHT}

Dimensions:

$341 \times 82 \times 19 \mathrm{~mm}$

Weight: with battery $627 g$

without battery $573 \mathrm{~g}$

CESWA isstrwments, sh reserves the right to change spocifications and accessories without nosce. 


\section{Appendix 3: ATS portable air test equipment model AW-1000 verification document}

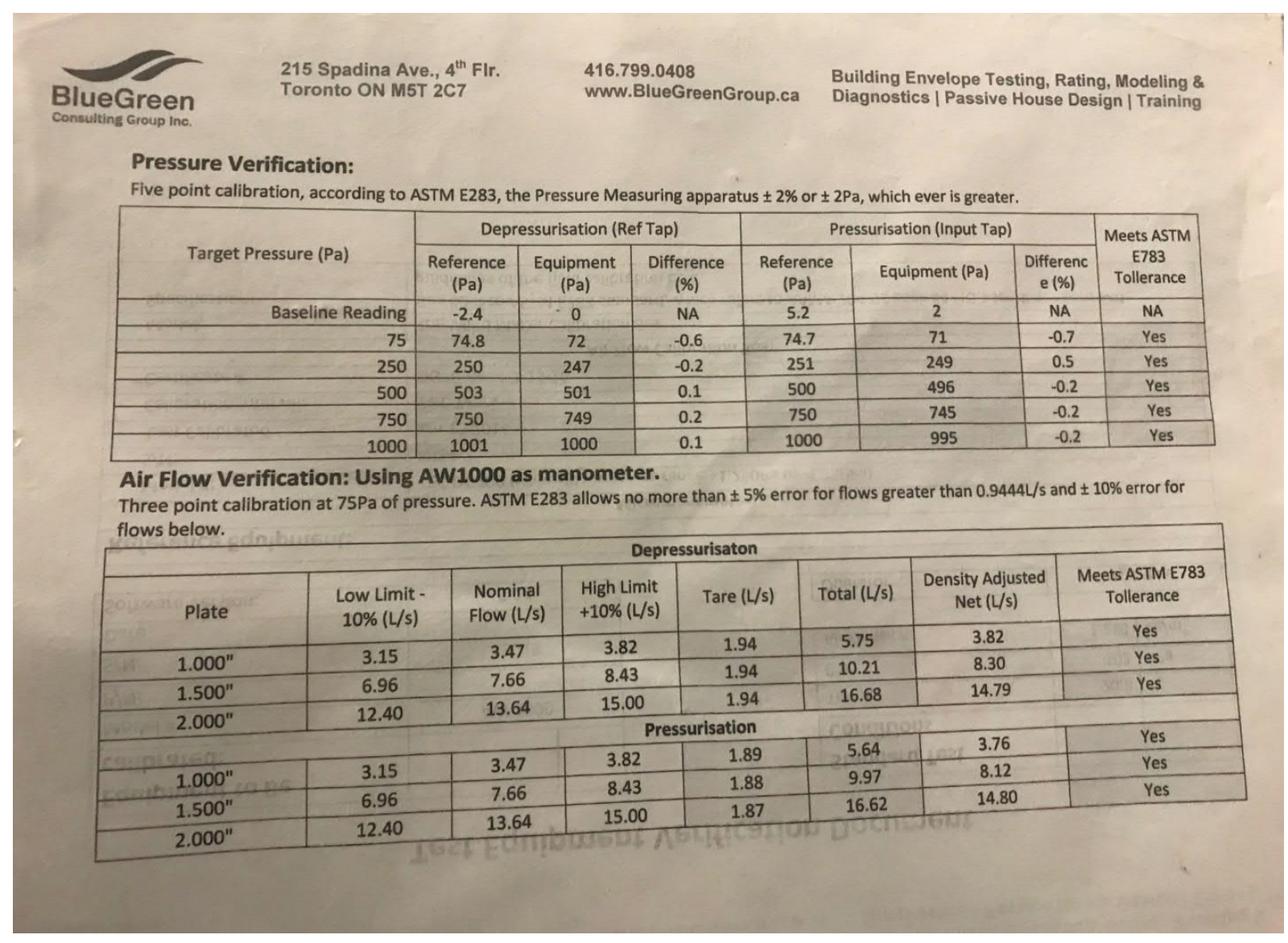




\section{Bibliography}

Alfano, F.R.d'Ambrosio, Dell'Isola, M., Ficco, G., \& Tassini, F. (2012). Experimental analysis of air tightness in Mediterranean buildings using the fan pressurization method. Building and environment, 53, 16-25.

Almeida, R. M., Ramos, N. M., \& Pereira, P. F. (2017). A contribution for the quantification of the influence of windows on the airtightness of southern european buildings. Energy and Buildings, 139, 174-185.

Anis, W., Brennan, T., Nelson, G., Olson, C., \& Bohac, D. (2013). ASHRAE 1478 RP: Measuring AirTightness of Mid-and High-Rise Non-Residential Buildings. ASHRAE Transactions, 119(2), 113.

ASTM E1186 standard. (2017). Standard Practices for Air Leakage Site Detection in Building Envelopes and Air Barrier Systems. ASTM International.

ASTM E741 . (2011). Standard test method for determining air change in a single zone by means of a tracer gas dilution. ASTM International.

ASTM E779-10. (2010). Standard Test Method for Determining Air Leakage Rate by Fan Pressurization. ASTM International.

ASTM E783-02 Standard. (2010). Standard Test Method for Field Measurement of Air Leakage Through Installed Exterior Windows and Doors. ASTM Internatinal.

Balaras, C. A., \& Argiriou, A. A. (2002). Infrared thermography for building diagnostics. Energy and buildings, 34(2), 171-183. 
Bruel \& Kjaer. (2018, January). Product data - PULSE Array-based Noise Source Identification Solutions: Beamforming Type 8608, Acoustic Holography Type 8607 and Spherical Beamforming Type 8606. Retrieved from bksv: https://www.bksv.com// media/ literature/ Product-Data/ bp2144.ashx

Canada Morgage and Housing Corporation (CMHC). (2007). Air Leakage Control Manual for Existing Multi-unit Residential Buildings.

Chelliah, K., Raman, G., \& Muehleisen, R. T. (2014). Advanced aeroacoustic testing techniques using various methods of acoustic holography. 20th AIAA/ CEAS Aeroacoustics Conference, 3071, pp. 1-21. Atlanta, Georgia, USA.

Chelliah, K., Raman, G., \& Muehleisen, R. T. (2017). An experimental comparison of various methods of nearfield acoustic holography. Journal of Sound and Vibration, 403, 21-3.

Cho, Y. T., \& Roan, M. J. (2009). Adaptive near-field beamforming techniques for sound source imaging. Journal of the Acoustical Society of America, 152(2), 944-957.

Cuce, E. (2017). Role of airtightness in energy loss from windows: Experimental results from in-situ tests. Energy and Buildings, 139, 449-455.

Emmerich, S. J., McDowell, T. P., \& Anis, W. (2007). Simulation of the impact of commercial building envelope airtightness on building energy utilization. ASHRAE Transactions, 113(2).

Fernandez-Grande, E., Xenaki, A., \& Gerstoft, P. (2017). A sparse equivalent source method for nearfield acoustic holography. The Journal of the Acoustical Society of America, 141(1), 532-542.

Ghazi, C., \& Marshall, J. (2014). A CO2 tracer-gas method for local air leakage detection and characterization. Flow Measurement and Instrumentation, 38, 72-81. 
Hald, J. (2016). Fast wideband acoustical holography. Journal of the Acoustical Society of America, 139(4), 1508-1517. doi:10.1121/1.4944757

Hassan, O. A. (2013). An alternative method for evaluating the airtightness of the building components. Building and Environment, 67, 82-86.

Henry, R., Patenaude, A., Elmahdy, H., \& Wright, J. (1998). Measurements of window air leakage at cold temperatures and impact on annual energy performance of a house. ASHRAE Transactions, 104, 1254 .

IDIS. (2018). Ambisonics. Retrieved from proyectoidis: http:/ / proyectoidis.org/ ambisonics/

InspectAPedia. (2017). Guide to Blower Doors \& Air Infiltration in buildings. Retrieved from InspectAPedia: https:/ / inspectapedia.com/ Energy/ Blower__oor_Test_Procedure.php

Iordache, V., \& Catalina, T. (2012). Acoustic approach for building air permeability estimation. Building and Environment, 57, 18-27.

Ji, Y., \& Duanmu, L. (2017). Airtightness field tests of residential buildings in Dalian, China. Building and Environment, 119, 20-30.doi:10.1016/j.buildenv.2017.03.043

Jokisalo, J., Kalamees, T., Kurnitski, J., Eskola, L. J., \& Vinha, J. (2008). A comparison of measured and simulated air pressure conditions of a detached house in a cold climate. Journal of Building Physics, 32(1), 67-89.

Kalamees, T. (2007). Air tightness and air leakages of new lightweight single-family detached houses in Estonia. Building and Environment, 42, 2369-2377.

Kalamees, T., Alev, Ü., \& Pärnalaas, M. (2017). Air leakage levels in timber frame building envelope joints. Building and Environment, 116, 121-129. 
Kim, M.-H., Jo, J.-H., \& Jeong, J.-W. (2013). Feasibility of building envelope air leakage measurement using combination. Energy and Buildings, 62, 436-441.

Kraus, M., Bednarova, P., \& Kubecka, K. (2016). Risk Assessment of Airtightness of Building Envelope. Applied Mechanics and Materials, 824, 657-665.

Lambda. (2018). Blower door test. Retrieved from Lambda: https:// www.lambda.be/ nl/ blowerdoortest

Martellotta, F. (2013). On the use of microphone arrays to visualize spatial sound field information. Applied Acoustics, 74(8), 987-1000.

Mattsson, B., \& Claesson, J. (2007). A Transient Pressurization Method for Measurement of Airtightness. Journal of Building Physics, 31(1), 35-53.

Muddeen, F., \& Copeland, B. (2012). Sound radiation from Caribbean steelpans using nearfield acoustical holography. The Journal of the Acoustical Society of America, 131(2), 1558-1565.

Musha, T., \& Taniguchi, J. I. (2005). Measurement of sound intensity using a single moving microphone. Applied acoustics, 66(5), 579-589.

Ng, L. C., Persily, A. K., \& Emmerich, S. J. (2015). IAQ and energy impacts of ventilation strategies and building envelope airtightness in a big box retail building. Building and Environment, 92, 627-634.

Ortolani, F., \& Uncini, A. (2016). On sound source localization with a 3D ambisonic monopulse SONAR. Radar Methods and Systems Workshop (RMSW), IEEE, pp. 81-86. doi:10.1109/ RMSW.2016.7778556 
Park, H. K., \& Kim, H. (2015). Acoustic insulation performance of improved airtight windows. Construction and Building Materials, 93, 542-550.

Raman, G., Prakash, M., Ramachandran, R. C., Patel, H., \& Chelliah, K. (2014). Remote detection of building air infiltration using a compact microphone array and advanced beamforming methods. Berlin Beamforming Conference, (pp. 1-10). Berlin.

Ren, Z., \& Chen, D. (2015). Estimation of air infiltration for Australian housing energy analysis. Building Physics, 39(1), 69-96.

Salehi, A., Torres, I., \& Ramos, A. (2017). Experimental analysis of building airtightness in traditional residential Portuguese buildings. Energy and Buildings, 151, 198-205.

USI Blog. (2018). Retrieved from USI: http:// www.usiinc.com/ blog/ energy-savings/ what-areblower-door-tests-and-why-do-they-matter/

Vandersluis, J. 101 St. Clair Avenue West. Todglen, Toronto. Retrieved from http:/ / toddglen.com/ wp-content/ uploads/2017/ 05/101_45.jpg

Varshney, K., Rosa, J. E., Shapiro, I., \& Scott, D. (2013). Air-infiltration measurements in buildings using sound transmission loss through small apertures. International Journal of Green Energy, 10(5) , 482-493.

Younes, C., Abi Shdid, C., \& Bitsuamlak, G. (2011). Air infiltration throgh building envelope: A review. Journal of Building Physics, 267-302.

Yuill, G. K. (1985). Method and apparatus for testing the air-tightness of a building using transient pressurization. U.S. Patent No. 4,510,791. Washington: U.S. Patent and Trademark Offic. 